\title{
Characterizing the Variability in Particulate Mass Emissions from Current Model Year Diesel and Natural Gas Engines
}

Pragalath Thiruvengadam Padmavathy West Virginia University

Follow this and additional works at: https://researchrepository.wvu.edu/etd

\section{Recommended Citation}

Padmavathy, Pragalath Thiruvengadam, "Characterizing the Variability in Particulate Mass Emissions from Current Model Year Diesel and Natural Gas Engines" (2013). Graduate Theses, Dissertations, and Problem Reports. 4987.

https://researchrepository.wvu.edu/etd/4987

This Thesis is protected by copyright and/or related rights. It has been brought to you by the The Research Repository @ WVU with permission from the rights-holder(s). You are free to use this Thesis in any way that is permitted by the copyright and related rights legislation that applies to your use. For other uses you must obtain permission from the rights-holder(s) directly, unless additional rights are indicated by a Creative Commons license in the record and/ or on the work itself. This Thesis has been accepted for inclusion in WVU Graduate Theses, Dissertations, and Problem Reports collection by an authorized administrator of The Research Repository @ WVU. For more information, please contact researchrepository@mail.wvu.edu. 


\title{
Characterizing the Variability in Particulate Mass Emissions from Current Model Year Diesel and Natural Gas Engines
}

\author{
Pragalath Thiruvengadam Padmavathy
}

Thesis submitted to the

Benjamin M. Satler College of Engineering and Mineral Resources

at West Virginia University

in partial fulfillment of the requirements

for the degree of

Master of Science

in

Mechanical Engineering

\author{
Committee Members: \\ Mridul Gautam, Ph.D., Chair \\ Gregory J. Thompson, Ph.D. \\ Hailin Li, Ph.D.
}

Department of Mechanical and Aerospace Engineering Morgantown, West Virginia

2013

Keywords: Diesel Engines; Natural Gas Engines; Aftertreatment Devices, Variability, Particulate Matter Measurement, Particulate Number Count Measurement Method, Mass Measurement 


\section{ABSTRACT \\ CHARACTERIZING THE VARIABILITY IN PARTICULATE MASS EMISSIONS FROM CURRENT MODEL YEAR DIESEL AND NATURAL GAS ENGINES}

\section{PRAGALATH THIRUVENGADAM PADMAVATHY}

The objective of this study is to discern and characterize the factors contributing to the variability in Particulate Matter (PM) mass emissions from current model year diesel and natural gas engines observed during in-use chassis dynamometer testing and compare it with an alternate method of mass measurement involving instantaneous particle size distribution and number count. The study involves the analysis of engine and chassis dynamometer data collected from different engine technologies and chassis dynamometer test cycles in order compare the variability in gravimetric PM mass as well as the PM mass estimated by number-concentration.

PM and oxides of nitrogen (NOx) have been the two most stringently regulated emissions constituents from heavy-duty diesel engines. Current US-EPA 2010 PM regulations, set at 0.01 $\mathrm{g} / \mathrm{bhp}-\mathrm{hr}$, have forced manufacturers to implement the use of diesel particulate filters (DPF) in order to comply with the regulations. The use of DPF's has resulted in PM mass decreasing by orders of magnitude since 2004, hence laboratory measurement techniques and instrumentation to accurately quantify the true mass of PM emitted from such engines have been posed with a challenge. Also, the widely gained acceptance of heavy-duty natural gas engines, characterized by their low soot combustion, has inevitably resulted in significant measurement variability due to the high volatile organic content in the exhaust.

Particulate matter mass comparisons are performed between PM sampled using the regulated "CFR 1065 Methodology" and PM number count measurements performed with similar exhaust dilution conditions as employed for gravimetric PM sampling. Particle size distribution and number concentration measurements were performed using the Engine Exhaust Particle Sizer ${ }^{\circledR}$ (EEPS) spectrometer for transient engine operation and Scanning Mobility

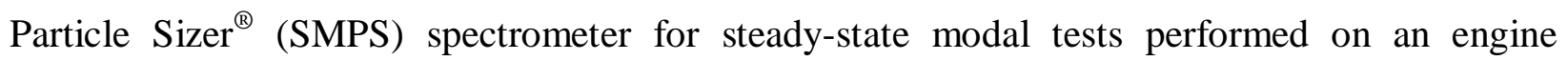


dynamometer. Additionally, PM mass comparisons are extended to an in-use study in order to compare Not-To-Exceed (NTE) PM emission limits.

Results from this study showed that an "effective-density" based conversion technique correlated well with gravimetric filter mass for pre-2010 engine technologies without aftertreatment systems, in particular DPFs for diesel fueled vehicles. Gravimetric PM measurements from a natural gas engine resulted in a standard deviation of $3.1 \mathrm{mg} / \mathrm{bhp}-\mathrm{hr}$ in comparison to mass calculated through particle size distributions, which resulted in a standard deviation of 0.36 mg/bhp-hr. The use of particle size based measurements for in-use PM monitoring resulted in better resolution of PM mass during short, valid NTE windows. 


\section{ACKNOWLEDGEMENTS}

With the utmost gratitude to all those who supported me, I write this as my short but eventful master's comes to an end.

"Events are moving so fast and what in one moment seems impossible, the next is happening. I'm sure historians will, in time, provide theories and analysis, but for now I think most of us simply want the tide stemmed."

-Lucy Powell

These words explain my brief experience during my masters. My family has been and will always be my greatest strength. Their love, affection and motivation has always been my driving force behind me. I thank my mom and dad from the bottom of heart for their vision and their sacrifices to make their vision a reality. Arvind, thank you for being patient and guiding me in the right direction throughout my life. Dada, thank you for being the greatest source of inspiration in my life, your knowledge and passion never seizes to amaze me. Amma, thank you for your unconditional love and affection, you are the strongest person I know.

I thank Dr. Mridul Gautam for the trust he placed in me and the wisdom he imparted, which drove me to learn more in this field. I am extremely grateful to you for being an excellent advisor and friend to me. I thank Dan Carder for all the help, support and the trust you placed in me.

"That's the great thing about having your friends around you. I've known these guys forever. I really enjoy their company just as people. You couldn't ask for a better work environment".

-Drew Carey

This is describes my opinion of working in CAFEE. I am extremely fortunate to be part of this group of brilliant engineers and personal. I thank Marc Besch and Hemanth Kappanna for their help and patiently answering to many of my questions. I would specially like to thank Tom Spencer for all his help, I learned a lot that is important for my career from you. I thank Brad Ralston, Chris Rowe and Jason England for being extremely during the long testing hours.

I am forever in debt to my friends back home and in Morgantown. 


\section{TABLE OF CONTENTS}

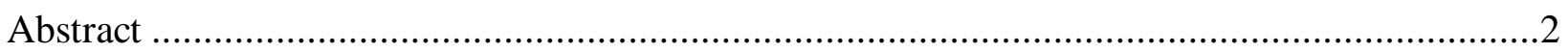

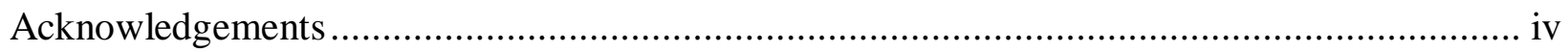

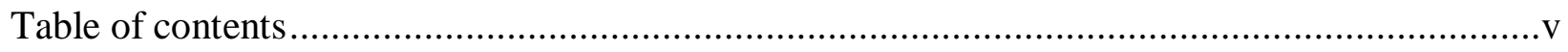

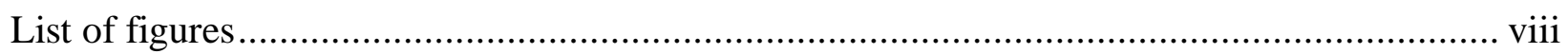

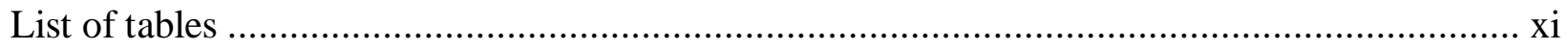

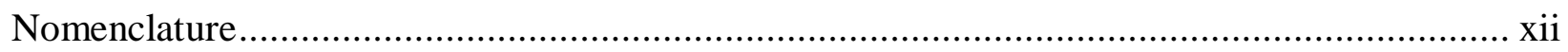

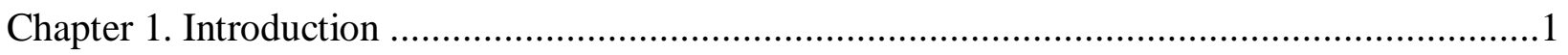

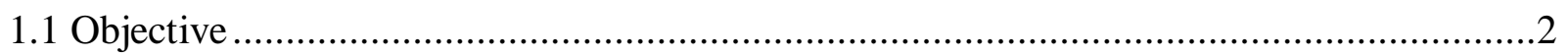

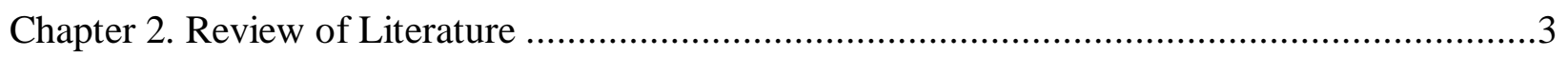

2.1 Formation of Particulate Matter Emissions ………….....................................................

2.2 Evolution of PM Emissions from Heavy-duty Diesel Engines..........................................

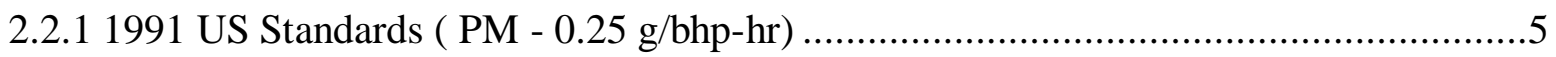

2.2.2 1994 US Standards ( PM - 0.1 g/bhp-hr ) ..........................................................

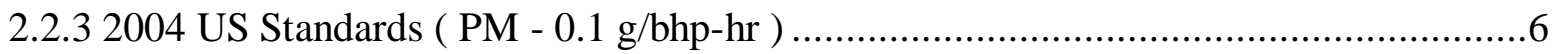

2.2.4 2007 US Standards ( PM - 0.01 g/bhp-hr; NOx - 0.2 g/bhp-hr) ................................ 9

2.2.5 2013 Euro-VI Standards ( PM - $0.01 \mathrm{~g} / \mathrm{kWh}$; PN - $6.0 \times 10^{11} \mathrm{kWh}^{-1}$ ) .....................11

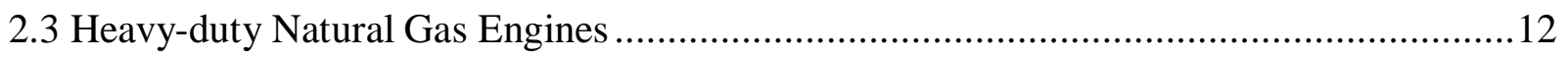

2.4 Influence of Aftertreatment Systems on PM Emissions................................................13

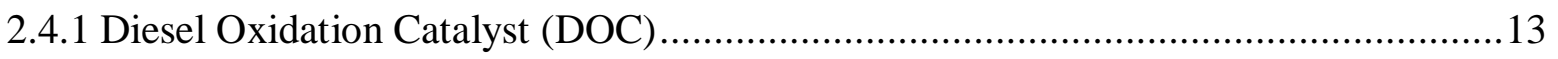

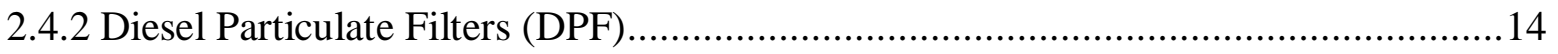

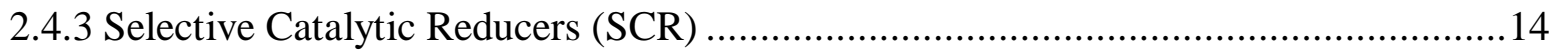

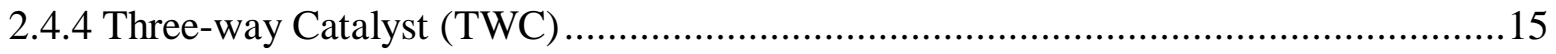

2.5 Particulate Mass Measurement Techniques ...................................................................... 16

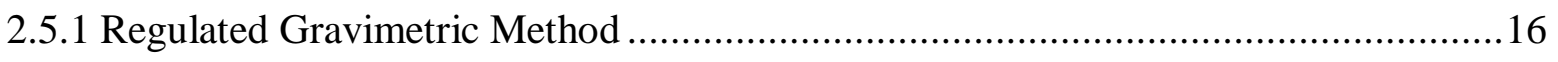


2.5.2 PM Portable Emission Measurement System (PEMS) ………................................18

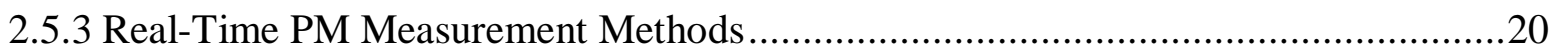

2.5.3.1 Tapered Element Oscillating Microbalance (TEOM) .......................................20

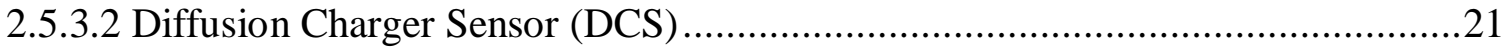

2.5.3.3 Photo-acoustic Sensor (AVL Micro Soot Sensor) ..............................................21

2.5.3.4 Exhaust Emissions Particle Sizer Spectrometer (TSI EEPS) ...............................21

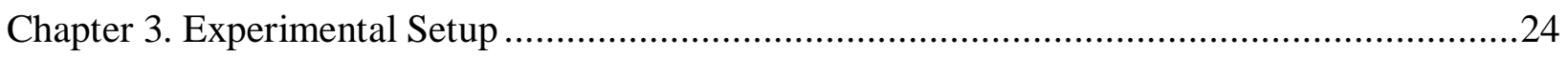

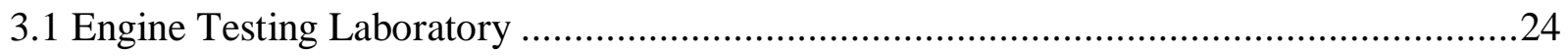

3.2 Vehicle Emissions Testing Laboratory...................................................................25

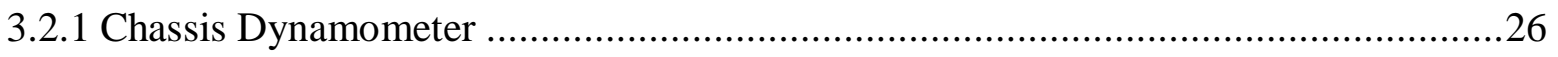

3.2.2 Transportable Emissions Measurement Systems (TEMS)........................................29

3.3 Gaseous Emissions Sampling System …………........................................................ 31

3.4 40 CFR §1065 Compliant PM Sampling and Measurement System ..................................33

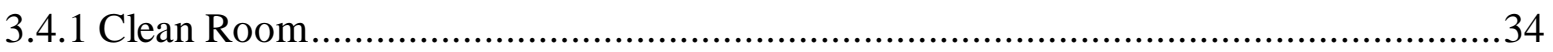

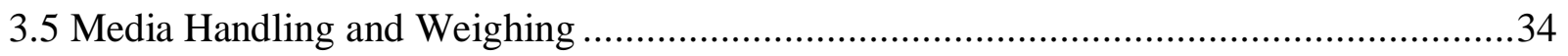

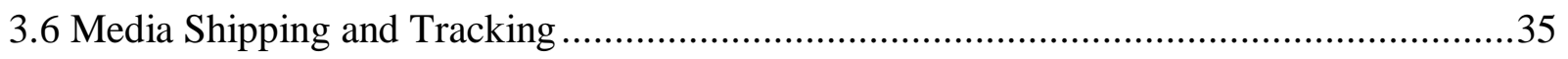

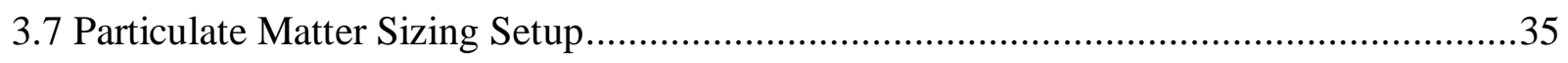

3.8 Test Engine and Vehicle Specifications …………............................................................

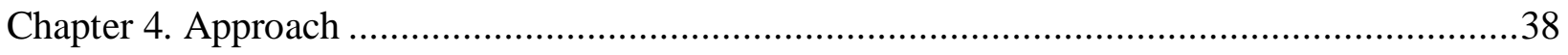

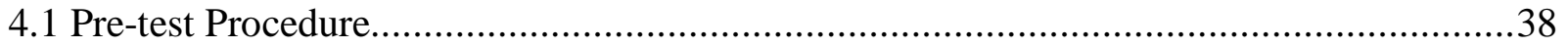

4.2 Test Procedure

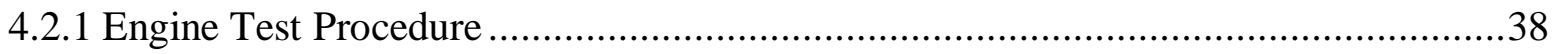

4.2.2 Chassis Dynamometer Test Procedure ………………..............................................39

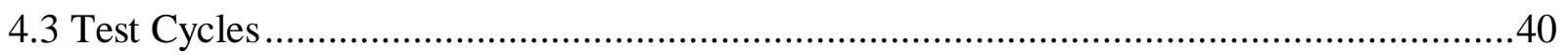

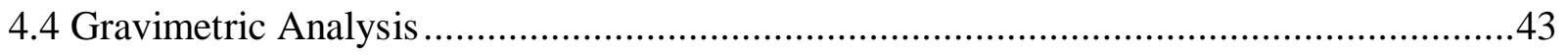




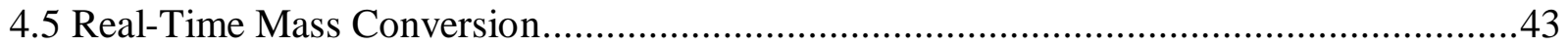

4.5.1 Effective Density Functions ..................................................................44

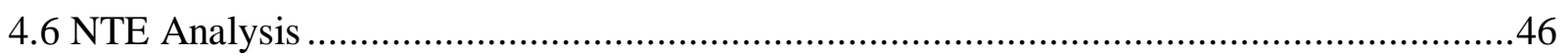

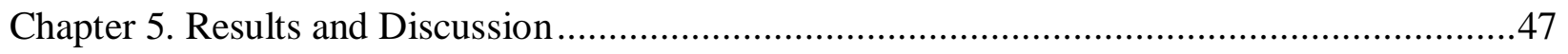

5.1 PM Mass Measurement Method Comparison:.......................................................4 47

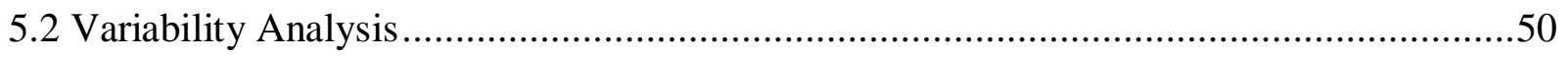

5.3 Influence of Background Correction on Gravimetric PM Mass Measurement .................55

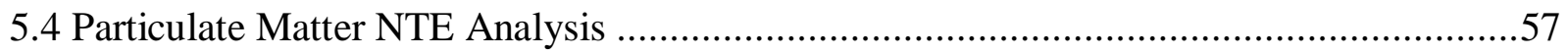

5.5 Total Particle Number Count Emissions ..............................................................60

5.6 Drawbacks in PM Measurement Technique ......................................................63

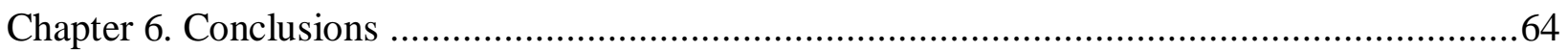




\section{LIST OF FIGURES}

Figure 2.1 Schematic diagram of soot formation in homogenous systems or in pre-mixed combustion [9] 3

Figure 2.2 Typical aerosol size distribution of Pre-MY2007 Heavy-duty diesel engine exhaust $[20,23]$. .7

Figure 2.3 Typical composition for a Pre-MY2007 heavy-duty diesel engine tested in heavy-duty transient cycle [20] 7

Figure 2.4 Categorization of the mass based size classification of particles from each engine exhaust emissions. PM mass calculated using integrated particle size distribution (IPSD) method for low and ultra-low emissions from Engines A and B, respectively. Engine A is a low emitting MY2004 engine compliant with 2004 US-EPA regulations. Engine B is ultra-low emitting MY2007 engine compliant with 2007 US-EPA regulations and equipped with a DOC-DPF aftertreatment system [22] 10

Figure 2.5 EC/OC Emissions from Riverside Transit Authority bus [38] ...............................13

Figure 2.6 Record from air pressure changes within a time period between 7/2/2012 to 16/2/2012

Figure 2.7 Accuracy of the standard gravimetric measurement as function of the mass emission .18

Figure 2.8 HORIBA TRPM system setup [47] 20

Figure 2.9 Schematic Diagram of the Model 3090 TSI EEPS Spectrometer [51] ....................22

Figure 3.1 Schematic overview of WVU CAFEE EERL's engine testing laboratory ...............24

Figure 3.2 Full flow CVS dilution system at WVU CAFEE's EERL facility .........................25

Figure 3.3 Schematic of WVU CAFEE's TEMS. .26

Figure 3.4 WVU CAFEE's transportable heavy-duty chassis dynamometer and its components [3] .28

Figure 3.5 View of the Diesel with DOC-DPF-SCR vehicle being tested on WVU CAFEE's transportable heavy-duty chassis dynamometer at the test facility ............................28

Figure 3.6 CAD overview of WVU CAFEE's TEMS container[3] .....................................30

Figure 3.7 View of the WVU CAFFE's TEMS container at the test facility ............................31

Figure 3.8 MEXA 7200D analytical bench at WVU CAFEE's EERL facility .........................32 
Figure 3.9 MEXA 7200D analytical bench and the full scale CVS dilution system onboard WVU CAFEE's TEMS

Figure 3.10 40 CFR $\S 1065$ compliant PM sampling system at WVU CAFEE's EERL facility and on-board the TEMS .33

Figure 3.11 Class Six clean room as specified by ISO 14644-1 at WVU CAFEE's EERL facility

Figure 4.1 Speed Vs. Time trace of trip length UDDS cycle 41

Figure 4.2 Speed Vs. Time trace of trip length Near-dock cycle ..... .41

Figure 4.3 Speed Vs. Time trace of trip length Local cycle. .41

Figure 4.4 Speed Vs. Time trace of trip length Regional cycle 42

Figure 4.5 Correlation between gravimetric filter mass concentrations and mass concentration measured by alternative online methods of Diesel PM [54].

Figure 4.6 Correlation of effective density versus mobility diameter used for this study [55-57]. Note: The size distribution range under study extends from $6 \mathrm{~nm}$ to $254 \mathrm{~nm}$ in mobility diameter only 45

Figure 5.1 Number concentration and distribution of diluted diesel exhaust from the TRU engine, measured by the SMPS at the CVS tunnel sample plane .48

Figure 5.2 Mass concentration and distribution using unit density $(1 \mathrm{~g} / \mathrm{cc})$ of diluted diesel exhaust from the TRU engine, measure by the SMPS at the CVS tunnel sample plane...48

Figure 5.3 A comparison of the total mass emissions from TRU engine without any aftertreatment systems over the 4-Mode steady state test cycle as measured by the regulated gravimetric method and as calculated using different effective density functions

Figure 5.4 A comparison of the total mass emissions from TRU engine with a DOC-DPF aftertreatment system over the 4-Mode steady state test cycle as measured by the regulated gravimetric method and as calculated using different effective density functions

Figure 5.5 Brake specific PM emissions by measurement method with grand means shown in red mean lines

Figure 5.6 Mean standard deviation of brake specific PM emissions by measurement method with grand means in red. 
Figure 5.7 Variability chart for engine brake specific PM emissions showing variability between different measurement method that are grouped within different vehicle technologies ...53

Figure 5.8 Variability Chart showing the engine brake specific PM emissions for different measurement method grouped across test cycle and vehicle tested ...............................54

Figure 5.9 Average brake specific PM emissions observed in regional cycle from the CNG with TWC vehicle. Variation bars indicate standard deviation

Figure 5.10 Comparison of coefficient of variations between gravimetric PM mass that has been corrected for background contaminants and not corrected for background contaminants in the dilution air .57

Figure 5.11 Average brake specific NTE emissions from diesel with DOC-DPF vehicle. The filled portion of the bar graph indicates the average NTE emissions observed, while the total height of the bar indicates average emissions over the entire cycles. The standard deviations are indicated by the variation bars respectively

Figure 5.12 Average brake specific NTE emissions from CNG with TWC vehicle. The filled portion indicates the average NTE emissions observed, while the total height of the bar indicates average emissions over the entire cycles. The standard deviations are indicated by the variation bars respectively .60

Figure 5.13 Variability chart for brake specific particle number count emissions showing variability between the two different ranges particle size distribution used in this study. Mobility Diameter (Dp) in $\mathrm{nm}$ .62

Figure 5.14 PM mass emission rates long with post three way catalyst temperature for the CNG with TWC vehicle. Particle number distribution plot shows TSI EEPS is over ranging at high temperature operation during the regional goods movement cycle. Particle number distribution plot represents PM number concentrations in the CVS tunnel .63 


\section{LIST OF TABLES}

Table 3.1 Test vehicle specification for chassis dynamometer testing. ................................36

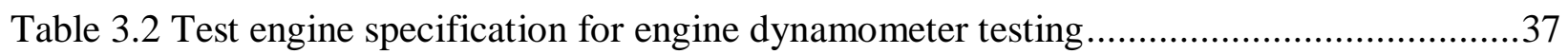

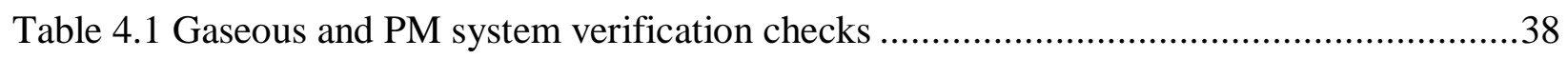

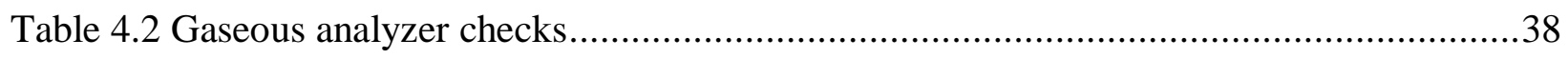

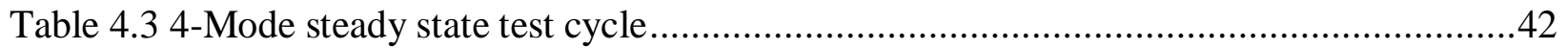

Table 5.1 NTE analysis event history along with NTE threshold limits that the vehicle must

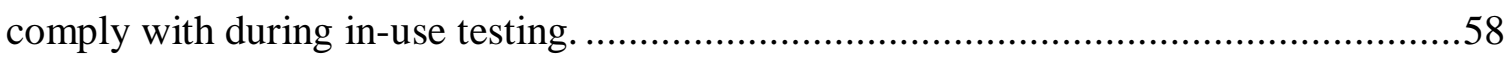




\title{
NOMENCLATURE
}

\author{
AECD - Auxiliray Emission Control Device \\ CAA - Clean Air Act \\ CFR - Code of Federal Regulations \\ CMD - Count Mode Diameter \\ CNG - Compressed Natural Gas \\ CO - Carbon MonoOxide \\ CO2 - Carbon-di-Oxide \\ CRT - Continuously Regenerating Traps \\ CVS - Constant Volume Sampling \\ DCS - Diffusion Charger Sensor \\ DF - Dilution Fraction \\ DOC - Diesel Oxidation Catalyst \\ DPF - Diesel Particulate Filter \\ EC - Elemental Carbon \\ ECU - Engine Control Unit \\ EEPS - Engine Exhaust Particle Sizer \\ EERL - Engines and Emissions Research Laboratory \\ EGR - Exhaust Gas Recirculation \\ FTP - Federal Test Protocol \\ HC - Hydrocarbons
}


HEPA - High Efficiency Particulate Filters

LSD - Low Sulphur Diesel

MY - Model Year

NMHC - Non-Methane Hydrocarbon

NOx - Oxides of Nitrogen (NO \& NO2)

NTE - Not-To-Exceed

OBD - On-board Diagnostics

OC - Organic Carbon

OEM - Original Equipment Manufacturer

PAH - Polycyclic Aromatic Hydrocarbons

PEMS - Portable Emission Measurement System

PM - Particulate Matter

PNC - Particle Number Counter

PTFE - Poly-Tetra-Flouro-Ethane

QCM - Quartz Crystal Microbalance

SCR - Selective Catalytic Reducer

SMPS - Scanning Mobility Particle Sizer

SSV - Sub-Sonic Venturi

TEMS - Transportable Emissions Measurement System

TEOM - Tapered Element Oscillating Microbalance

THC - Total Hydrocarbons 
TPM - Total Particulate Mass

TRU - Transportable Refrigeration Unit

TWC - Three-Way Catalyst

UDDS - Urban Dynamometer Driving Schedule

ULSD - Ultra-low Sulphur Diesel

US - United States

US-EPA - United States Environmental Protection Agency

VGT - Variable Geometry Turbo

VOR - Volatile Particle Remover

WHSC - World Harmonized Stationary Cycle

WHTC - World Harmonized Transient Cycle 


\section{CHAPTER 1. INTRODUCTION}

The United States Environmental Protection Agency's 2010 particulate matter (PM) regulations and United Nations Economic Commission for Europe's 2013 EURO-VI regulations have required manufacturers to produce a new range of low emission vehicles. These vehicles are currently being certified at $0.01 \mathrm{~g} / \mathrm{bhp}$-hr in the United States (US), and they are fitted with advanced aftertreatment systems such as diesel particulate filters (DPF) and selective catalytic reduction (SCRs) systems for diesel fueled vehicles and three-way catalysts (TWCs) for natural gas fueled vehicles. The use of these modern aftertreatment systems has resulted in PM mass emissions decreasing by nearly two orders of magnitude since 2004. As a result, the laboratory measurement capabilities have been significantly challenged in measuring the true mass of PM emitted from current model year (MY) engines/vehicles.

Detailed studies have been performed on variability associated with measuring PM emissions using the regulated method of gravimetric analysis [1,2]. The sources of variability are influenced by several factors such as dilution ratio, dilution methods, gas phase hydrocarbons, filter face temperature, filter weighing and filter handling. With the PM emissions from modern heavy duty engines being close to detection limits of the gravimetric analysis measurement method, the noise-to-signal ratio is significantly higher than measuring PM emissions from older MY engines/vehicles. Thus, the noise introduced during regulated PM measurement plays an important role in quantifying PM emissions. In addition to this repeatability and reproducibility are greatly reduced at low PM emissions levels [1]. Hydrocarbon adsorption by the PM filter also influences the PM emission measurement.

The chemical and physical composition of particulate matter of PM emissions from these modern heavy vehicles are significantly different than older model year (MY) engines [3-6]. Thus variability studies performed in the past are not representative of emissions characteristics from modern engine/vehicle technologies. In addition to this, the requirement of in-use compliance also poses a significant challenge in measuring PM emissions during valid Not-ToExceed (NTE) windows. 


\subsection{Objective}

The objective of this study is to characterize the variability in PM mass emissions measurements observed during in-use chassis dynamometer testing from advanced current model year diesel and natural gas engines and compare against an alternate real time mass measurement method. Alternate real time mass measurement method involves the measurement of instantaneous particle size distribution and number counts.

The study involves the variability analysis performed on results obtained from engine and chassis dynamometer tests. Chassis dynamometer tests were performed on four current model year goods movement vehicles with different engine and aftertreatment technologies. The test vehicles were operated over four different goods movement cycles. The engine dynamometer tests performed on a transportable refrigeration unit (TRU) engine retrofitted with DOC-DPF aftertreatment system. The TRU engine was compliant with US EPA's off-road Tier-4 emission standards and was operated over the 4-mode steady state test cycles. Particle size distribution and number count measurements were performed using the Engine Exhaust Particle Sizer ${ }^{\circledR}$ (EEPS) spectrometer for transient engine operation and Scanning Mobility Particle Sizer ${ }^{\circledR}$ (SMPS). Additionally, the study was extended to an in-use study in order to compare emissions during NTE regions. 


\section{CHAPTER 2. REVIEW OF LITERATURE}

\subsection{Formation of Particulate Matter Emissions}

Diesel combustion in direct injection diesel engines primarily comprises two stages in combustion, namely pre-mixed combustion and diffusion combustion. Pre-mixed combustion is the rapid combustion of vaporized fuel that has mixed with air to form a localized fuel-rich region. This mode is characterized by rapid rise in-cylinder pressure or apparent heat release rate in the cylinder. This leads to the breakdown of the fuel resulting in the formation of polycyclic aromatic hydrocarbons (PAHs) emissions towards the end of the pre-mixed combustion phase. $\mathrm{PAH}$ emissions are also known to be the precursor to soot formation, transitioning from gas phase to particulate phase though a complex chemical and physical process [7-9] which is illustrated in Figure 2.1.

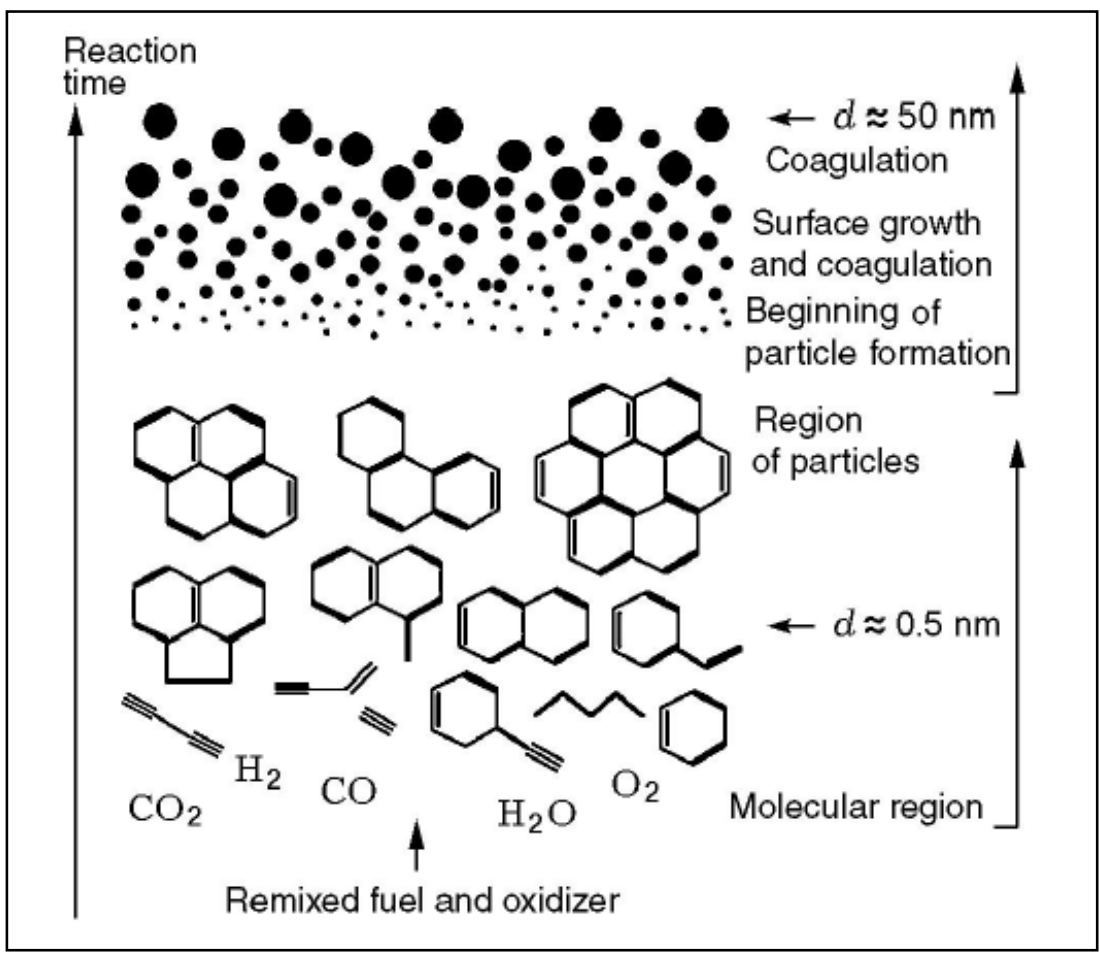

Figure 2.1 Schematic diagram of soot formation in homogenous systems or in pre-mixed combustion [9]

Once the transition of the PAH molecules from gas phase to particle phase is completed, the soot particles begin to grow and coagulate forming larger and larger particles. As the particles continue to grow, being influenced by various engine parameters, the particles also begin to absorb gas phase PAH emissions at the same time, which intern increases overall 
particle density. The end results of this highly advanced chemical and physical process is diesel soot characterized by the black smoke emitted from diesel engine exhaust in older model year vehicles. Throughout the soot formation process the hydrogen-to-carbon ratio of the particle continuously decrease.

The process of nucleation also produces a large number of particles due to the condensation of volatile and semi-volatile compounds at high partial pressures of the compounds. These small particles impose an insignificant amount of soot loading on particulate filters. During surface growth the particles gain most of their solid-phase material due to condensed nucleation mode particles depositing hydrocarbons on to the surface of the soot particles. Over time, particle diameter of these soot particles increase with simultaneous decrease in total particle number count [10]. In general, during surface growth the nucleation mode particles transition to accumulation mode particles. Further, during the dilution process these large soot particles grow even more in mobility diameter through aggregation.

Various engine parameter also affect soot formation, but pressure in particular has a great influence, particularly in soot density. Soot particle density increases significantly due to elevated pressure during the soot formation process. Controlled combustion studies using ethylene flames has shown that the density of the carbon atoms in the soot particles are significantly increased at higher pressures [9, 11]. Temperature also affects soot formation greatly, as pyrolysis at elevated temperature leads to the formation of free radicals. These free unstable radicals begin to form higher hydrocarbons through polymerization, thus limiting soot formation process to $1000-2000 \mathrm{~K}[9,11,12]$. Detailed correlation studies relating flame temperature to particulate emissions have been performed on a single cylinder diesel engine [13]. In addition to soot, particulate emissions from heavy-duty vehicles also consists of nucleation mode particles formed due to condensation of gas phase hydrocarbons when the exhaust cool down, mineral salts from the lubrication oil and sulphates emitted during high temperature operation [14-16].

\subsection{Evolution of PM Emissions from Heavy-duty Diesel Engines}

Particulate matter emissions from engines or motor vehicles are defined as anything that is collected on the gravimetric filter, making it also the only exhaust emission that is not 
chemically defined by the United States Environmental Protection Agency (US EPA) [17]. On the other hand it is important to identify the different constituents of PM that contribute to the total mass measured through the regulated gravimetric method as being physical or chemical in nature. This allows the identification of source and cause of total PM emissions measured during various studies and certifications that have been or will be performed on internal combustion engines.

The physical and chemical characteristics of particulate matter emissions has always been governed by the particulate emissions standards set during the that period by the respective environmental protection agencies in the US or Europe. The reason for this is that the manufacturers have always had to develop suitable engines and engine technologies to meet these standards. Thus the environmental standards set during the respective periods can also be known as technology forcing standards.

\subsubsection{US Standards ( PM - $0.25 \mathrm{~g} / \mathrm{bhp}-\mathrm{hr}$ )}

Beginning with 1991, US-EPA made the first announcement for heavy-duty diesel engines of a particulate standard of $0.25 \mathrm{~g} / \mathrm{bhp}-\mathrm{hr}$, prior to this period the particulate emission standards were set at $0.60 \mathrm{~g} / \mathrm{bhp}-\mathrm{hr}$. The $0.25 \mathrm{~g} / \mathrm{bhp}-\mathrm{hr}$ standard for PM emissions was based on the revisions of the Clean Air Act of 1977 [18] which later became the 1991 standard for heavyduty diesel engines. In order to comply with these standards manufacturers approached the

problem by optimizing and improving the mixing of air and fuel inside the cylinder. This was done with the help of an axis-symmetric arrangement of the combustion chamber and orientation and geometry of the piston bowl. In addition to this lubrication oil consumption was also controlled. During this period PM emitted from heavy duty engines primarily constituted of elemental carbon (EC) or soot, sulphuric acid particles or sulphates, volatile and semi-volatile organic fraction and significant amounts of lubrication oil but EC, sulphates and lubrication oil being the dominating constituents in PM emissions of this period [19].

\subsubsection{US Standards ( PM - $0.1 \mathrm{~g} / \mathrm{bhp}-\mathrm{hr}$ )}

In the following years several advancements where made in diesel combustion technology mainly though fuel injection system optimization and modification in combustion chamber geometry and orientation. In 1994, the $0.1 \mathrm{~g} / \mathrm{bhp}-\mathrm{hr}$ was in effect and called for the 
manufacturers to reduce the particulate emissions by $60 \%$ from 1991 particulate levels. The sulphur content in the fuel was regulated down to 500ppm making it low sulphur diesel (LSD). The low sulphur content in the fuel also reduced particulate emissions contributed due to sulphates significantly. Further optimization in injection strategies and mixture formation were used while continuing to reduce lubrication oil consumption in order to reduce PM emissions However, lubrication oil consumption was still significant enough to affect PM emissions as one of the dominating contributors along with soot. With the introduction of diesel oxidation catalyst (DOC) in the later years, diesel PM levels continued to drop especially those contributed by volatile and semi-volatile organic compounds[19].

\subsubsection{US Standards ( PM - $0.1 \mathrm{~g} / \mathrm{bhp}-\mathrm{hr}$ )}

In October 1997, United states EPA adopted the new emission standards for model year 2004 and later heavy-duty engines. Although the emissions standards for non-methane hydrocarbons (NMHC) and NOx were reduced to approximately $0.5 \mathrm{~g} / \mathrm{bhp}-\mathrm{hr}$ and $2.0 \mathrm{~g} / \mathrm{bhp}-\mathrm{hr}$ respectively, the standards for PM emissions remained the same as the 1998 levels. The aerosol size distribution of the diesel engine exhaust during this period was in general bi-modal in nature having two count mode diameters (CMD) as shown in Figure 2.2. The smaller CMD were nucleation mode particles caused due to nucleated hydrocarbons and sulphate particles and larger CMD was due to accumulation mode particles consisting of carbonaceous soot particles that have adsorbed hydrocarbons and sulphates [5, 19, 20]. Although the total particulate number count was dominated by the nucleation mode particles of less than $100 \mathrm{~nm}$ in mobility diameter, mass was still dominated by accumulation mode soot particles as seen in Liu et al. (2009) study [5, 19-22]. As for the chemical composition of soot was the primary dominating factor for PM emissions followed by sulphates, lubrication oil and ash which is due to combustion or burning of lubrication oil in the cylinder as shown in Figure 2.3. On the other hand, un-burnt fuel contributing to PM emissions were minimal due to improved fuel-injection systems and injection strategies $[4,19,20]$. 


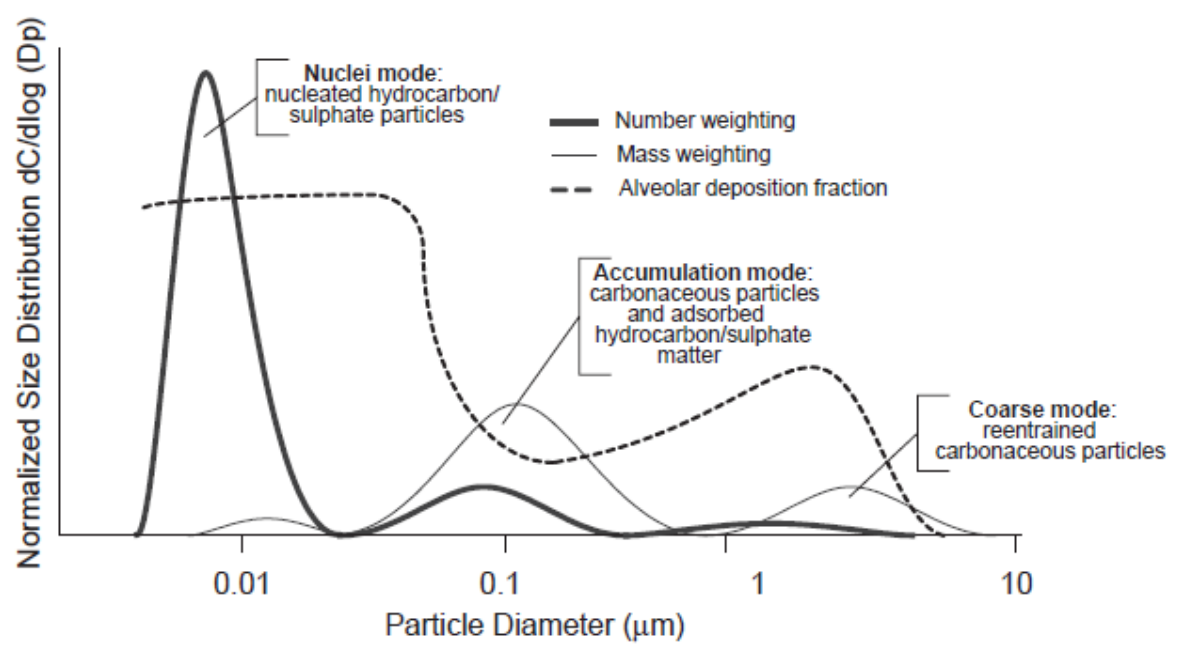

Figure 2.2 Typical aerosol size distribution of Pre-MY2007 Heavy-duty diesel engine exhaust [20, 23]

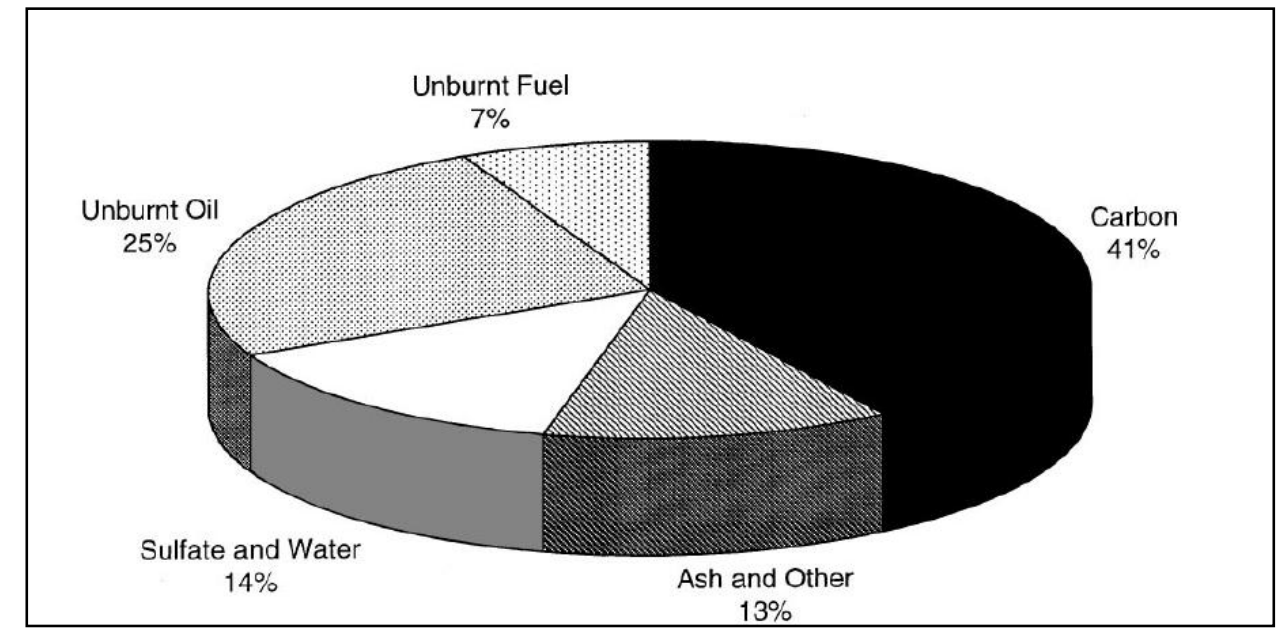

Figure 2.3 Typical composition for a Pre-MY2007 heavy-duty diesel engine tested in heavy-duty transient cycle [20]

With the reduction in NOx emission standards, manufacturers had to use more cost effective methods to control their emissions, mainly in-cylinder techniques involving the use of cooled exhaust gas recirculation (EGR) [24], optimizing intake charge parameters, and retarded injection timing. However, this increased the significance of the NOx to PM emissions trade-off as reducing one meant increased the other.

Firstly, injection timing greatly influenced the NOx emissions as well as the brake thermal efficiency of the engine. Since advancing or retarding injection timing increased or decreased peak in-cylinder pressure this, as a result, varied the NOx emissions produced by the engine $[8,25,26]$. In general, for every 10 bar of decrease in in-cylinder peak pressure the NOx 
emissions decrease roughly by 10 percent $[8,27]$. Second, reducing intake charge temperature played an important role in bringing down the overall combustion temperature and peak incylinder temperatures as well. This was a concern with turbo-charged engines which were widely used at this time since compressing air to a higher pressure increased the temperature of the intake air. Effective methods of inter-cooling were used to control the intake charge temperature. Reducing intake charge temperature brought down the NOx emission level. On the other hand, use of EGR systems introduced more concern for bringing down the intake charge temperature. EGR systems work by redirecting a portion of the exhaust back into the intake to be mixed in along with the intake charge entering the piston. With the presence of exhaust gas diluents in the intake charge the combustion is altered and combustion efficiency is altered reducing NOx emissions and peak in-cylinder pressures. But this increases the intake charge temperature due to the addition of hot exhaust to the fresh intake air, thus was the need for a cooled EGR system. This further introduced more complications such as EGR cooler fouling due to PM, thus it was important have a balance between PM emissions, EGR rate and NOx emissions.

Finally, the use of high injection pressure and rate shaping which greatly improved the performance of diesel engines and emission levels. With the use of injection pressure as high as 2000 bar and electronic fuel injection systems it was possible to perform extremely precise fuel injection strategies with maximum combustion efficiency. This drastically changed the physical and chemical characteristics of PM along with NOx emission levels. However, the emissions trade-off between NOx and PM still remained in the form of pre-mixed combustion and diffusion combustion. Pre-mixed combustion duration governed the amount of PM produced by the diesel engine whereas diffusion combustion duration governed the amount NOx produced during combustion. In addition to injection rate shaping, air management techniques such as turbocharging, inter-cooling, flow distribution in a multi-cylinder engine and tangential or helical intake-port geometry from an engine design perspective to reduce NOx emissions [8, 10, 24, 27]. Tangential and helical intake port were the most commonly used to provide swirl or air rotation in the cylinder while maintain good volumetric efficiency [10, 27]. Both swirlsupported combustion (combustion that usually occurs in an engine with helical intake port) and quiescent combustion (combustion that usually occurs in an engine with tangential intake port) both assist in proper mixing of air and fuel mixture and thus increased the rate and duration of 
diffusion combustion, hence it was the primary strategy to reduce PM emission levels. Thus manufacturers were able to optimize diesel combustion in order to comply with the emission standards

\subsubsection{US Standards ( PM - $0.01 \mathrm{~g} / \mathrm{bhp}-\mathrm{hr} ; \mathrm{NOx}-0.2 \mathrm{~g} / \mathrm{bhp}-\mathrm{hr}$ )}

On December 21, 2000 the United States Environmental Protection Agency (US EPA) finalized the emissions standards for model year 2007 and later heavy-duty engines. The 2007 regulations comprised of both diesel fuel as well as emission standards. Diesel fuel standards consisted of adopting ultra-low sulphur diesel (ULSD) containing less than $15 \mathrm{ppm}$ of sulphur for on-road application. However, non-road engines were exempt from using ULSD but rather had to move to LSD containing 500 ppm sulphur. The 2007 standard for PM and NOx standards were set at $0.01 \mathrm{~g} / \mathrm{bhp}-\mathrm{hr}$ and $0.2 \mathrm{~g} / \mathrm{bhp}-\mathrm{hr}$, respectively. This meant that in order for the manufacturers reduce their PM emissions by ten folds they had to employ aftertreatment devices, specifically combination of DOC and continuously regenerating trap (CRT) or diesel particulate filters (DPF) and/or selective catalytic reduction (SCR) systems, in order to comply with emission regulations. This however introduced the problem of increased sulphate emissions since the catalyzed surface oxidized $\mathrm{SO}_{2}$ to $\mathrm{SO}_{3}$ [28]. Moreover, high sulphur levels in the exhaust causes sulphur poisoning of the catalyst, reducing active catalyst sites where the reactions can occur $[16,29]$. Thus, the US EPA required the use of the above mentioned ULSD fuel for on-road diesel fueled vehicles which brought down the overall particulate emission levels [30, 31]. The engine manufacturers were given a phase in period between 2007 and 2010 on a sales basis [8], during which the manufacturers came up with several combination of incylinder strategies and aftertreatment devices to meet the necessary emission level. By the end of 2009, almost all of the model year 2009 or later on-road heavy duty diesel vehicles where equipped with DOC-DPF-SCR aftertreatment package. DOC-DPF used to reduce carbon monoxide (CO), HC and PM emissions and the SCR which was typically a urea-SCR system was used reduce NOx emissions. In addition to this, manufacturers also began to use variable geometry turbo-chargers (VGT) instead of using a fixed geometry turbo-charger. VGT allowed more precise control over the boost pressure of the intake charge and eliminated problems such as 'turbo-lag' which is caused due to in-sufficient boost provided by fixed geometry turbochargers at low speeds. 
There were drastic changes in the physical and chemical composition of PM from 2004 onwards. The domination accumulation mode particles contributing to PM mass was no longer found in model year 2007 [5, 32] and later engines that were equipped DOC-DPF aftertreatment devices. These particulate traps captured almost $99 \%$ of the accumulation particles or soot from the engine [5, 22, 33, 34]. Moreover, the nucleation mode consisted of 30-100 nm particles composed mainly of sulphate particles released during high temperature operations $[5,6,14,22$, 33, 34]. Chemically, PM composition was dominated by sulphates during high temperature operations followed by volatile and semi-volatile organic fractions. High temperature operations are usually associated with passive or active regeneration of the DPF. On the other, the volatile organic fraction also introduces variability in measuring regulated PM mass emissions using gravimetric analysis due to $\mathrm{HC}$ adsorption of the filter [2].

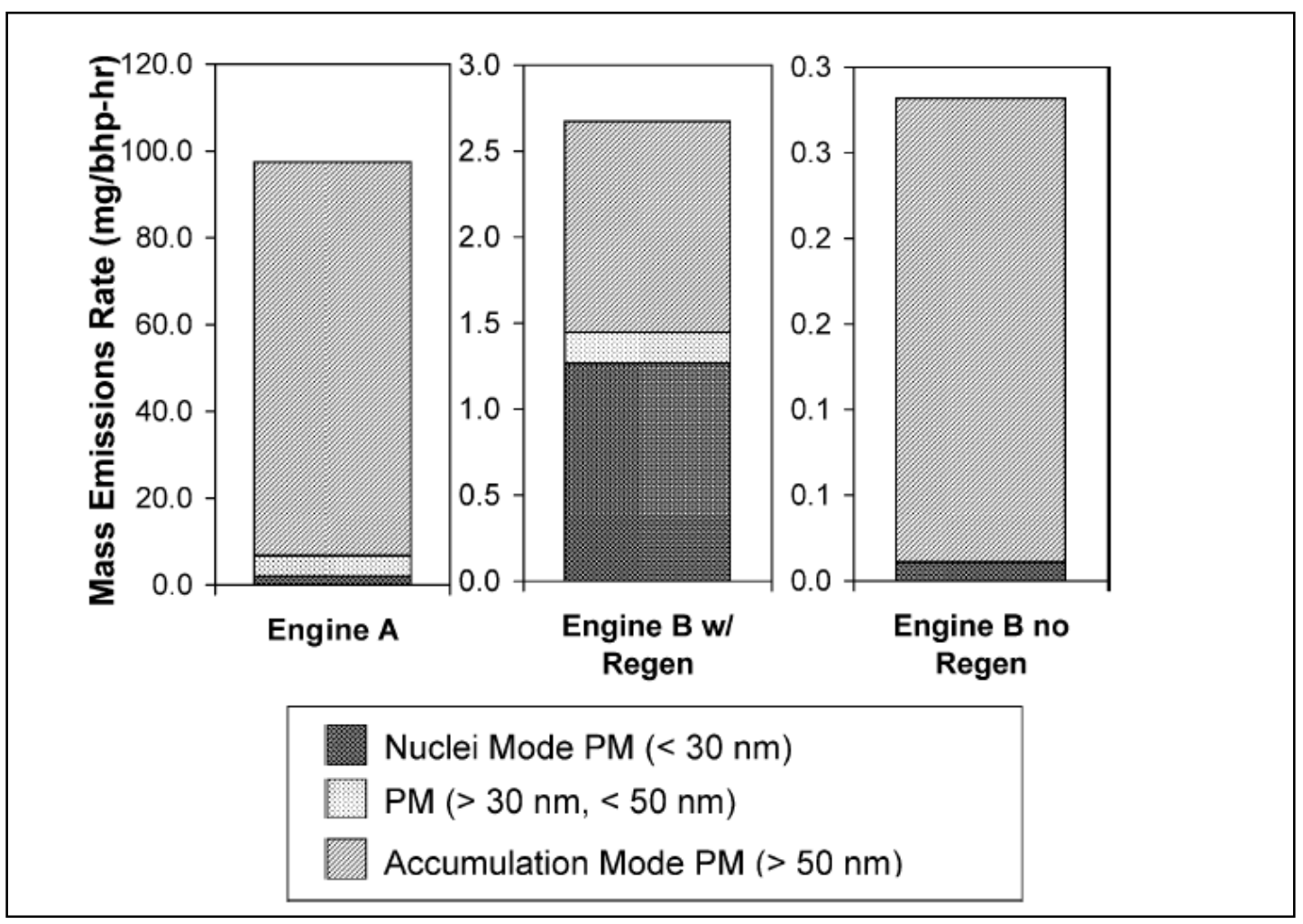

Figure 2.4 Categorization of the mass based size classification of particles from each engine exhaust emissions. PM mass calculated using integrated particle size distribution (IPSD) method for low and ultralow emissions from Engines A and B, respectively. Engine A is a low emitting MY2004 engine compliant with 2004 US-EPA regulations. Engine B is ultra-low emitting MY2007 engine compliant with 2007 US-EPA regulations and equipped with a DOC-DPF aftertreatment system [22]

With the use of advanced after-treatment systems such as DOC to reduce CO and HC emissions, DPFs to reduce PM emissions and SCR systems to reduce NOx emissions 
manufacturers turned their attention towards fuel penalties incurred due to maintenance of these advanced systems. DPFs, being active or passive in regeneration, had to have the filter frequently cleaned to reduce the back pressure applied to the engine due to increasing soot load during operation. This was done by the use of electrical heater or injecting diesel in the exhaust for active DPF systems or running the engine at a high temperature mode where the engine out exhaust temperature was higher than usual levels. As for the DOC and SCR systems they too had to be regenerated as sulphur deposition overtime on the DOC reduced its active catalytic sites and SCR systems also incurred problems with HC deposition on the catalyzed surface thus the need for maintenance events or auxiliary emission control device (AECD) event.

\subsubsection{Euro-VI Standards ( PM - $0.01 \mathrm{~g} / \mathrm{kWh} ; \mathrm{PN}-6.0 \times 10^{11} \mathrm{kWh}^{-1}$ )}

In June of 2009, the 2013 Euro-VI standard was adopted across Europe and in effect from January of 2013 onwards. Along with gaseous and PM emission limits that are comparable to 2010 US EPA emissions level standards, particle number (PN) count limits were also introduced. Engines certified under this standard had to comply with $0.1 \mathrm{~g} / \mathrm{kWh}$ PM standard in World Harmonized Stationary Cycle (WHSC) and World Harmonized Transient Cycle (WHTC). Engines also had be under $5.97 \times 10^{11} \mathrm{bhp}-\mathrm{hr}^{-1}$ in the WHSC and $4.47 \times 10^{11} \mathrm{bhp}-\mathrm{hr}^{-1}$ in the WHTC in total PN emission for compression ignition engine and $5.97 \times 10^{12} \mathrm{bhp}^{-\mathrm{hr}^{-1}}$ in the WHSC and $4.47 \times 10^{12} \mathrm{bhp}-\mathrm{hr}^{-1}$ in the WHTC in total PN emission for spark ignite engines. In addition to this Euro-VI also included stricter on-board diagnostics (OBD) requirements and new testing requirements including off-cycle and in-use testing.

The recommended method to measure PN emissions according to EU standards consists of using a dilution tunnel and a volatile particle remover (VPR) between the PM sampling probe and particle number counter (PNC). A portion or all of the exhaust is initially diluted in the dilution tunnel. The primary diluted exhaust is sampled once again using a PM probe and preclassified using a particle pre-classifier before being sent to the VPR system. The VPR system primarily comprises a two dilution stage system, the first being a hot dilution and the later being a cold dilution. The VPR works by heating up the sample using hot dilution gas $\left(150{ }^{\circ} \mathrm{C}<\mathrm{T}_{\text {dil }}<\right.$ $400{ }^{\circ} \mathrm{C}$ ) which are further heated to about $400{ }^{\circ} \mathrm{C}$. The diluted sample is then rapidly cooled to a filter face temperature of $45^{\circ} \mathrm{C}$ to $50{ }^{\circ} \mathrm{C}$ with the help of a very cold dilution gas but the total residence time of the system does not exceed 20 seconds [35]. The idea is to heat the sample to a 
high temperature so that it will cause all the gas phase condensates to vaporize. The partial pressures of the volatile organic compound is also brought down by hot dilution and then the sample is rapidly cooled to prevent re-condensation of the volatile organic compounds. However, detailed studies done in the past have shown that re-condensation of volatile compounds takes place during rapid cold dilution [36].

\subsection{Heavy-duty Natural Gas Engines}

The Energy Policy Act of 1992 mandated the used use of alternative fueled vehicles. This drove the growing demand for compressed natural gas (CNG) infrastructure for fueling and vehicle technology. In the late 1990s the focus shifted to heavy-duty vehicle fleets for transit agencies, refuse trucks and delivery trucks. Currently, there are over 1,000 CNG refueling stations in the United States with a growing demand for more with the increased extraction of natural gas from the Marcellus Shale [37]. Concurrently over the years, natural gas fueled engine technology has advanced significantly. This reduced United States' dependency on imported oil as more and more heavy-duty vehicle fleets where converted to natural gas.

Natural gas is considered as a clean burning fuel since heavy-duty vehicles powered by natural gas fueled engines produce lower PM and NOx emissions as compared to their fellow diesel engines [34, 38-40]. These engines have to meet only NOx, NMHC and PM emission standards (NOx - 0.20 g/bhp-hr; NMHC - 0.14 g/bhp-hr and PM - $0.01 \mathrm{~g} / \mathrm{bhp}-\mathrm{hr}$ for model year 2007 and later engines) which is met with the help of a TWC aftertreatment systems and are exempt from methane emissions. However, these engines fuelled by natural gas are known to produce higher amounts of $\mathrm{CO}$ and THC emissions than diesel engines of similar size and power rating, but the Clean Air Act (CAA) of 1977 exempt these vehicles from complying with methane $\left(\mathrm{CH}_{4}\right)$ emission and as for PAH emissions are minimal and within detection limits of the instruments for some cases [41]. Moreover, combustion in a modern stochiometric natural gas engine is dominated by pre-mixed combustion thus resulting in more NOx emissions as compared to PM emissions which is mainly formed during diffusion combustion. Thus PM mass measured for these engines consists mostly of volatile and semi-volatile organic compounds that have condensed into nucleation mode particles during dilution [3]. Figure 2.5 shows the elemental carbon (EC) and organic carbon (OC) split of the PM emissions from a natural gas fuelled vehicle. 


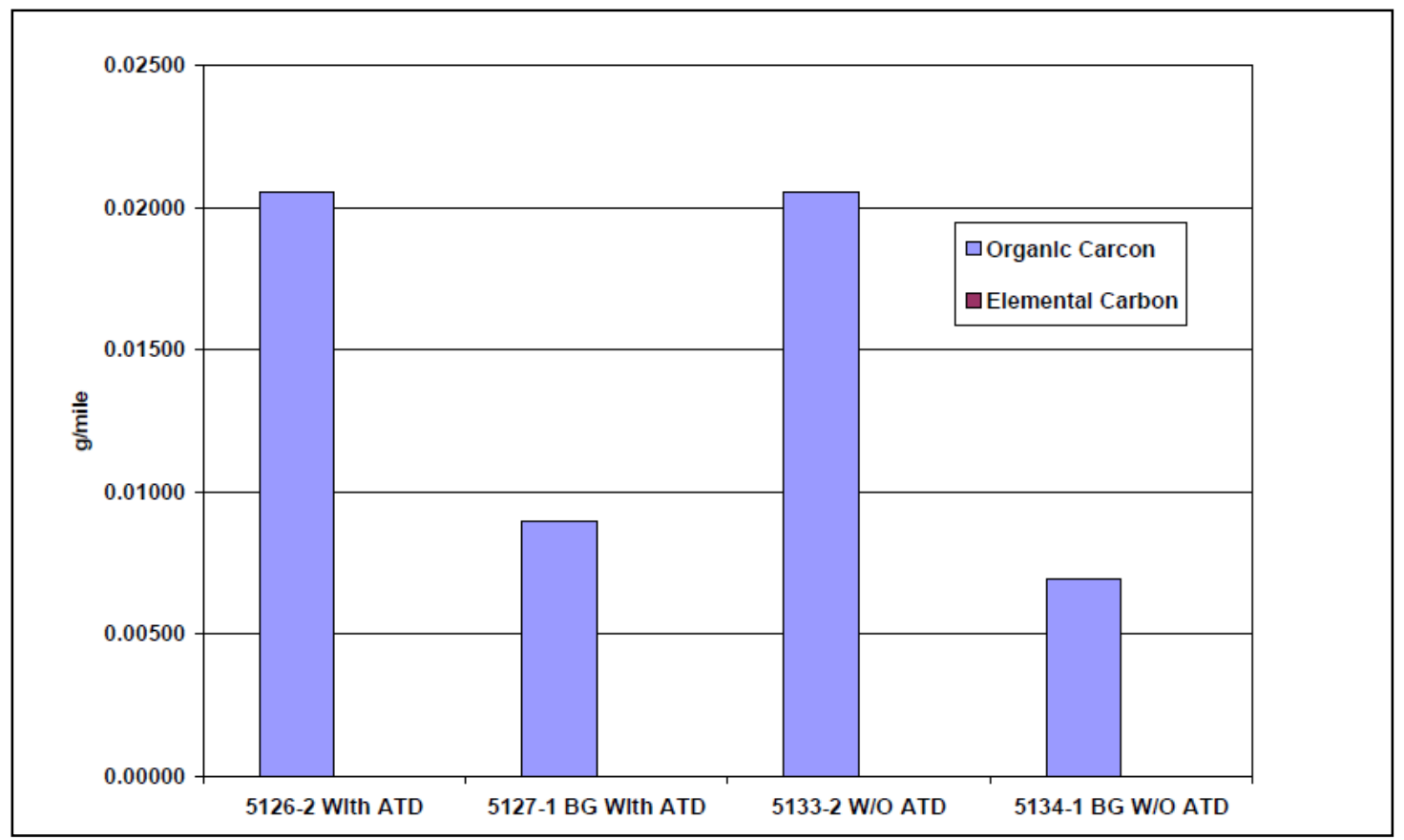

Figure 2.5 EC/OC Emissions from Riverside Transit Authority bus [38]

\subsection{Influence of Aftertreatment Systems on PM Emissions}

The 2007 US EPA standards forced engine manufacturers to use advanced emission control devices to reduce engine/vehicle emissions. Although different manufacturers used different approaches to reduce their engine-out emissions, they used more or less a similar method to reduce the tail-pipe emissions. Diesel engines used DOC to reduce $\mathrm{HC}$ and $\mathrm{CO}$ emissions, DPFs to filter out PM and urea-SCR systems to reduce NOx from the exhaust. On the other hand engines that were powered by natural gas were certified with the three-way catalyst (TWC) systems. Although other emission control devices were also being used, the above mentioned devices were commonly used as OEM units.

\subsubsection{Diesel Oxidation Catalyst (DOC)}

DOCs are flow through catalyst that are coated with noble metals that promote oxidation in the presence of oxygen. DOCs are mainly used to reduce $\mathrm{CO}, \mathrm{HC}$ and organic fraction of diesel particulates or SOF. In addition to this, DOC also help reduce NMHC emissions, but most importantly it is used to bring $\mathrm{NO}$ to $\mathrm{NO}_{2}$ ratio to 1 . Diesel combustion typically produces high levels of $\mathrm{NO}$ as compared to $\mathrm{NO}_{2}$, optimal use of DOC allow this ratio to reach one, thus allowing SCR systems effectively reduce NOx at these ratios [42, 43]. However, since DOCs 
are primarily used to oxidize $\mathrm{NO}, \mathrm{CO}$ and $\mathrm{HC}$ in the exhaust, they also aid in the conversion of $\mathrm{SO}_{2}$ to $\mathrm{SO}_{3} . \mathrm{SO}_{3}$ in the presence of water vapor forms sulphuric acid particles also known as sulphates that contribute to $\mathrm{PM}$ emissions. $\mathrm{SO}_{3}$ molecules are also adsorbed onto the surface of the catalyst thus reducing the catalyst activity sites in the case of fuels and lubrication oils with high sulphur content being used. These stored [19] $\mathrm{SO}_{3}$ molecules are only released during high temperature operation, thus if the catalyst does not experience a high temperature event, the operational efficiency will reduce over time [14]. This is usually handled by periodic aftertreatment maintenance events.

\subsubsection{Diesel Particulate Filters (DPF)}

Diesel particulate filters are, as the name suggest, filters that capture diesel soot particles that are formed during combustion. DPFs that have been developed in the recent years have an extremely good filtration efficiency over $90 \%$ in mass basis. Wall flow type DPF are the commonly used filters in newer model year engines which have alternating channels of ceramic monoliths. The exhaust gas is forced through the porous walls and traps the soot inside the channels. In most cases, the DPF have wash coats of noble metals that aid in catalytic oxidation of the soot particles. In addition to this DPFs also use $\mathrm{NO}_{2}$ to oxidize the soot particles during passive regeneration process.

The filtration efficiency is greatly dependent on the soot loading of the DPF at that instant $[10,27]$. Newer DPF usually exhibit lower filtration efficiency, but as the DPF is degreened with several regeneration events it acquires a layer of ash that help trap smaller soot particles greatly increasing the DPF's filtration efficiency [5, 19]. However, DPF are not able to trap nucleation mode efficiently since a majority of them are formed during the dilution process [5]. The use of DPFs greatly changed the physical characteristics of PM. PM from late model year engines equipped with DPF aftertreatment systems are mostly comprised of nucleation mode particles [22].

\subsubsection{Selective Catalytic Reducers (SCR)}

SCR systems reduce NOx using ammonia, which is injected into the exhaust stream as

urea. The solution of urea and water is heated and injected into the exhaust at a high pressure. The urea undergoes thermolysis and hydrolysis to form ammonia and water vapor at 
temperatures above $200^{\circ} \mathrm{C}$. The catalyst brick adsorbs the $\mathrm{NH}_{3}$ radicals and then reduces $\mathrm{NOx}$ radicals to $\mathrm{N}_{2}$ and $\mathrm{H}_{2} \mathrm{O}$. When the ratio of $\mathrm{NO}$ to $\mathrm{NO}_{2}$ is 1 the NOx reduction rate is maximum [42] due to the temperature dependence of the reactions. Urea injection into the exhaust manifold takes place only after the exhaust temperature, as well as the catalyst brick temperature is above $200^{\circ} \mathrm{C}$. This is due to the fact that below this temperature the Urea does not hydrolyze properly and produces an undesired byproduct known as biuret $\left(\mathrm{NH}_{2} \mathrm{CONHCONH}\right)_{2}$ [43]. Moreover, at temperatures below $200^{\circ} \mathrm{C}$, there is a possibility for ammonium nitrate formation due to the influence of the $\mathrm{NH}_{3}$ radicals previously adsorbed on to the surface of the catalyst [42]. Thus, many manufacturers do not start Urea injection until the catalyst brick attains the minimal light-off temperature of roughly $200^{\circ} \mathrm{C}$. Studies have shown that engine operations at high temperature could result in higher nanoparticle formation with favorable dilution conditions [41]. The study also shows that there is an apparent increase in the number of nucleation mode particles found in the exhaust due to the presence of a SCR systems at high temperatures operations typical found during higher loads.

\subsubsection{Three-way Catalyst (TWC)}

Three way catalyst are typically used to cut down green house gas emissions from natural gas fuelled engines. They consist of multiple wash coats that can carry out oxidation of $\mathrm{CO}$ and $\mathrm{HC}$ to $\mathrm{CO}_{2}$ and water as well as reduction of NOx to oxygen and nitrogen. The ability of TWCs to effectively remove $\mathrm{CO}$ and $\mathrm{NOx}$ from the exhaust is influenced by the air-fuel ratio at which the engine is operated. In the case of modern stochiometric natural gas engines there is limited amounts of oxygen in the exhaust for oxidation reactions to take place. On the other hand, natural gas engine manufacturers use different strategies such as 'dithering' to control and regulate their air-fuel ratio for such engines to effectively reduce pollutants from the exhaust. Detailed studies have shown the influence of air-fuel strategies and its control [44]. However, the influence of TWCs on PM emissions are minimal because the sulphur content in methane

minimal hence PM emissions contributed by sulphates are also minimal. Detail studies have shown that majority of the PM emissions from natural gas fuelled engines are due to metal emissions originating from the combustion of the lube oil and engine wear [41]. 


\subsection{Particulate Mass Measurement Techniques}

\subsubsection{Regulated Gravimetric Method}

Gravimetric method of measuring PM is the regulated method of measuring PM where diluted exhaust gas is passed through a special poly-tetra-fluoro-ethylene (PTFE or Teflon) filter. Title 40 Parts 1065 of the Code of Federal Regulation (CFR) regulates that PM collected on filters during in-use or engine testing must be condition for at least one hour in a class six clean room [ISO 14644-1; $40 \mathrm{CFR} \S 1065.1010$ ] maintained at a temperature of $22 \pm 1{ }^{\circ} \mathrm{C}$, dew point of $9.5 \pm 1^{\circ} \mathrm{C}$ and air-return velocities less than $0.05 \mathrm{~m} / \mathrm{s}$. The low dew point is set to control the amount of water associated with sulfuric acid $\left(\mathrm{H}_{2} \mathrm{SO}_{4}\right)$ or sulphates. At these conditions about 1.2216 grams of water will be associated with each gram of $\mathrm{H}_{2} \mathrm{SO}_{4}$ [40 CFR $\S 1065.190$ ]. In addition to this the absolute pressure of the room is also continuously recorded, this is done in order to apply buoyancy correction on the measured mass to obtain the true mass of the filter. In order to obtain the true mass of PM collected the measured mass is multiplied by the correction coefficient calculated as follows[40 CFR $\S 1065.690]$ [45].

$$
m_{\text {cor }}=m_{\text {uncor }} *\left[\frac{1-\frac{\rho_{\text {air }}}{\rho_{\text {weight }}}}{1-\frac{\rho_{\text {air }}}{\rho_{\text {media }}}}\right]
$$

Equation 2.1 40 CFR $§ 1065.690-1$

$$
\rho_{a i r}=\frac{p_{a b s} * M_{m i x}}{R * T_{a m b}}
$$

\section{Equation 2.2 40 CFR § 1065.690-1}

Where:

$$
\begin{aligned}
& \mathrm{m}_{\text {cor }}=\text { PM mass corrected for buoyancy. } \\
& \mathrm{m}_{\text {uncor }}=\text { PM mass uncorrected for buoyancy. } \\
& \rho_{\text {air }}=\text { density of air in balance environment. } \\
& \rho_{\text {weight }}=\text { density of calibration weight used to span balance. } \\
& \rho_{\text {media }}=\text { density of PM sample media, such as a filter. } \\
& p_{\text {abs }}=\text { absolute pressure in balance environment. }
\end{aligned}
$$


$\mathrm{M}_{\text {mix }}=$ molar mass of air in balance environment.

$\mathrm{R}=$ molar gas constant.

$\mathrm{T}_{\mathrm{amb}}=$ absolute ambient temperature of balance environment.

However, this introduces errors into measuring the true mass of the PM collected as it does while measuring the true value of a quantity. Studies show that of samples who's densities are similar to steel are almost always correct, on the other hand samples with densities ranging from 500-4000 kg/m ${ }^{3}$ have significant errors arising from changing localized air densities [46]. Studies have also shown that there are significant variability of absolute pressure in an area with time, Figure 2.6 shows variability in the absolute pressure measure at specific place over a long period of time.

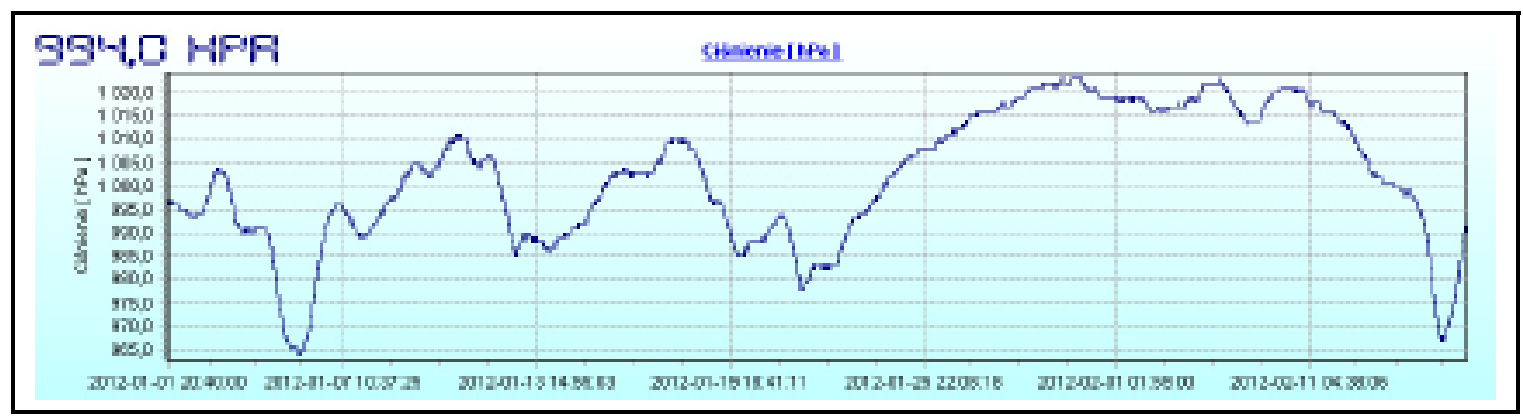

Figure 2.6 Record from air pressure changes within a time period between 7/2/2012 to 16/2/2012 [46]

As a result, the accuracy of the true mass measured through gravimetric analysis is dependent on the accuracy of measuring the localized absolute pressure and several other parameters such as ambient temperature of the clean room that must also been taken into consideration along with weighing and handling errors [2]. Moreover, the accuracy of gravimetric analysis also decreases while measure ultra-low levels of PM emitted as shown in Figure 2.7 along with laboratory-to-laboratory variations also known as reproducibility and test to test variations also known as repeatability are shown [1]. In addition to this there are also issues of positive artifacts being collected on the filters due to absorption and volatilization especially in the case of measuring natural gas engines which are characterized by their ultra-low PM emissions and high HC emissions [22]. Detailed studies show the effects of effects of dilution ratio, filter face temperature, filter face velocity and various other parameters that affect artifact deposition and measurement on variability of PM mass measurement [2]. 


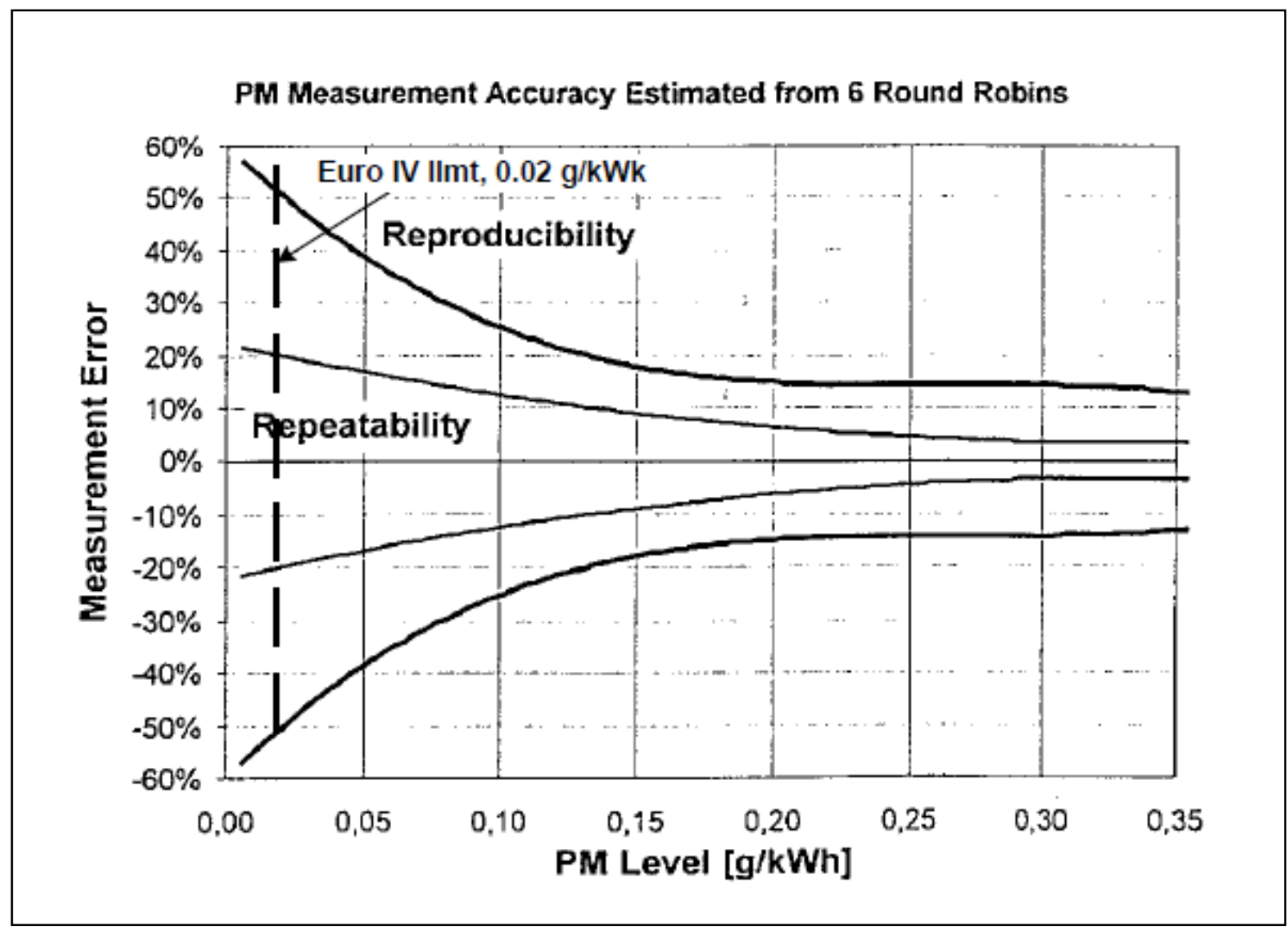

Figure 2.7 Accuracy of the standard gravimetric measurement as function of the mass emission [1]

\subsubsection{PM Portable Emission Measurement System (PEMS)}

In order to monitor the emissions performance of heavy duty engines when operated under real world conditions during typical on-road operations in in-use emission standards were introduced. Not-To-Exceed (NTE) standards were also introduced to the in-use compliance standards. The heavy duty in-use compliance program also took into consideration engine deterioration and provided an additive compliance margin. NTE emissions thresholds are a function of the respective engine certification standards along the with accuracy and compliance margins [45]. Portable emission measurement systems (PEMS) measures continuous concentration of regulated gaseous emissions and particulate matter emissions along with exhaust flow rate, ambient conditions, Global Position System (GPS) data and Engine Control Unit (ECU) broadcast. PEMS devices uses the regulated gravimetric method to collect PM emissions on Teflon filters. However, in order to quantify PM emissions during NTE events it is necessary to continuously track the amount of PM emissions in real-time. This is method of 
tracking PM emissions in real-time is done differently by different PEMS equipment manufacturers.

Three main PEMS manufacturers have their own unique version of PM PEMS devices which are all compliant with the US-EPA regulations. HORIBA's TRPM that connects to the HORIBA OBS-2200, the SEMTECH ECOSTAR by Sensors and AVL M.O.V.E consisting of the PM PEMS and GAS PEMS. All three of these devices uses a real time particulate measurement device which also makes it unique in its own way. The HORIBA TRPM uses TSI's EAD , SEMTECH ECOSTAR's SEMTECH CPM module utilizes ion mobility technique based on the Pegasor® PPS and the AVL M.O.V.E PM PEMS utilizes the AVL's Micro Soot Sensor. TSI's EAD and Pegasor® PPS are both diffusion charger sensors (DCS) but the Micro Soot Sensors is a Photo-Acoustic sensor that measures soot particles in the exhaust. The real-time particulate matter sensor continuously tracks and measures the particulate matter concentration that is being collected by the gravimetric filter as shown in Figure 2.8. The real-time PM sensor signal is then integrated over a valid NTE event and divided by the total integrated signal to obtain a PM sensor signal ratio. This signal ratio is multiplied against the total particulate matter (TPM) mass measured using gravimetric analysis to obtain the PM mass emitted during the valid NTE event. It should be noted that each system uses small variations of this methods to calculate the NTE-PM due to different measurement principles and instrument performance specifications. 


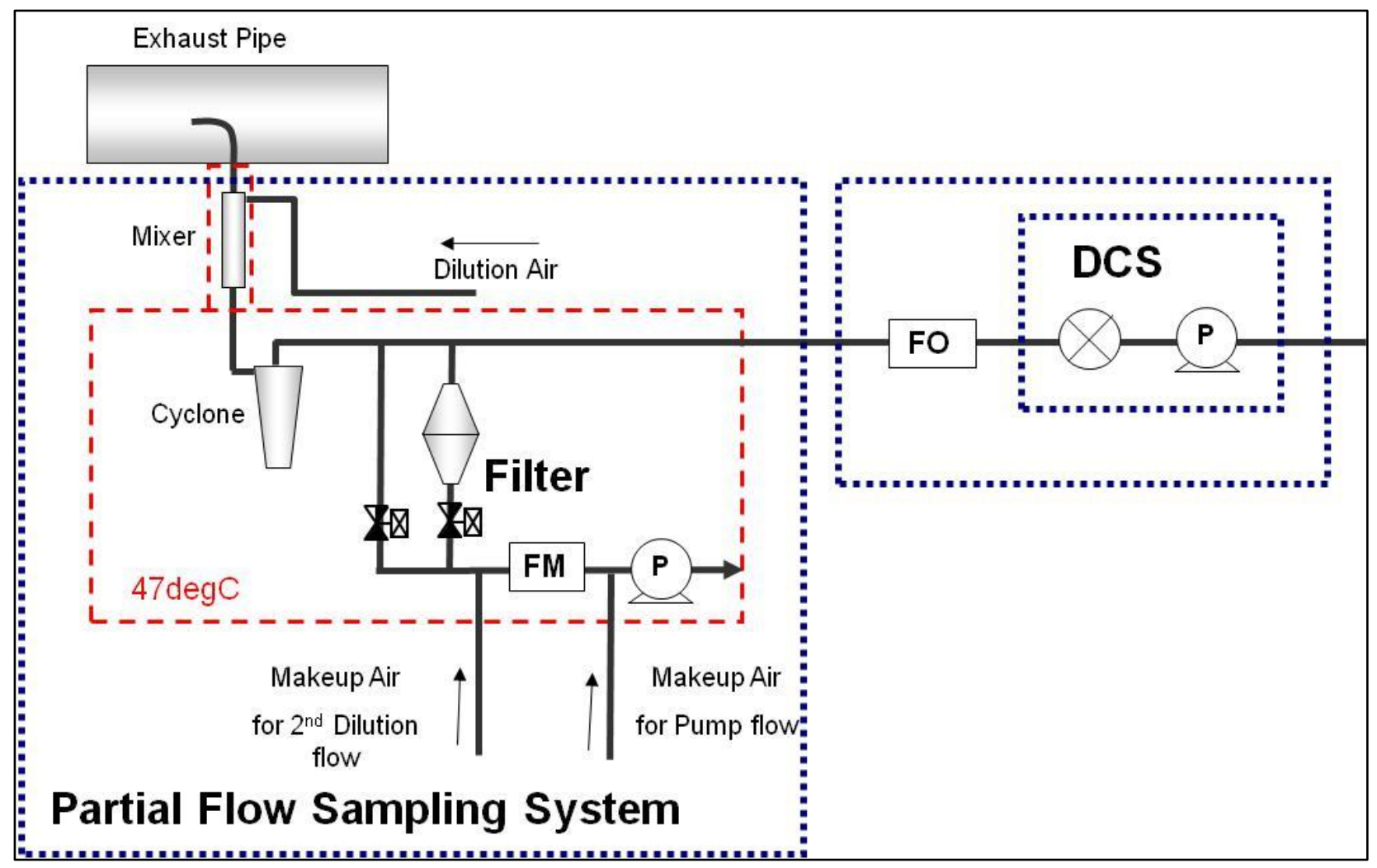

Figure 2.8 HORIBA TRPM system setup [47]

\subsubsection{Real-Time PM Measurement Methods}

There are several measurement techniques other than the US-EPA regulated gravimetric method to measure PM emitted by engines in real time using instruments like the Tapered Element Oscillating Microbalance (TEOM), Quartz Crystal Microbalance (QCM), Nephelometer, Aethalometer Photoacoustic Instrument. However, while measuring PM mass emission rates from engines using these instruments, errors involved in the measurement technique employed in some cases can obtain skewed results. On the other hand, PM size distribution and number count, measured using TSI's Scanning Mobility Particle Scanner ${ }^{\mathrm{TM}}$ $\left(\mathrm{SMPS}^{\mathrm{TM}}\right)$, TSI's Engine Exhaust Particle Scanner ${ }^{\mathrm{TM}}$ (EEPS $\left.^{\mathrm{TM}}\right)$ or Cambustion's DMS500 can also be used to calculate and estimate the instantaneous mass emitted by the engine. Some of these instruments are discussed in detail as follows.

\subsubsection{Tapered Element Oscillating Microbalance (TEOM)}

The TEOM uses a tapered glass tube with the base of the tube fixed while the tip is free to vibrate. The electronics in the TEOM makes sure that the amplitude of vibration is maintained constant. The tapered element or the mass transducers has a teflon-coated glass fiber 
filter cartridge mounted at the tip of the tapered element. As the particles get deposited on the filter cartridge, the change in mass causes change in particle mass which is continuously measured by the instrument. The change in frequency correlates to the change in mass deposited on the filter. This allows the instrument to perform regulated gravimetric analysis on the filter after the test as well. However, the TEOM exhibits negative mass emission rates at high dilution ratios which could be caused due to hydrocarbon desorption and variation in humidity content of the diluted exhaust [48].

\subsubsection{Diffusion Charger Sensor (DCS)}

The DCS uses a corona charger to ionize the dilution air which is mixed with the sample inlet. The ionized air transfers its charge onto the particles in the sample. As the diluted samples exits the DCS, the particles carry the charge along with them while ionized air is attracted to ion trap before exiting the DCS. The sensor measures the electrical current lost due to the charged particles escaping the DCS. The escaping current is equal to the charge carried by the particles, this is known as the escaping current principle. However, the DCS signal correlates well with surface area of the particles rather than the mass or volume of the particle. Thus using a signal that correlates well with the surface area of the particle to estimate mass emission during a NTE events could cause uncertainties in measurement.

\subsubsection{Photo-acoustic Sensor (AVL Micro Soot Sensor)}

Unlike the DCS, a photo-acoustic sensor does not measure anything that can carry a electrical charge. Rather, it uses a modulated and chopped light beam to heat up the incident soot particle, this causes periodic on-off heating of the particle results in pressure fluctuations. These pressure fluctuations are detected though a microphone, the microphone signal is linearly related to the soot concentration being measured. The principle of measurement for a Photo-Acoustic sensor limits the measurement of PM to black carbon or Soot and does not account for other PM artifacts such as HC, sulphates and metallic ash [49]. Further it introduces errors in the estimation of the NTE-PM when used as a real-time particle sensors for PEMS devices [50].

\subsubsection{Exhaust Emissions Particle Sizer Spectrometer (TSI EEPS)}

The TSI model 3090 EEPS spectrometer measures the particle size based on differential electrical mobility classification. The sample aerosol entering the measurement column is first charged by a negative diffusion charger in order to reduce the number of highly positive charged 
particles and prevent particle overcharging in the second charger. A predictable net positive charge is then applied to the particles before they enter the measuring section. The charged particles are then deflected radially outwards toward the outer cylinder wall by means of a positive high-voltage center-electrode and collected on electrically isolated electrode rings, depicted in Figure 2.9. Small particles, which have high electrical mobility, are deflected to the electrode rings near the top, whereas larger particles are deflected further downstream as flow moves from the top to the bottom of the measurement column. Particles, which land on the sensing electrodes, transfer their charge. The particle number concentration is then determined by measuring the electrical current at the electrode rings with electrometers, see Figure 2.9. Conceptually, the EEPS spectrometer works similarly to a Differential Mobility Analyzer (DMA) used in the TSI SMPS, with the difference that particles are deflected towards the outer cylinder wall, rather than to the center, as in a DMA.

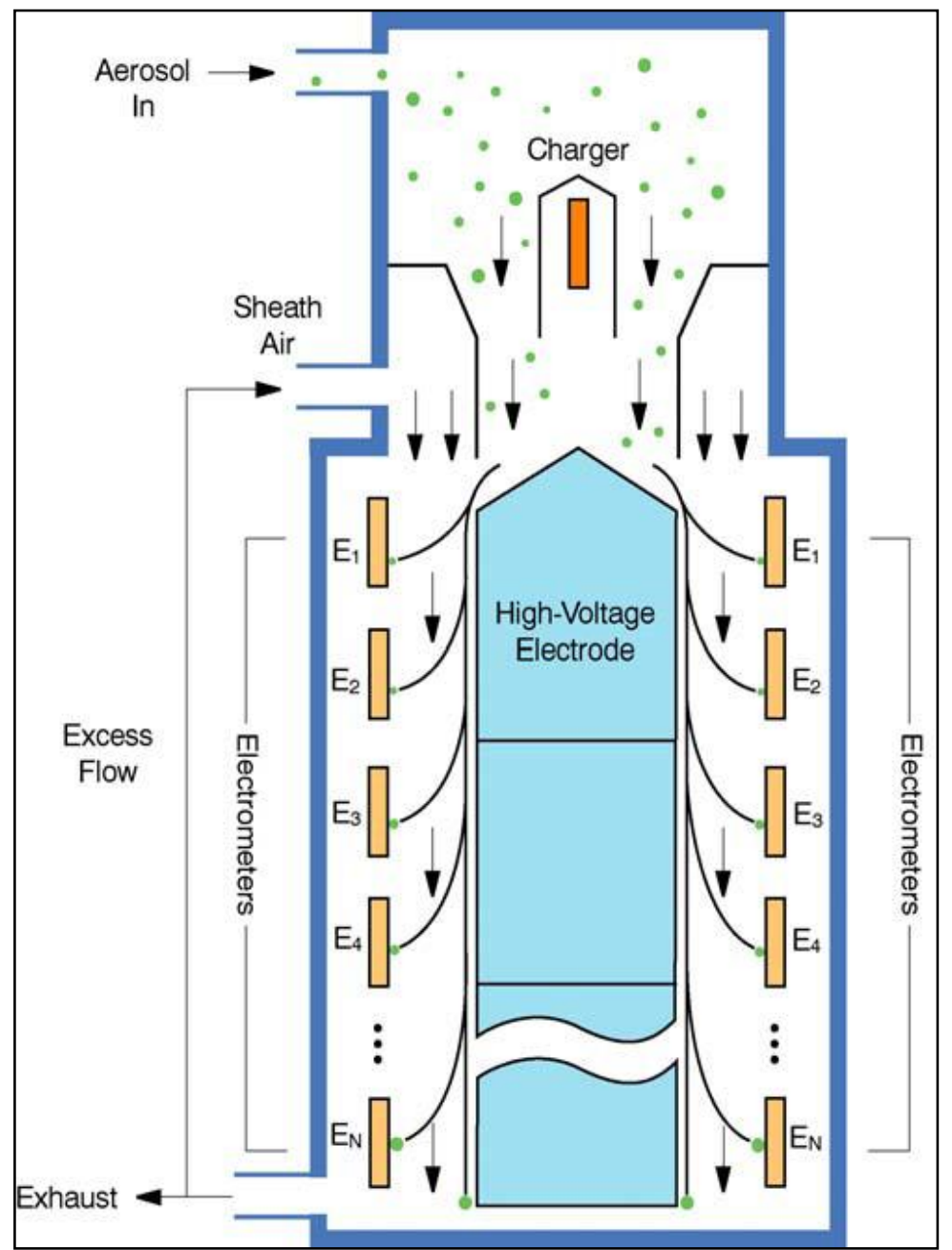

Figure 2.9 Schematic Diagram of the Model 3090 TSI EEPS Spectrometer [51] 
The EEPS spectrometer can measure a particle size range of 5.6 to $560 \mathrm{~nm}$, has a particle size resolution of 16 channels per decade (32 in total) and incorporates 22 electrometer channels. An inlet cyclone with a cut point of $1 \mu \mathrm{m}$ removes large particles that are above the instrument's size range. The maximum data rate allows up to 10 size distributions per second. 


\section{CHAPTER 3. EXPERIMENTAL SETUP}

\subsection{Engine Testing Laboratory}

CAFEE's main research facility is the Engines and Emissions Research Laboratory (EERL) located at West Virginia University's Evansdale campus in Morgantown, West Virginia. The laboratory houses two dilution tunnels, one compliant with 40 CFR Part 86 and the other with 40 CFR Part 1065 making the laboratory flexible from an regulatory aspect. The heavyduty engine test cell follows the recommendations outlined in the Title 40 of CFR, Parts 86 and 1065 [45]. EERL facility houses four heavy-duty engine test cell, however this study used only the steady state engine test cell. The steady state engine test cell consists of a $100 \mathrm{hp}$ eddy current dynamometer along with Dyn-Loc control system. A schematic overview of the EERL's air handling and measurement system, for regulated engine exhaust emissions, is given in Figure 3.1 .

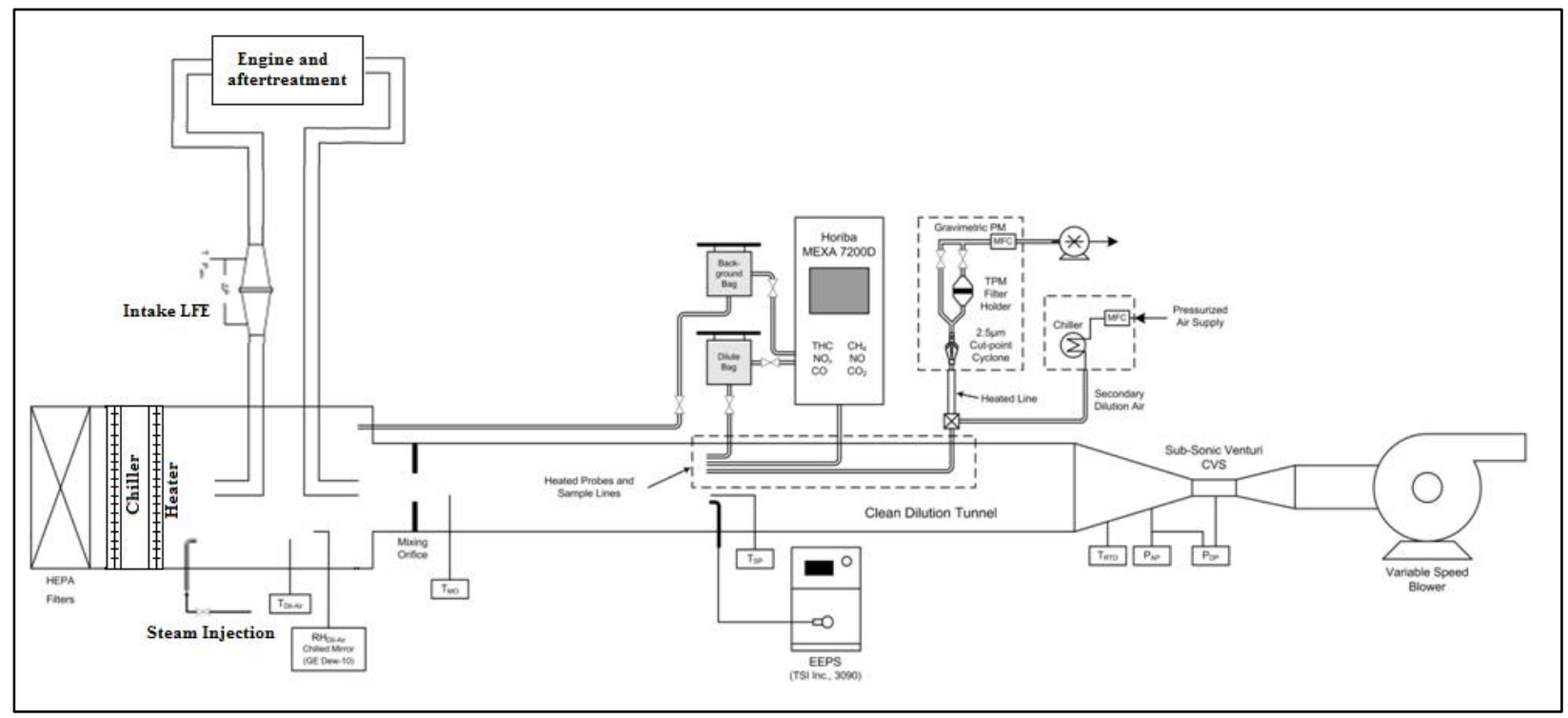

Figure 3.1 Schematic overview of WVU CAFEE EERL's engine testing laboratory

The full flow constant-volume sampling (CVS) tunnel at EERL used for this study is designed to simulate the mixing of exhaust gas with ambient air conditions, maintains a nominally constant total molar flow rate of the diluted exhaust, as outlined in the Title 40 of CFR Part 1065 Subpart 140 [52]. To accurately measure and actively control the flow rate maintaining proportional sampling of the exhaust constituents, a subsonic venturi (SSV) flow meter shown in 
Figure 3.2. The SSV was calibrated for a Reynolds number at the throat greater than the maximum Reynolds number expected during testing and used only between the minimum 1500 scfm and maximum of 1900 scfm calibrated flow rates.

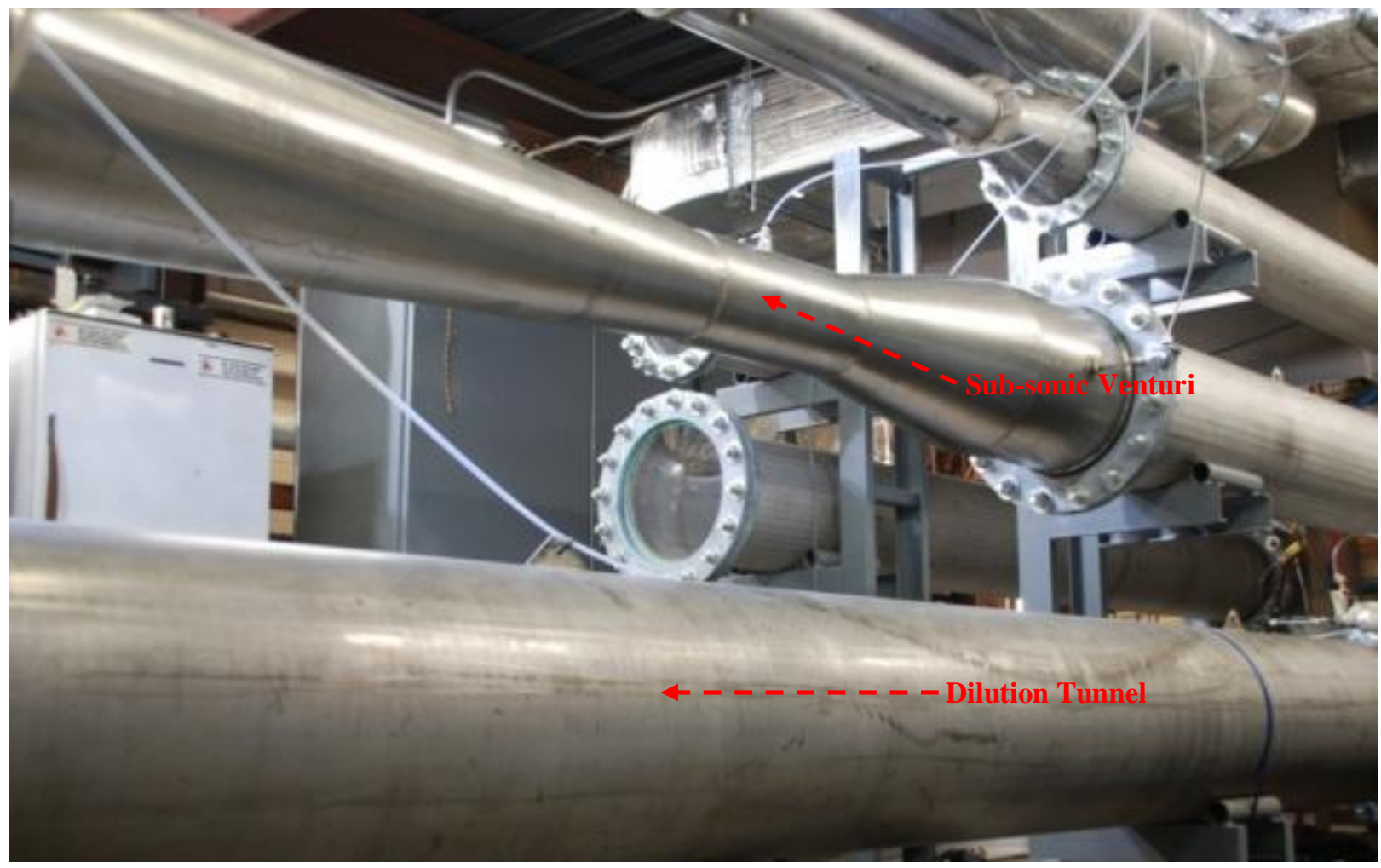

Figure 3.2 Full flow CVS dilution system at WVU CAFEE's EERL facility

\subsection{Vehicle Emissions Testing Laboratory}

West Virginia University's Transportable Heavy Duty Emissions Laboratory consists of transportable heavy-duty chassis dynamometer and a laboratory grade Transportable Emissions Measurement System (TEMS). A schematic of the TEMS is shown below in Figure 3.3. 


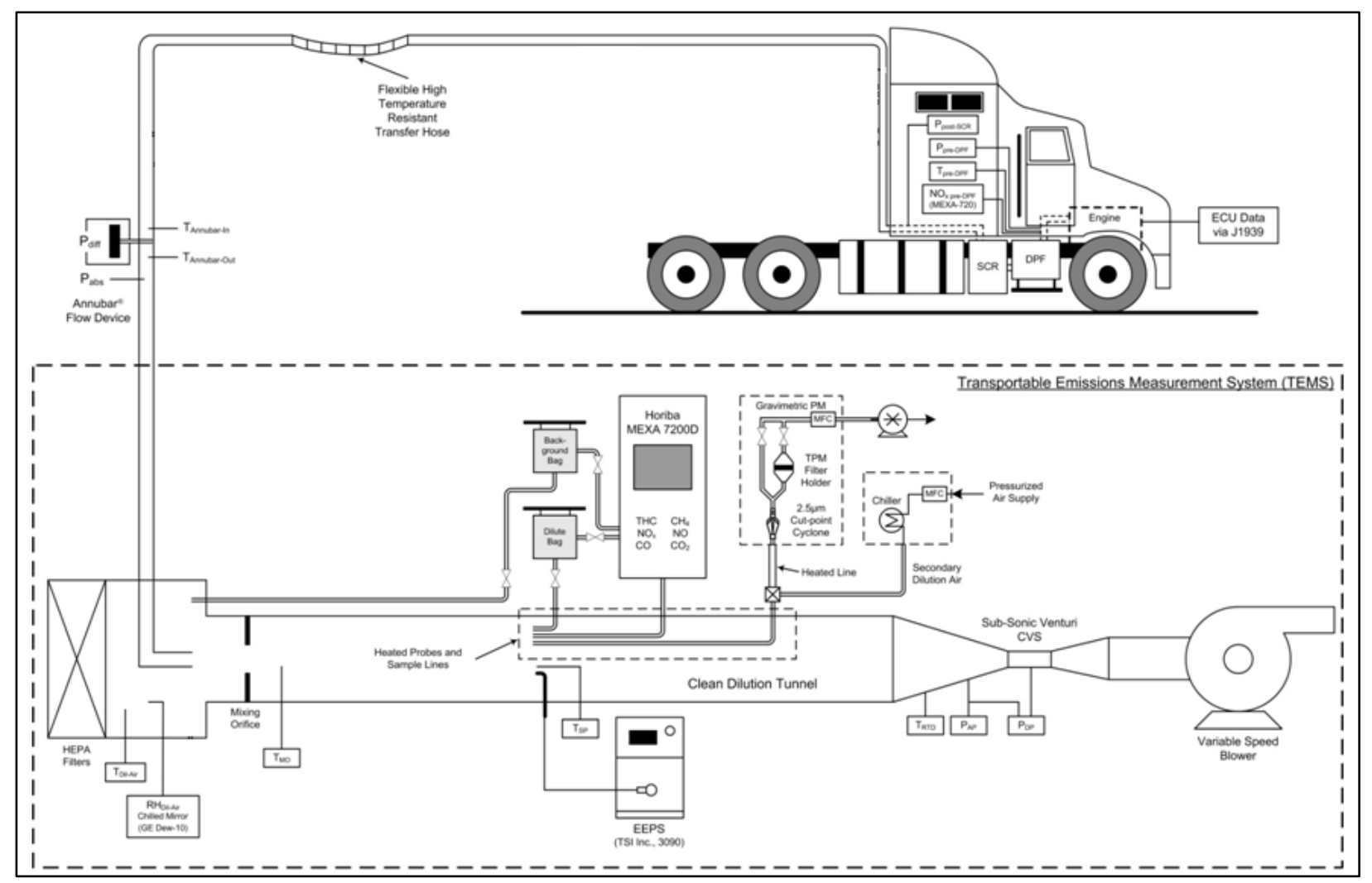

Figure 3.3 Schematic of WVU CAFEE's TEMS

\subsubsection{Chassis Dynamometer}

The transportable heavy-duty chassis dynamometer consists of roller, flywheel assembly, power absorbers, differentials, hub adapters, torque and speed transducers built onto a tandem axle semi-trailer as shown in Figure 3.4. The various components of the chassis dynamometer are discussed in detail below.

- Rollers: The chassis dynamometer consists of two sets of free spinning rollers that support the single or forward drive axle and rear axle for tandem axle vehicles. The rear pair of free spinning roller used to support the rear axle, can be placed in three different positions to accommodate tandem spacing of 4 to $5 \mathrm{ft}$ (1.2 - 1.5m) and each roller is 12.6 in $(32 \mathrm{~cm})$ in diameter with their axis along the length of the test bed. The roller are linked together with the help of a flexible coupling to have uniform rotational speed on either side of the vehicle and the coupling was designed to accept $20 \%$ of the wheel torque in case of any imbalance due to uneven surface at the test location [53]. 
- Hub adapters: The hub adapters are used to couple the engine drive axle with the flywheel assembly and power absorber via torque and speed transducers. The adapter are used to couple the engine drive axle with the flywheel assembly and power absorber via torque and speed transducers. The adapter is made of a 0.5 inch $(13 \mathrm{~mm})$ thick aluminum plate of $1.8 \mathrm{ft}(0.55 \mathrm{~m})$ in diameter [53].

- Road Load Simulation System: The road load simulation system consists of a flywheel assembly, power absorbers, torque and speed transducers, double differentials and universal couplings on either side of the vehicle to be tested as shown in Figure 3.4 in below. The power from the vehicle's drive axle is transmitted to the flywheel assembly and power absorbers through the double differentials connected via the speed and torque transducers. The speed and torque transducers are capable of providing the data logging computer torque output signal at $10 \mathrm{~Hz}$ time resolution [53].

- Flywheel Assembly: The flywheel assembly is designed to simulate the gross vehicle weight of the vehicle during normal operation. The flywheels are rated to simulate a maximum weight of $40,000 \mathrm{lbs}(18,144 \mathrm{~kg})$ at a wheel diamter of $4 \mathrm{ft}$ $(1.22 \mathrm{~m})$ and 66,000 $\mathrm{lbs}(30,000 \mathrm{~kg})$ at a wheel diameter of $3.25 \mathrm{ft}(1 \mathrm{~m})$. Each drive shaft consisting of four drive rotors in the flywheel assembly support a total of eight flywheels of different sizes. By selectively engaging the flywheels to the drive rotors, the required test weight can be simulated in $250 \mathrm{lbs}$ (113kg) increments [53].

- Power Absorbers: The eddy current power absorbers consists Mustang model CC300 air cooled eddy current dynamometer mounted on bearings. The power absorbers are used to simulate the road load due to rolling friction of the tires and aerodynamic drag resistance of the vehicle. The power absorbers are capable of absorbing $300 \mathrm{hp}(224 \mathrm{~kW})$ continuously and $1000 \mathrm{hp}(745.7 \mathrm{~kW})$ intermittently during peak operation. The load at any speed is controlled by the direct current supplied to the coils and the power absorbed is measured using an arm force load cell [53]. 


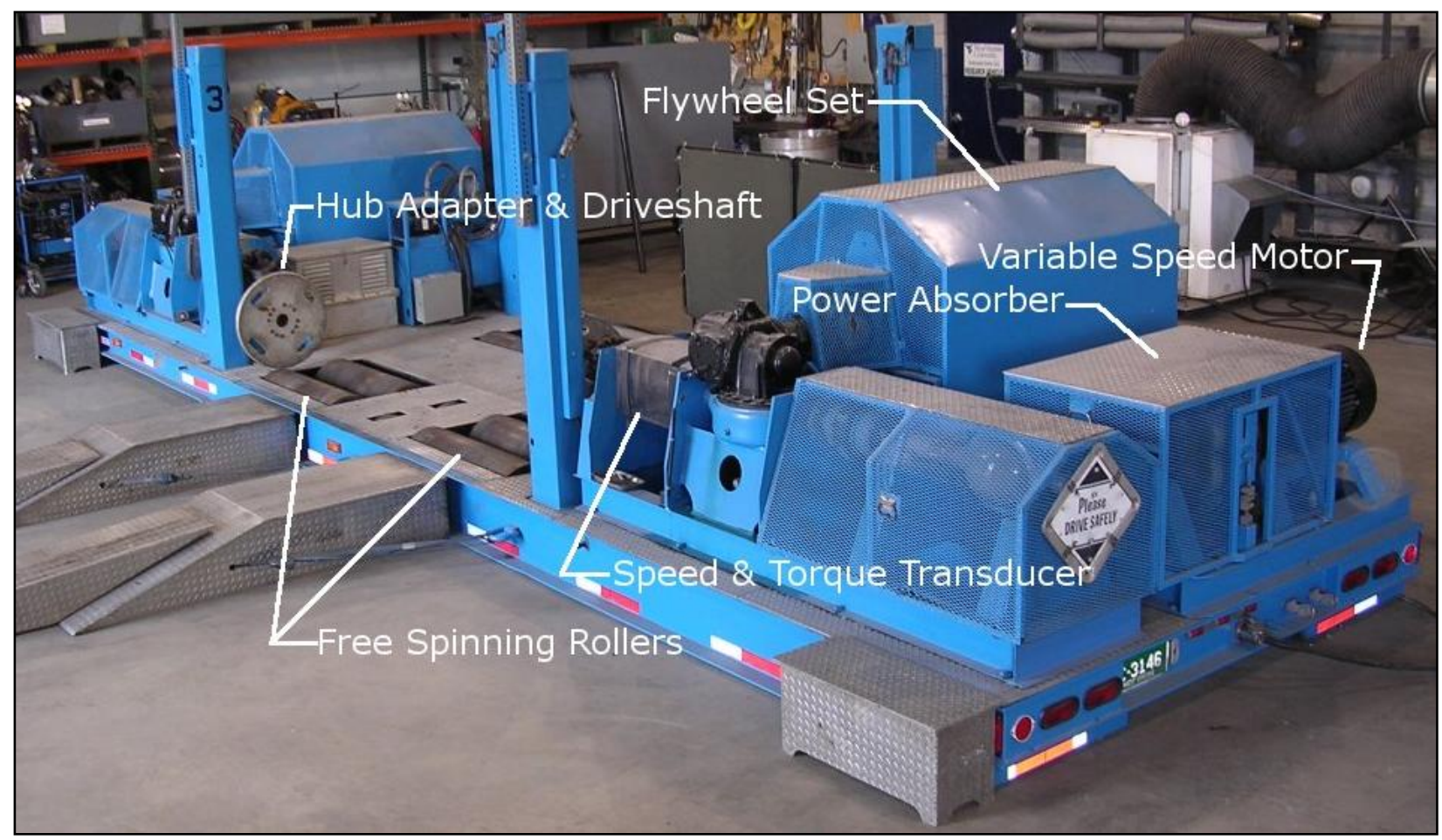

Figure 3.4 WVU CAFEE's transportable heavy-duty chassis dynamometer and its components [3]

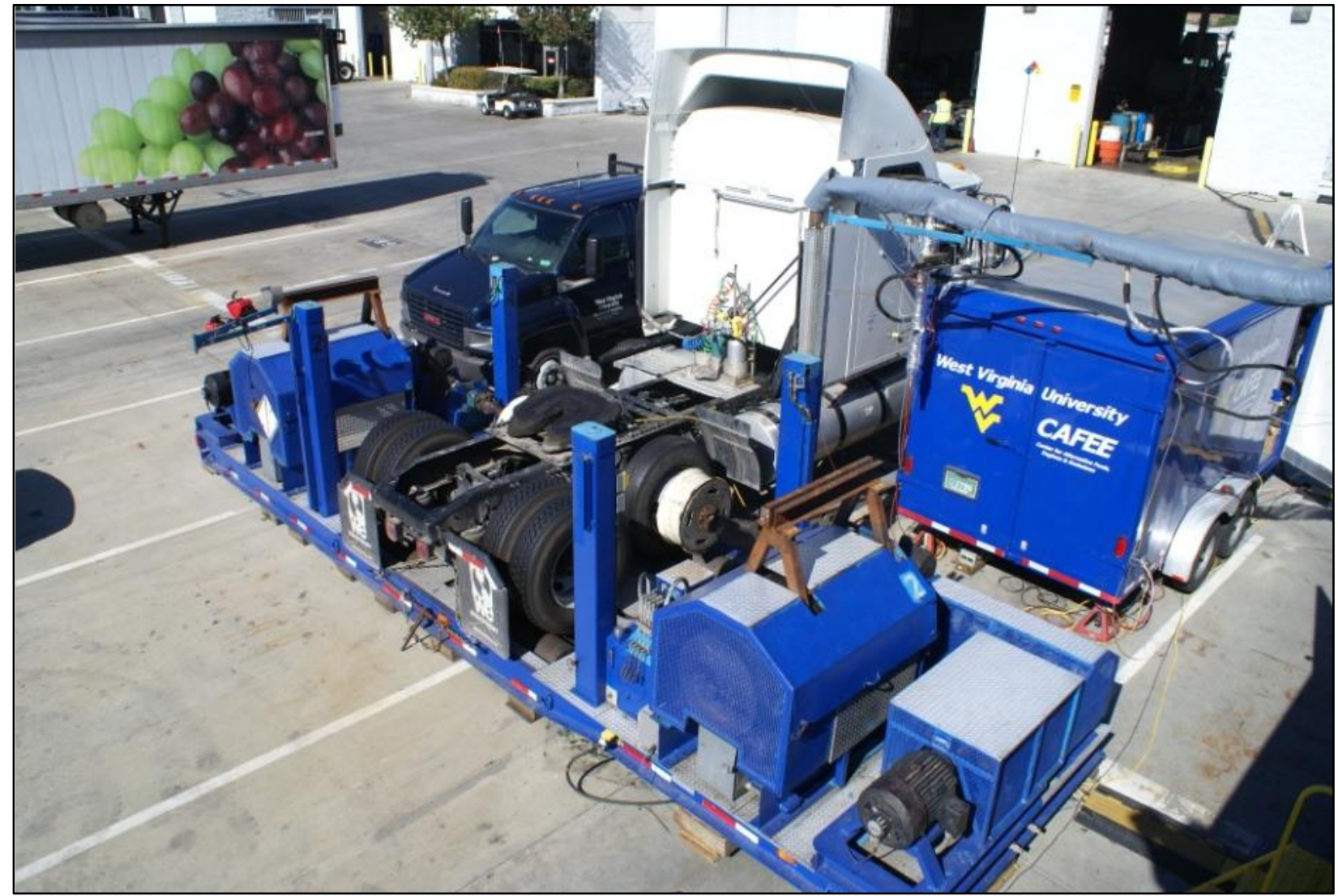

Figure 3.5 View of the Diesel with DOC-DPF-SCR vehicle being tested on WVU CAFEE's transportable heavy-duty chassis dynamometer at the test facility 
An automated system controls the transient torque that must be applied while the speed changes over time during chassis dynamometer testing. The load supplied by the flywheels simulates the inertial mass of the vehicle while the rolling friction and aerodynamic drag resistance is simulated by the power absorbers when being operated on the chassis dynamometer. The power absorbers are controlled by Dyn-Loc IV control systems provided by Dyne-Systems which is operated by a PID control loop. The control system provides a fast and smooth response in controlling the transient torque set points while data is being logged by the data acquisition system at $10 \mathrm{~Hz}$. The torque set points of the control system are updated at $10 \mathrm{~Hz}$ and are calculated using the following Equation 3.1.

$$
\text { Equation 3.1 } \quad \mathbf{P}_{\mathbf{R L}}=\left(\mathbf{C}_{\mathbf{r r}} * \mathbf{M} * \mathbf{g}+\left(\frac{\mathbf{1}}{2}\right) * \boldsymbol{\rho}_{\mathrm{air}} * \mathbf{C}_{\mathbf{d}} * \mathbf{A} * \mathbf{V}^{2}\right) * \mathbf{V}
$$

Where:

$$
\begin{aligned}
& P_{R L}=\text { Road load power } \\
& C_{r r}=\text { Coefficient of rolling resistance } \\
& M=\text { Mass of vehicle being simulated } \\
& \rho_{\text {air }}=\text { Air density } \\
& A=\text { Frontal area of vehicle } \\
& C_{d}=\text { Coefficient of drag } \\
& V=\text { Vehicle speed }
\end{aligned}
$$

\subsubsection{Transportable Emissions Measurement Systems (TEMS)}

Transportable Emissions Measurement System (TEMS) designed and built in-house by WVU is targeted toward on-road emissions measurement of advanced heavy-duty engines. The system is comprised of a dual, full-scale dilution tunnels with analytical systems designed in accordance with 40 CFR Part 1065. The TEMS system provides transportable flexibility along with laboratory flexibility. WVU CAFEE's TEMS is a $30 \mathrm{ft}(9.1 \mathrm{~m})$ long cargo container which houses a high efficiency particulate filter (HEPA) primary dilution unit, two primary full-flow dilution tunnels, a subsonic venturi, a secondary particulate matter sampling system, a computerbased data acquisition and control system, chassis dynamometer control system along with heating, ventilating and air conditioning (HVAC) system. The analytical systems on-board the 
TEMS trailer for measuring gaseous as well as PM emissions are nearly identical to the analytical system used at WVU CAFEE's EERL facility. However, the humidity in the primary dilution air in not conditioned or controller in the TEMS trailer.

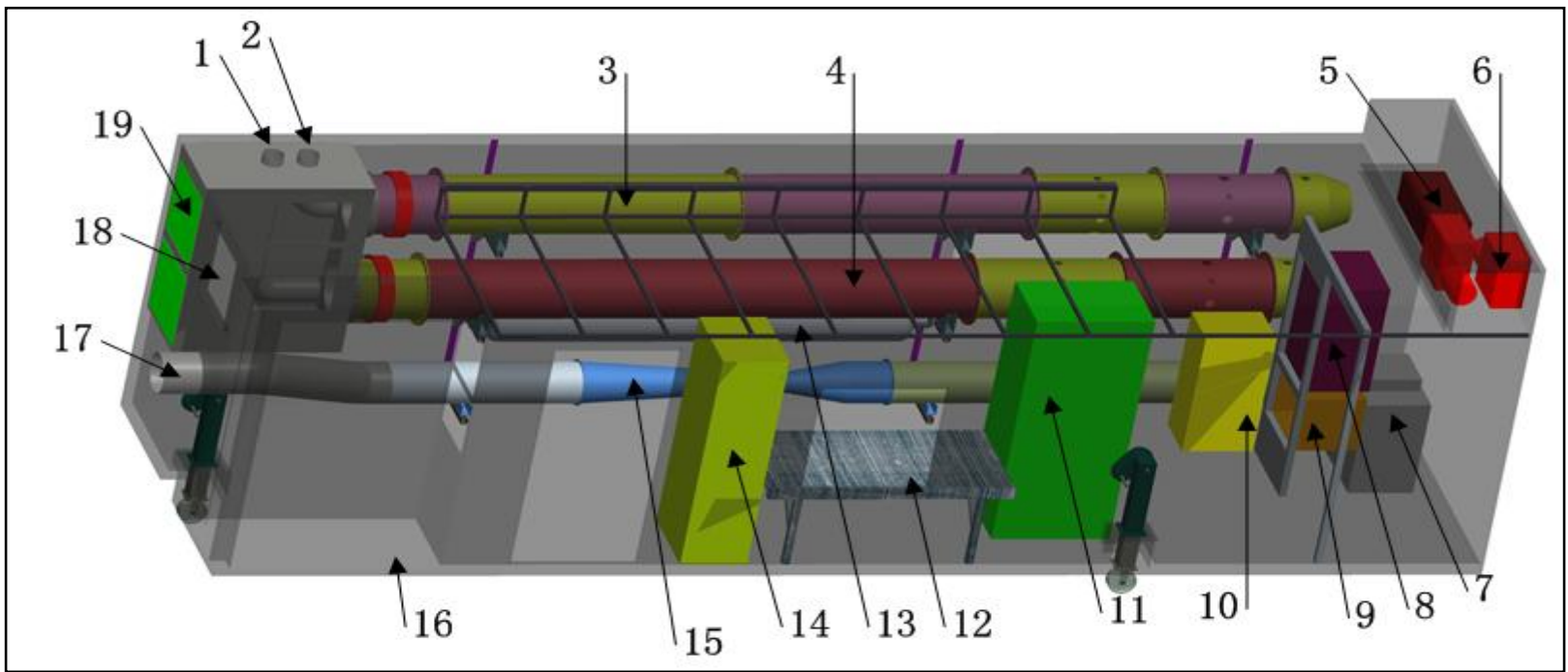

Figure 3.6 CAD overview of WVU CAFEE's TEMS container[3]

1- Exhaust inlet of dirty tunnel; 2- Exhaust inlet of clean tunnel; 3-Clean tunnel; 4-Dirty tunnel; 5-Air compressor; 6-Vacuum pumps; 7- Oven; 8- PM sampling box; 9- Glove box; 10 Zero air generator; 11-MEXA-7200D motor exhaust gas analyzer; 12-Computer table; 13-Air tank; 14-DAQ rack; 15- Subsonic venturi; 16-Air conditioner deck; 17- Outlet to blower; 18-

Ventilation fan; 19- HEPA filters [3] 


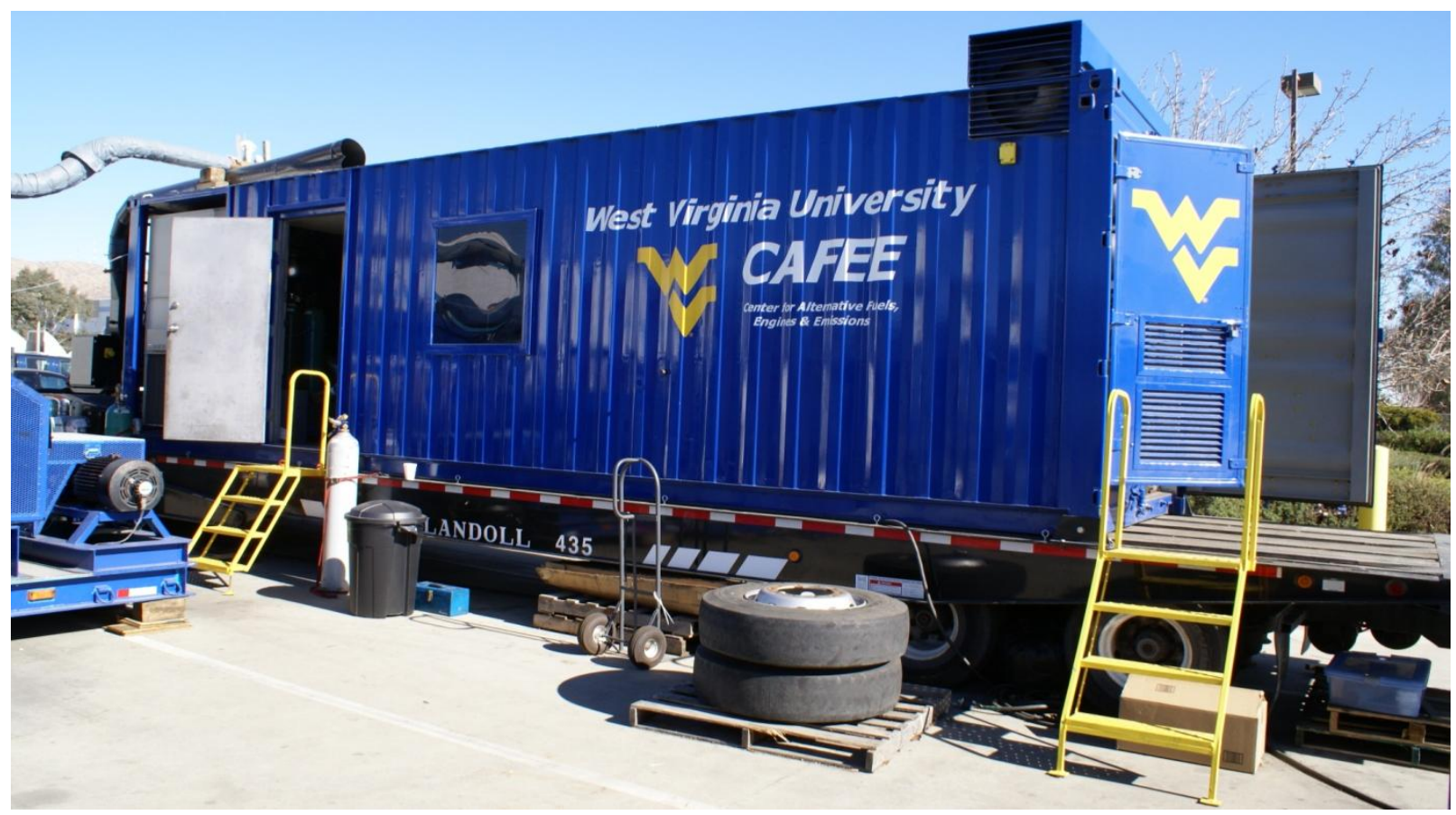

Figure 3.7 View of the WVU CAFFE's TEMS container at the test facility

Figure 3.6 shows the schematic of the TEMS container. In addition to this, the TEMS trailer also houses laboratory grade emissions sampling system that is compliant with test procedures recommended in Title 40 of the CFR Part 1065 and Part 86 Subpart N. The two primary dilution tunnels located in the TEMS container are 18 inches $(0.46 \mathrm{~m})$ in diameter and $20 \mathrm{ft}(6.1 \mathrm{~m})$ long. The two tunnels namely, "clean tunnel" or the upper tunnel which is used to sample emissions for newer model year low PM emissions vehicles and "dirty tunnel" or the lower tunnel which is used measure older model year legacy diesel engines with high PM levels provides the capability of using dedicated sampling systems. The dedicated sampling systems reduces tunnel history effects between different test programs of varying exhaust composition. Primary dilution is supplied to the tunnels are supplied via the plenum box that house two HEPA filters.

\subsection{Gaseous Emissions Sampling System}

Diluted exhaust gas emissions extracted from the CVS tunnel were measured continuously using a Horiba MEXA-7200D gaseous emissions analyzer The MEXA7200D is capable of measuring all regulated emission species that includes $\mathrm{THC}, \mathrm{CO}, \mathrm{CO}_{2}, \mathrm{NOx}$ and methane through a non-methane cutter equipped secondary hydrocarbon channel. 


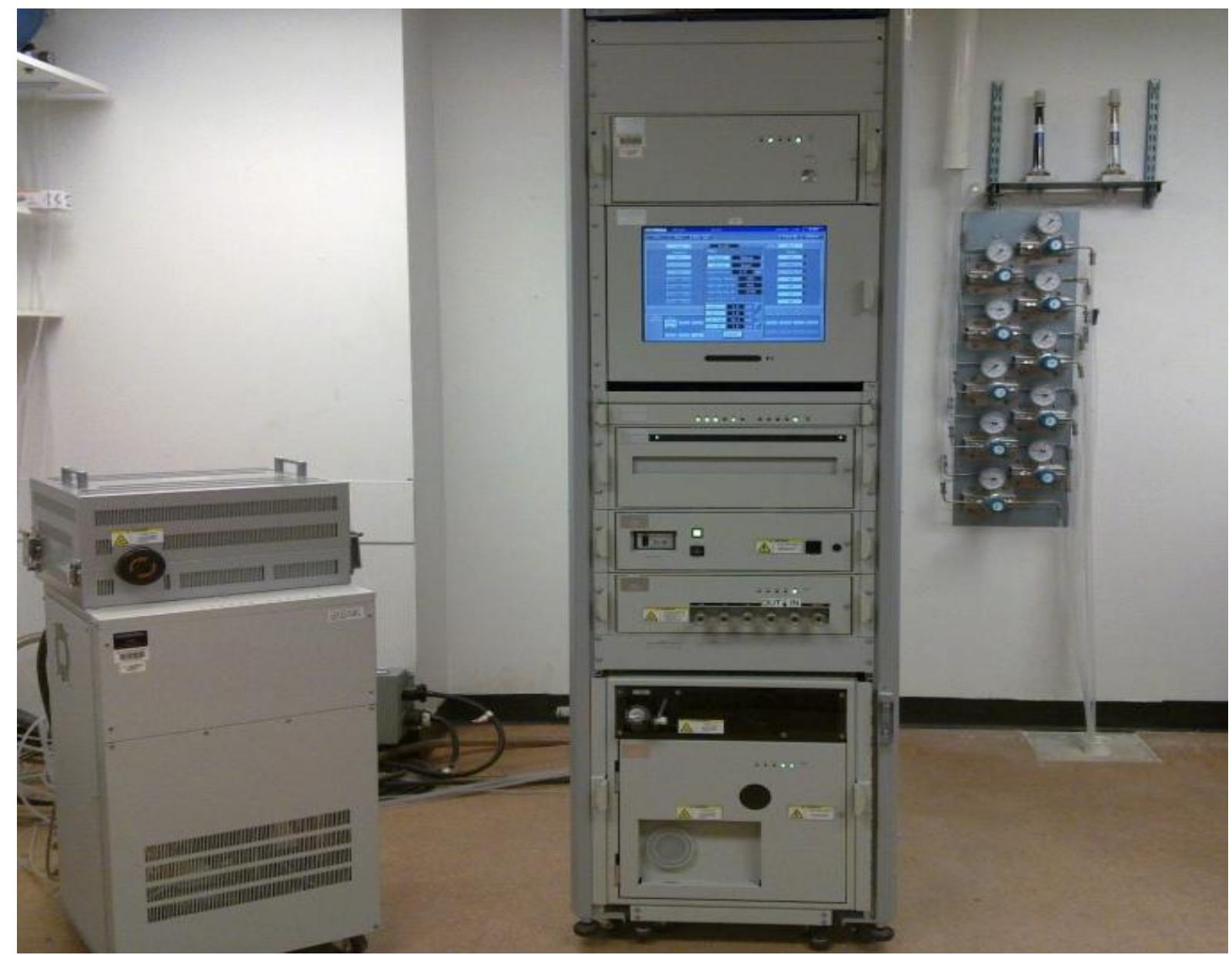

Figure 3.8 MEXA 7200D analytical bench at WVU CAFEE's EERL facility

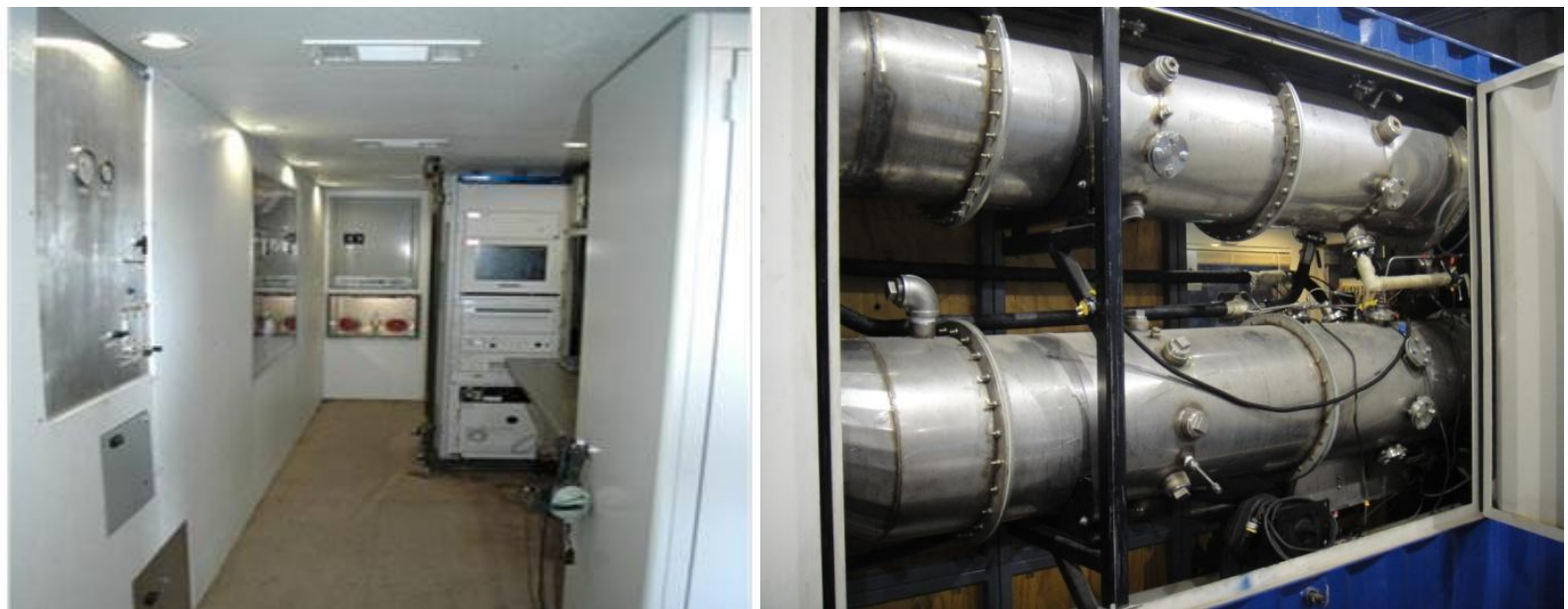

Figure 3.9 MEXA 7200D analytical bench and the full scale CVS dilution system onboard WVU CAFEE's TEMS

The Horiba automotive emission analyzer system MEXA-7200D is a modular components system consisting of a main control unit, an interface controller (provides 
communications between the modules and the main control unit), an analyzer rack with up to five analyzer modules, a power supply unit, as well as a solenoid valve selector, which routes zero, span and sample gas to the analyzer modules, and a sample handling system dehumidifying the sample gas and directing it to the analyzers. However this study utilized only the $\mathrm{CO}_{2}$ analyzer module.

\subsection{CFR §1065 Compliant PM Sampling and Measurement System}

The PM sampling system for both the transportable laboratory and engine testing laboratory is compliant with 40 CFR Parts 86 and 1065 regulations as shown in Figure 3.10. The measurement system is operated with in-house developed software to calibrate the scales, perform measurements, and also to monitor the filters history. However, all pre-weighing and post weighing of the gravimetric filters are carried out in WVU CAFEE's EERL facility which houses a clean room, with controlled environment for accurate weighing of the filters.

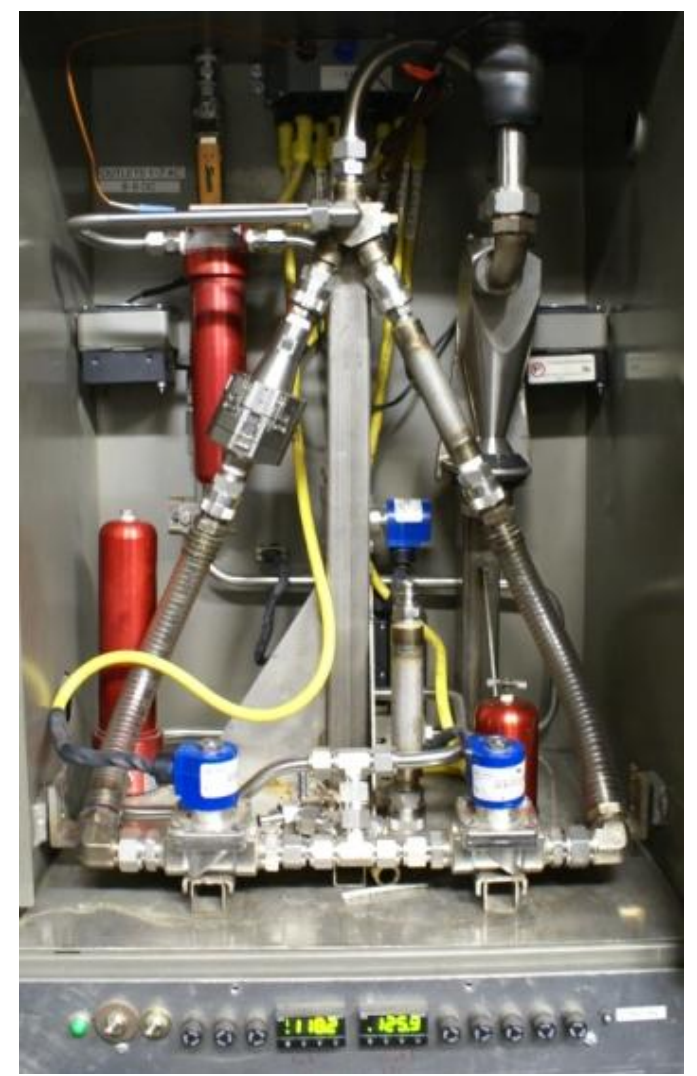

Figure 3.10 40 CFR $§ 1065$ compliant PM sampling system at WVU CAFEE's EERL facility and on-board the TEMS 


\subsubsection{Clean Room}

All gravimetric analysis are performed inside the Class 1000 or Class Six clean room located at WVU CAFEE's EERL facility. The clean room is in specifications according to ISO 14644-1, PM weighing room that provides climate controlled environment for PM filter weighing and storage. The weighing room floor area is $10 \mathrm{ft} . \mathrm{x} 10 \mathrm{ft}$. and was designed to allow two personnel to be present at a time. A gowning room $6 \mathrm{ft}$. $\mathrm{x} 10 \mathrm{ft}$, climate controlled environment the same way as the clean room, acts as a buffer between the outside and the clean room air conditions. The clean room is constantly maintained at the following conditions

- Temperature: $22 \pm 3^{\circ} \mathrm{C}$

- Dew Point: $9.4 \pm 3^{\circ} \mathrm{C}$

- Relative Humidity: $45 \pm 8 \%$

Environmental condition logs are monitored based on window moving averages as specified in 40 CFR Parts 86 and 1065. If the above conditions are not met the room conditions are brought to within the above specifications and allowed to remain in that state for one hour prior to performing filter weighing operations.

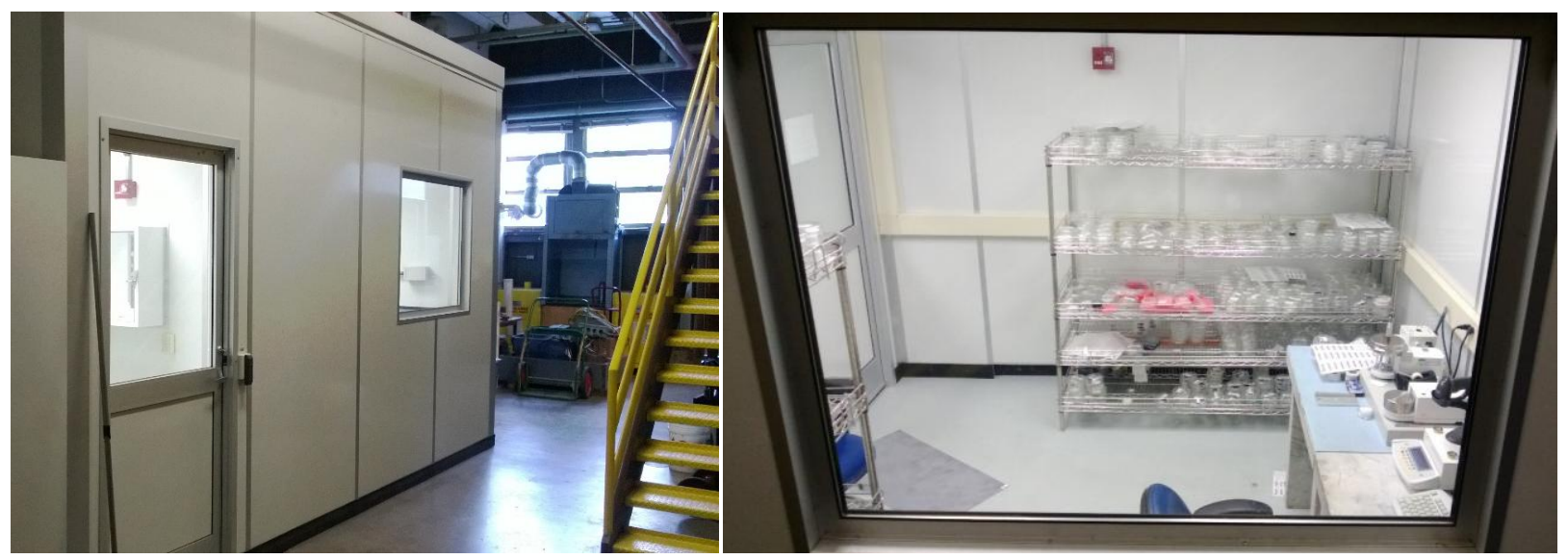

Figure 3.11 Class Six clean room as specified by ISO 14644-1 at WVU CAFEE's EERL facility

\subsection{Media Handling and Weighing}

The media used in collecting PM for gravimetric analysis were conditioned and preweighed in the WVU CAFEE's EERL facility before transporting them to the test site. The filters were conditioned in an environmentally controlled chamber (Class 1000 or Class six clean room 
as specified by ISO 14644-1) maintained at $22 \pm 3^{\circ} \mathrm{C}$ with a relative humidity of $45 \pm 8 \%$, for at least 1 hour and not more than 80 hours before being weighed according to 40 CFR, Part 1065 specifications. The $47 \mathrm{~mm}$ filters were placed in plastic analyslides, with their lids closed but not

sealed in order to prevent dust from accumulating on the media while allowing for humidity exchange. Three reference filters were conditioned with the test filters and placed in the environmental chamber in order to account for change in the filter weight due to fluctuation in humidity. The reference filters were weighed before and after any set of media were weighed to ensure that the conditions in the environmental chamber were stable.

The filters were pre-weighed after a stabilization period of 24 hours using a model SE2-F Sartorius Filter Microbalance. The balance was interfaced with a computer in which the filter weights were logged for future reference and use. The filters were conditioned for several hours in the chamber before the petri-dishes were sealed and packed in padded envelopes for shipping to the test site.

\subsection{Media Shipping and Tracking}

The filter media are placed in analyslides and sealed after they had been pre-weighed. The set of analyslides containing media required for one test are placed together to aid in quick loading of the media into the sampling system. The sealed media were transported overnight to the test site in coolers filled with dry ice packs. After the media was received at the test site it was placed in the conditioning room until used. A media tracking application was developed to identify the media with the test sequence and run number. The tracking tool also aided in QA/QC protocol. The used media were placed back into their respective petri-dishes in the conditioning room and were tracked before shipping back to the EERL facility, where the gravimetric analysis on the PM filter media was performed.

\subsection{Particulate Matter Sizing Setup}

The study employed the TSI EEPS (TSI Model 3090) for transient particle size distribution measurement and the TSI SMPS (TSI Model 3936) for steady state engine dynamometer testing. Both the TSI EEPS and the TSI SMPS were setup up for sampling from the CVS dilution tunnel as shown in Figure 3.1 and Figure 3.3. This method of sampling was chosen over partial flow dilution of raw exhaust using ejector pumps in order to better correlate the gravimetric PM and the particle size distribution and concentration formed as a result of dilution within the CVS. As preliminary 
procedures sample flow rates of the EEPS were verified with a standard flow meter, and the operation of the instrument was checked against the standard TSI SMPS. The instrument was cleaned and electrometers were zeroed before the commencement of the study.

\subsection{Test Engine and Vehicle Specifications}

This study involved two phases of testing, the engine and vehicles chosen for this study have been certified under the current US EPA 2010 standards and are within their useful life of operation. The first phase comprised of in-use testing four newer model year heavy duty vehicles with advanced aftertreatment systems that are known to produce very low emissions. All the vehicles chosen for this study are used for goods movement and are found to be used in large fleet operations. The vehicle and engine specifications for these modern heavy duty engines are give below in Table 3.1 .

Table 3.1 Test vehicle specification for chassis dynamometer testing

\begin{tabular}{|c|c|c|c|c|}
\hline Vehicle Manufacturer & $\begin{array}{l}\text { Mack Trucks } \\
\text { Inc. }\end{array}$ & $\begin{array}{l}\text { International } \\
\text { Inc. }\end{array}$ & $\begin{array}{c}\text { Peterbilt Motors } \\
\text { Co. }\end{array}$ & Kenworth \\
\hline Vehicle Model & cXU613 & $\begin{array}{c}\text { Prostar } \\
\text { Premium } 6 \times 4\end{array}$ & 358 & T800 \\
\hline $\begin{array}{l}\text { Gross Vehicle Weight } \\
\text { (GVW) (lb.) }\end{array}$ & 52000 & 52000 & 50000 & 34700 \\
\hline Vehicle Tested Weight (lb.) & 65000 & 69500 & 69500 & 69000 \\
\hline Odometer Reading (mile) & 36982.1 & 80412 & 63256 & 12300 \\
\hline Transmission Type & Manual & Manual & Automatic & Manual \\
\hline Engine Manufacturer & $\begin{array}{l}\text { Mack Trucks } \\
\text { Inc. }\end{array}$ & Navistar & $\begin{array}{l}\text { Cummins } \\
\text { Westport }\end{array}$ & Westport \\
\hline Engine Model & MP8-445C & Maxxforce 13 & ILS-G 320 & GX450 \\
\hline Engine Model Year & 2011 & 2009 & 2009 & 2011 \\
\hline Engine Displacement (Liter) & 12.8 & 12.4 & 8.9 & 14.9 \\
\hline Engine Rated Power (hp) & 445 & 430 & 320 & 450 \\
\hline Fuel Type & ULSD & ULSD & $\begin{array}{c}\text { CNG } \\
\text { (Stochiometric) }\end{array}$ & ULSD/CNG \\
\hline $\begin{array}{l}\text { CERT No. (NOx/PM) } \\
\text { (g/bhp-hr) }\end{array}$ & $0.12 / 0.003$ & $1.05 / 0.001$ & $0.11 / 0.01$ & $0.13 / 0.004$ \\
\hline Aftertreatment System & DOC-DPF-SCR & DOC-DPF & 3-way Catalyst & DOC-DPF-SCR \\
\hline Vehicle Application & $\begin{array}{c}\text { Goods } \\
\text { Movement }\end{array}$ & $\begin{array}{c}\text { Goods } \\
\text { Movement }\end{array}$ & $\begin{array}{c}\text { Goods } \\
\text { Movement }\end{array}$ & $\begin{array}{c}\text { Goods } \\
\text { Movement }\end{array}$ \\
\hline
\end{tabular}


The second phase of testing involved steady state engine dynamometer testing of a Tier IV compliant off-road engine that does not have any advanced engine control strategy or aftertreatment system to reduce exhaust emissions. The engine was tested under baseline conditions and later retro-fitted with a retrofit DOC-DPF aftertreatment system to further reduce PM emission levels. The test engine specification for engine dynamometer testing are given below in Table 3.2 .

Table 3.2 Test engine specification for engine dynamometer testing

\begin{tabular}{|l|c|}
\hline Engine Manufacturer & $\begin{array}{c}\text { Kubota Engine } \\
\text { Co. }\end{array}$ \\
\hline Engine Model & V2203L-DI-ET \\
\hline Compliance Standards & Tier 4 \\
\hline Engine Displacement (Liter) & 2.2 \\
\hline Number of Cylinders & 4 \\
\hline Engine Rated Power (hp/rpm) & $37.8 / 2200$ \\
\hline Fuel Type & ULSD \\
\hline Application & TRU \\
\hline Model Year & 2012 \\
\hline CERT Level: & Tier IV \\
\hline
\end{tabular}




\section{CHAPTER 4. APPROACH}

\subsection{Pre-test Procedure}

Initial laboratory set-up procedures include complete measurement system verification followed by instrument calibrations. All required system verifications are performed as per requirements stated in $40 \mathrm{CFR}$, Part 1065, Subpart D. Both EERL facility and the TEMS container are equipped with the HORIBA MEXA 7200D Motor Exhaust Gas Analyzer, which is capable of automatically performing the required analyzer verification tests. The verification procedure and pass criteria of the tests were in accordance to the provisions described in $40 \mathrm{CFR}$, Part 1065, Subpart D. Table 4.1 lists the set of analyzer verification checks that were performed pertaining to this study prior to the commencement of the testing. Table 4.2 lists the set of leak checks that were performed on the gaseous and PM measurement systems. In addition to this CVS system calibration and verification procedure were also performed prior to the commencement of the program as per 40 CFR, Parts 1065.340 and 1065.341 guideline.

Table 4.1 Gaseous and PM system verification checks

\begin{tabular}{|l|l|}
\hline Leak Checks & Pass Criteria \\
\hline Leak and Delay Time Check (all analyzers) & \multirow{2}{*}{ Within $\pm 5 \%$ over 30 sec interval } \\
\cline { 1 - 2 } PM System Leak Check & \\
\hline
\end{tabular}

Table 4.2 Gaseous analyzer checks

\begin{tabular}{|l|l|}
\hline Analyzer Checks & Pass Criteria \\
\hline $\mathrm{CO}(\mathrm{L}), \mathrm{CO}_{2}$ Interference Check & Within $\pm 1 \%$ Interference Check \\
\hline
\end{tabular}

\subsection{Test Procedure}

\subsubsection{Engine Test Procedure}

Detailed inspection of the engine was performed before mounting the engine on the dynamometer skid. Pre-test maintenance such as replacing engine oil, oil filter and fuel filters were performed as per manufacturer's recommendations and 40 CFR $\$ 1065.405$ recommendations. Proper operation of the engine was verified over steady state operations. The engine was mapped for maximum brake torque and speed as per 40 CFR $\$ 1065.510$ guideline. 
The engine was retrofitted with DOC-DPF aftertreatment system after baseline testing was performed. The DOC-DPF aftertreatment system was de-greened using a 20 minute extended version of the 4-mode steady state test cycle. The de-greening process was performed for 10 hours of continuous engine operation during which period differential pressure readings were monitored and logged to ensure aftertreatment performance and integrity.

\subsubsection{Chassis Dynamometer Test Procedure}

Appropriate flywheel combination was determined and locked in place to simulate the inertial load of the vehicle before mounting the vehicle onto the chassis dynamometer. The outer rear wheel on the drive axle was removed and fitted with hub adapters which is then connected to the face plate. The vehicle was backed onto the dynamometer and the vehicle drive axle which drives the flywheel assembly and power absorbers were connected through a hub adapter. The vehicle was leveled with the drive axle and the tires were visually inspected for any distortion as it would add to the vehicle loading. The vehicle exhaust was connected to the dilution tunnel with the help of insulated transfer tubes. The vehicle was chained down to the dynamometer bed as a safety measure.

The vehicle was made to run at a high speed after being mounted on the dynamometer to warm up the lubricating oil in the chassis dynamometer two-way differentials. This was done to reduce additional load on the vehicle due to highly viscous oil used in the two-way differentials. During warming up of the differentials the gas analyzers were zero-spanned with blower operating at set-point.

The communication head sets for the driver to communicate with the TEMS laboratory operator, were put in place to aid the driver in following the scheduled drive cycle. A dummy test was conducted by making vehicle to run over the scheduled drive cycle with dummy media loaded in the tunnel to check whether the gas analyzers operated within the range for which they were calibrated and to check the flow through the mass flow controllers. If the analyzers exceeded full range or measured below the range then they were recalibrated with proper span gas and the mass flow controllers were checked for any malfunction. After the warm up run the vehicle was shut down and allowed to soak for twenty minutes. During the soak time the official media required for sampling PM was loaded onto the filter holder and mounted onto PM 
sampling system. The media loading was carried out in the controlled chamber to avoid accumulation of dust or other debris, a set of field blanks were maintained to study the effect of transportation on the used and unused media.

\subsection{Test Cycles}

Four chassis dynamometer test cycles were used for phase 1 of this study. Urban Dynamometer Driving Schedule (UDDS), and the three drayage cycles being Near-dock cycle, Local cycle and Regional cycle. This study does not intend to investigate the causes of variability, but rather to discern the factors contributing to variability observed during normal chassis dynamometer test practices. Thus, the need for extended cycle repeats were not performed, therefore the tests were limited to three repeats. The coefficient of variation of the $\mathrm{CO}_{2}$ emissions for the three repeats were kept within $2.5 \%$ to minimize test-to-test variability due to the driver as shown in Appendix-A. Moreover, due to the length and nature of the drayage test cycles, it takes about 6 hours to complete one set of three hot starts with 20 minute soak time. This makes the logistics of performing extended cycle repeats difficult to handle.

The UDDS cycle simulates the freeway and non-freeway operation of a heavy-duty vehicle as shown in Figure 4.1. The UDDS and the heavy-duty federal test procedure (FTP) cycle used for engine certification were derived from the same data set. The cycle is of 1060 seconds in duration with a maximum speed of $58 \mathrm{MPH}$. The vehicle is exercised over 5.5 miles over the entire test cycle. Due to the expected low PM emissions levels from the test vehicles, the triplicate versions of the UDDS driving cycles were created. Regulated emissions were calculated over a three UDDS cycles and unregulated media were sampled over three repeats of a triple length UDDS on one media.

The three port cycle simulates goods movement operation of a heavy duty vehicle inside the ports. The port cycles are characterized by their extended idle operations in the cycle that represent loading and unloading of goods within the port followed by intermittent high speed operations. Near-dock cycle as shown in Figure 4.2 represents goods movement operation near the port. Local cycle as shown in Figure 4.3 represents goods movement operation in urban areas near the ports. The Regional cycle shown in Figure 4.4 is the most aggressive of the four cycles in used in for this study. 


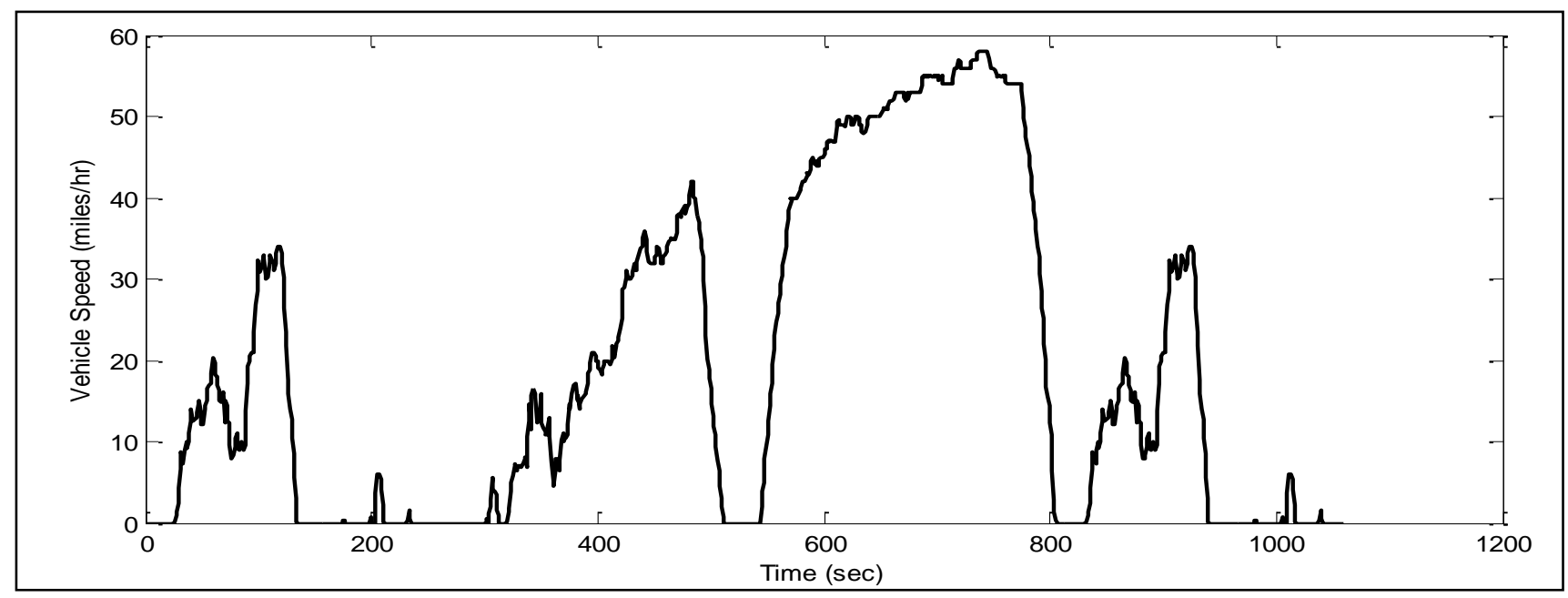

Figure 4.1 Speed Vs. Time trace of trip length UDDS cycle

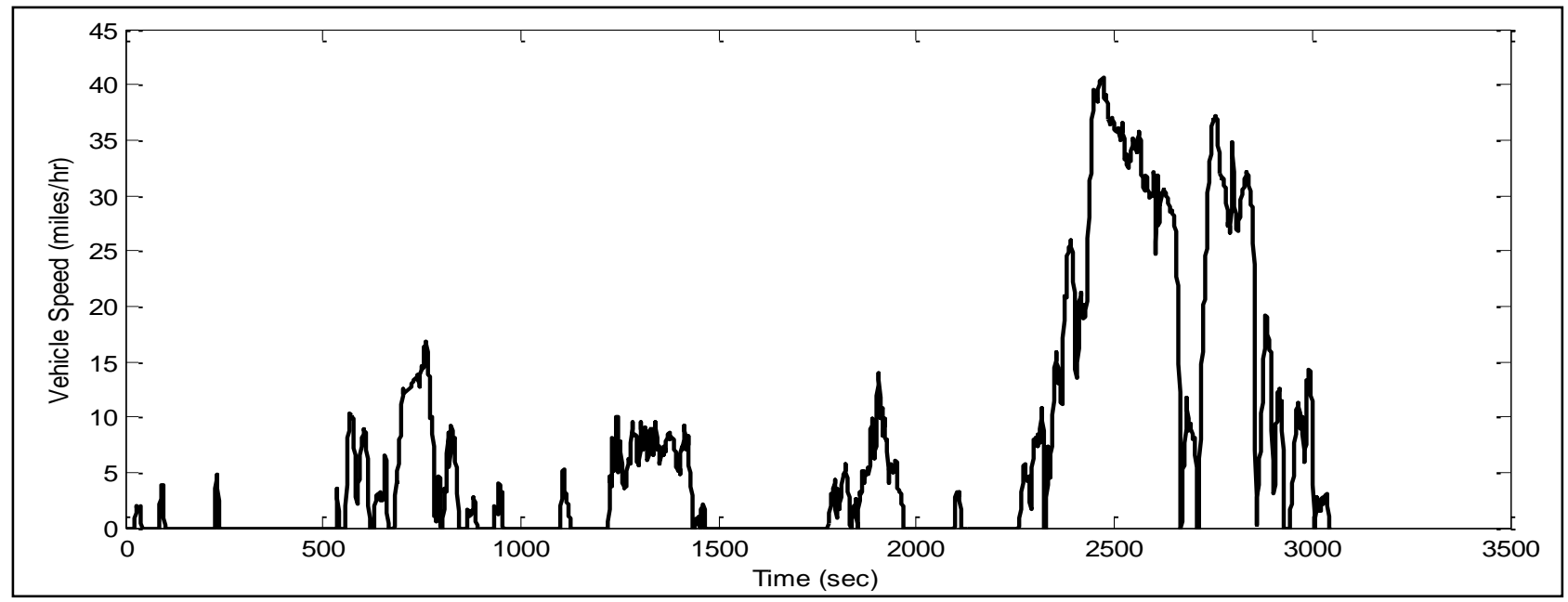

Figure 4.2 Speed Vs. Time trace of trip length Near-dock cycle

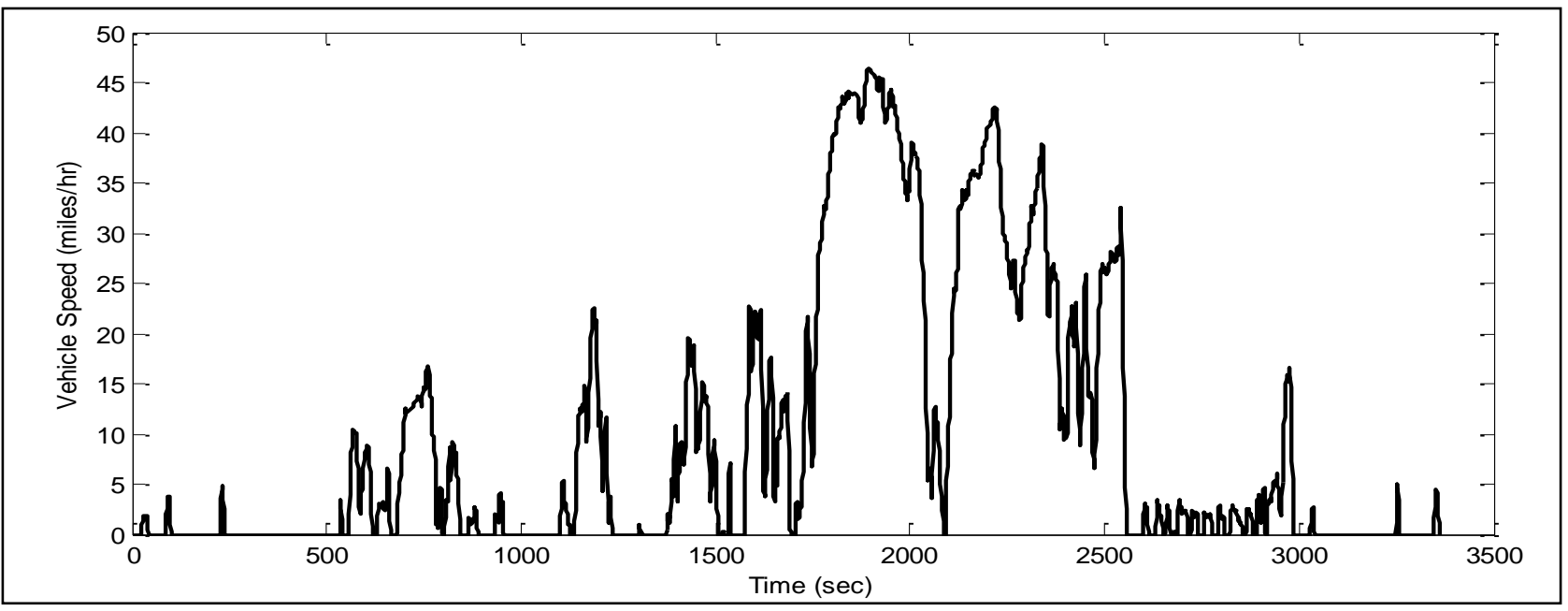

Figure 4.3 Speed Vs. Time trace of trip length Local cycle 


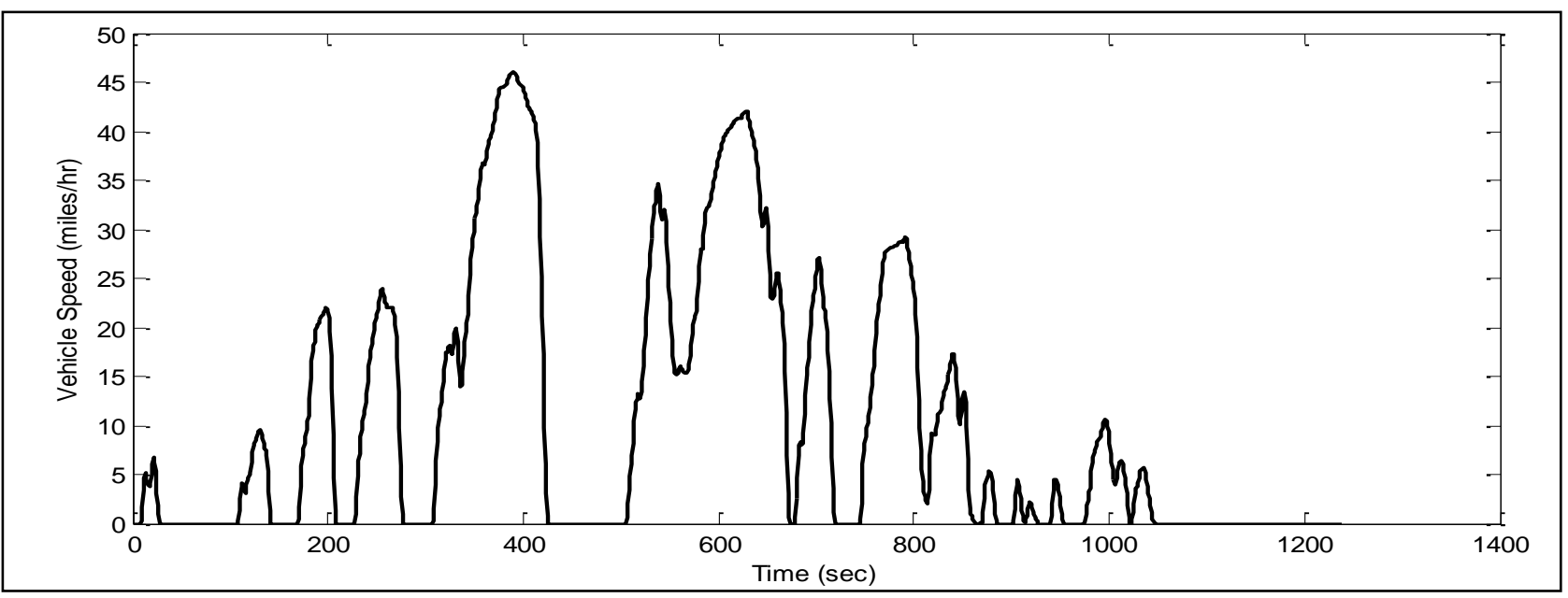

Figure 4.4 Speed Vs. Time trace of trip length Regional cycle

Phase 2 of this study that involved engine dynamometer testing of a Tier IV compliant TRU engine. Phase 2 of this study was essentially conducted in order to better understand the correlation between mass measured through the regulated gravimetric method and mass derived from particle size distribution and number count measurements for current model year diesel engines with and without particulate filters. The test engine was operated over the 4-Mode steady state test cycle followed by a 20 min soak time in between the three repeat runs that were performed. In order to minimize test-to-test variability during engine dynamometer testing, each test was subjected to cycle validation criteria as specified in 40 CFR $\$ 1065.514$ and a coefficient of variation of $\mathrm{CO}_{2}$ emissions within $1 \%$ was maintained for the repeat runs.

Table 4.3 4-Mode steady state test cycle

\begin{tabular}{|c|c|c|c|c|}
\hline $\begin{array}{c}\text { Mode } \\
\text { Number }\end{array}$ & $\begin{array}{c}\text { Engine } \\
\text { Speed }^{1}\end{array}$ & $\begin{array}{c}\text { Observed } \\
\text { Torque }^{2}\end{array}$ & $\begin{array}{c}\text { Minimum } \\
\text { Mode Length }\end{array}$ & Sample Time \\
\hline $\mathbf{1}$ & $\begin{array}{c}\text { Maximum } \\
\text { Test speed }\end{array}$ & $75 \%$ & $5 \mathrm{~min}$ & $5 \mathrm{~min}$ \\
\hline $\mathbf{2}$ & $\begin{array}{c}\text { Maximum } \\
\text { Test Speed }\end{array}$ & $50 \%$ & $5 \mathrm{~min}$ & $5 \mathrm{~min}$ \\
\hline $\mathbf{3}$ & $\begin{array}{c}\text { Intermediate } \\
\text { Test Speed }\end{array}$ & $75 \%$ & $5 \mathrm{~min}$ & $5 \mathrm{~min}$ \\
\hline $\mathbf{4}$ & $\begin{array}{c}\text { Intermediate } \\
\text { Test Speed }\end{array}$ & $50 \%$ & $5 \mathrm{~min}$ & $5 \mathrm{~min}$ \\
\hline
\end{tabular}

1 Speed terms as defined in 40 CFR Part 1065.

2 The percent torque is relative to the maximum torque at the given engine speed. 


\subsection{Gravimetric Analysis}

The data acquisition system consists of different modules for reading measurement signals from different sources. The measurement signal are received from various analyzers, temperature and pressure monitoring systems. An analog to digital converter (ADC) is used to convert the measurement signals to digital signals. The digital ADC signals are converted to their respective engineering units with the help of the calibration files for each channel. The reduction computer uses data from different channels and substitutes the values in the respective equations to calculate the integrated or instantaneous emission rates. For the calculation of the mass emissions of different exhaust constituents, it is necessary to calculate the flow through the tunnel (Vmix) and a factor known as the dilution factor (DF). Dilution factor is the ratio of theoretical amount of $\mathrm{CO}_{2}$ in the raw exhaust to the summation of the actual measured concentration of $\mathrm{CO}, \mathrm{CO}_{2}$, and $\mathrm{HC}$. The equations used to calculate the PM emission collected on filters from the secondary dilution tunnel is calculated using the following equation [45].

$$
\text { Equation 4.1 } \quad P_{\text {mass }}=\left(V_{m i x}+V_{s f}\right) *\left[\frac{P_{f}}{V_{s f}}-\left(\frac{P_{b f}}{V_{b f}} *\left(1-\frac{1}{D F}\right)\right)\right]
$$

Where:

$$
\begin{aligned}
& \text { Vmix = Total volume dilute exhaust drawn through the tunnel in a test period. } \\
& \text { Vsf = Total sample volume of dilute exhaust drawn through the PM filter media. } \\
& \mathrm{Pf}=\text { Actual mass of PM collected on the sample filter (grams) } \\
& \mathrm{Pbf}=\text { Actual mass of PM collected on the background filter (grams) } \\
& \mathrm{DF}=\text { Dilution factor. }
\end{aligned}
$$

\subsection{Real-Time Mass Conversion}

Several size resolved methods, such as the Lall-Friedlander aggregate model and the effective density method exist for converting particle size distribution and number count to mass concentrations. Studies show that the effective density method correlated $\left(R^{2}>0.99\right)$ better with mass collected on filter and accounted to about $99 \%$ of the mass collected as compared LallFriedlander aggregate model [54]. Figure 4.5 shows that the effective density method accounts for almost all the PM mass collected on the filter with minimal error in measurement. 


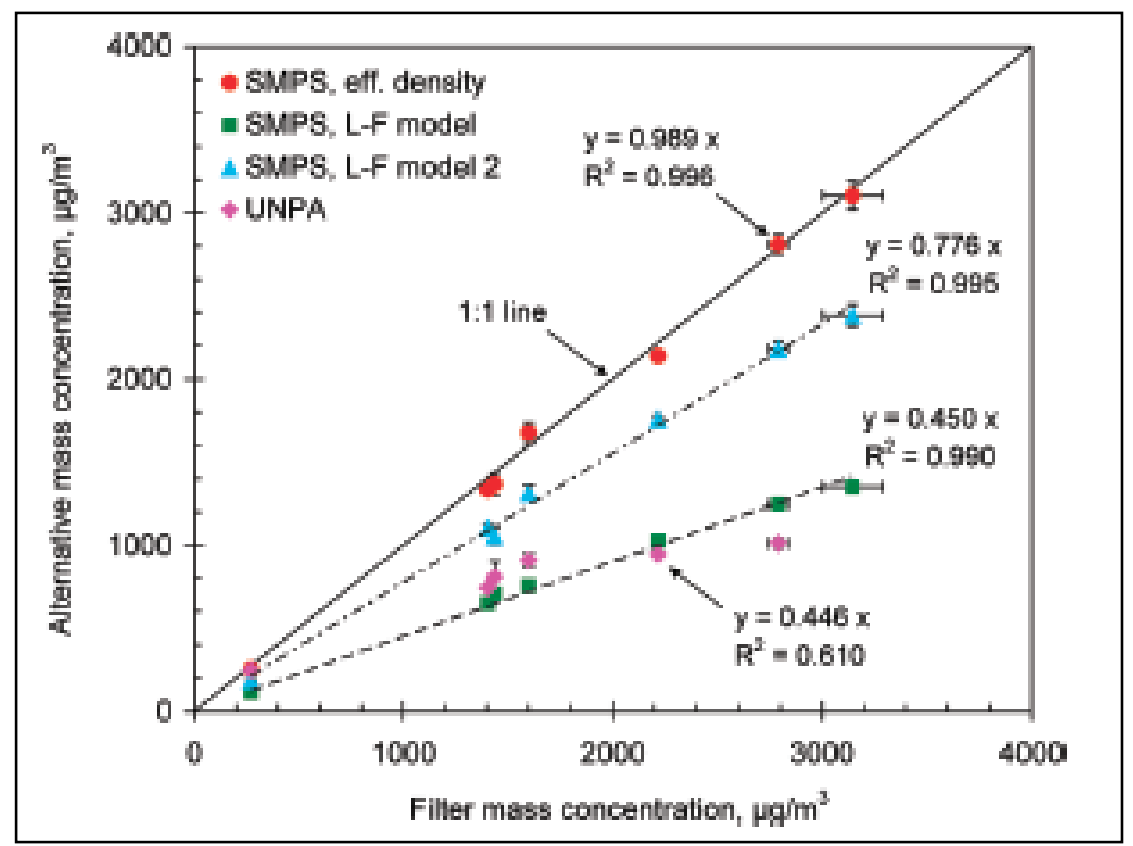

Figure 4.5 Correlation between gravimetric filter mass concentrations and mass concentration measured by alternative online methods of Diesel PM [54]

\subsubsection{Effective Density Functions}

Effective density is defined as the mass per particle per unit volume of the particle as shown in Equation 4.2. Effective density method assumes that every particle measured is a sphere with a diameter equal to the mobility diameter of the particle.

$$
\text { Equation } 4.2 \quad \rho_{\text {eff }}=\frac{m}{\pi d_{m}^{3} / 6}
$$

where $\mathrm{m}$ is the mass per particle and $\mathrm{dm}$ is the mobility diameter of the particle. Extensive research have been performed in the past to determine the density distribution of diesel particulate emissions [55-57]. The density distribution of diesel particulates emissions obtained from these studies which have been considered for real-time mass conversion are shown in Equation 4.3

$$
\text { Equation 4.3 } \rho_{\text {eff }}=1.2378 * e^{-0.0048 * D_{p}}
$$

Where, Dp is the mobility diameter of the particle. In order to obtain instantaneous PM mass have to directly multiply number size distribution with particle mass as shown in Equation 4.4

$$
\text { Equation 4.4 } d M=d n * m=d n * \rho_{e f f}\left(\pi d_{m}^{3} / 6\right)
$$


Where $\mathrm{dn}$ is the particle number count per distribution and $\mathrm{dM}$ is the instantaneous mass. Since this method accounts for almost every single particle emitted by engine, particle size based measurements for in-use PM monitoring is a better alternative due to better resolution of PM mass measurement during valid greater than 30 second NTE windows.

Four effective density functions where used for this study including unit density of $1 \mathrm{~g} / \mathrm{cc}$ as shown in Figure 4.5. However, the study performed by Park et. al. (2003) suggested that all particles below $50 \mathrm{~nm}$ had an average particle density of $1.2 \mathrm{~g} / \mathrm{cc}$ [57]. In order to account for the mass emissions from these ultrafine particles a modified version of a constant $1.2 \mathrm{~g} / \mathrm{cc}$ effective density was applied rather than size binned varying effective density. Since the vehicles under investigation were clean, newer MY engines equipped with DPFs for diesel fueled vehicles, particles over $254 \mathrm{~nm}$ as measured by the TSI EEPS were considered to be electrometer noise, thus excluded from the integrated mass calculations.

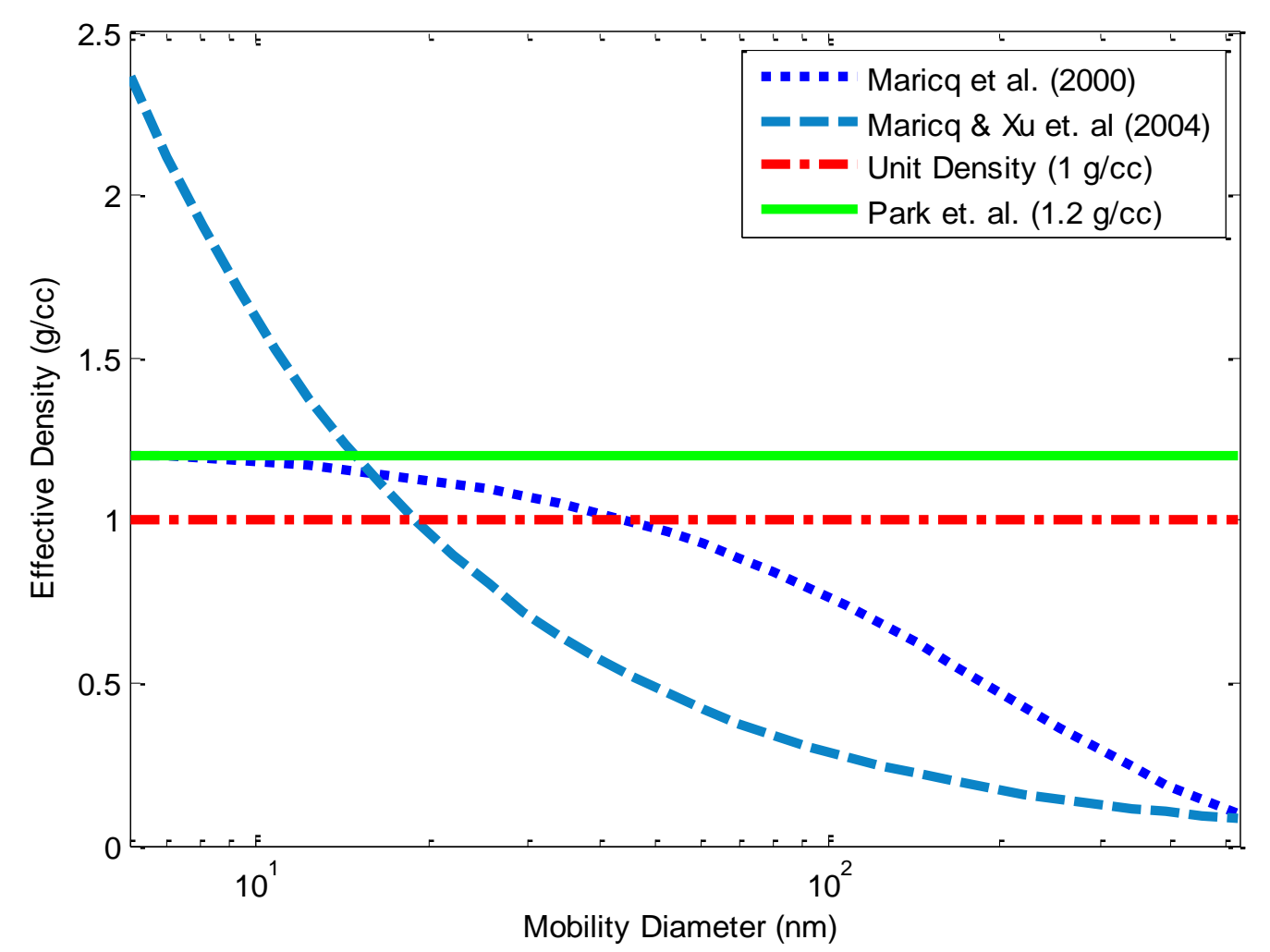

Figure 4.6 Correlation of effective density versus mobility diameter used for this study [55-57]. Note: The size distribution range under study extends from $6 \mathrm{~nm}$ to $254 \mathrm{~nm}$ in mobility diameter only 


\subsection{NTE Analysis}

In order to measure the in-use emissions of heavy-duty engines while operating within a wide range of operating speeds and loads, the brake specific PM emissions measured during valid NTE windows were calculated and compared against NTE threshold passage criteria. The calculations for NTE threshold passage criteria are give below in Equation 4.5 as specified by 40 CFR $\S 86.007$ guidelines. In addition to this threshold criteria, in order for a vehicle to comply with in-use emission standards the vehicle must pass at least $90 \%$ of the total valid NTE events observed during in-use testing. The remaining failed NTE events must have brake specific emissions not more than two times NTE threshold value.

\section{Equation 4.5 NTE Threshold $=($ CERTValue $*$ NTEMultiplier $)+$ Accuracy Margin + Compliance Margin}

Where:

NTE Threshold $=$ Brake specific emission limit during valid NTE window.

CERTValue $=$ Brake specific emissions report during engine cetrification .

NTEMultiplie $=$ Function of vehicle model year and Certification Standard .

Accuracy Margin = Function of flow measurement used.

Compliance Margin = Function of vehicle mileage . 


\section{CHAPTER 5. RESULTS AND DISCUSSION}

The TRU engine was tested in WVU's EERL facility and the four goods movement vehicles were tested on the WVU Transportable Chassis Dynamometer Laboratory. The TRU engine was tested with and without an DOC-DPF aftertreatment system. Regulated TPM and $\mathrm{CO}_{2}$ emissions were measured for both vehicle chassis dynamometer testing and engine dynamometer testing. Other emissions were also measured during the study, however they are beyond the scope of this topic. In addition to regulated emissions, particle size distribution and number counts were measured during the study. Results derived using particle size distribution and number counts that are presented here are not corrected for background PM in dilution air. Five percent confidence interval was assumed for all statistical analysis performed on results obtained from experimental investigation.

\subsection{PM Mass Measurement Method Comparison:}

The comparison between the TPM measured gravimetrically and PM mass derived from particle size distribution and number counts using different density function are shown below in Figure 5.1 and Figure 5.2. Particle size distribution and number counts were measured using TSI scanning mobility particle sizer (SMPS) for 4-Mode steady state tests performed on the TRU engine. Figure 5.1 and Figure 5.2 show the number and mass concentration distributions measured at the CVS tunnel respectively. Figure 5.3 shows brake specific PM mass emissions measured during the 4-Mode steady state test cycle without any aftertreatment system and Figure 5.4 shows brake specific PM mass emissions with a DOC+DPF aftertreatment system. The standard deviation as indicated by the variation bars are significantly lower in size distribution derived masses than the mass measured by regulated gravimetric method Amongst the four different density functions the effective density of $1.2 \mathrm{~g} / \mathrm{cc}$ (Park et. al.) accounts for the most mass collected in the gravimetric filter. The modified density function assumes a constant 1.2 $\mathrm{g} / \mathrm{cc}$ density for the entire distribution. The modified Park et. al. density function accounts for about $73 \%$ of the mass collected by the gravimetric filter when measuring diesel engine exhaust without any aftertreatment devices. However, this difference in mass between the different

density functions and gravimetric PM measurement greatly increases when measuring diesel engine exhaust with an aftertreatment system, specifically when the engine uses a diesel oxidation catalyst and diesel particulate filter as one of the aftertreatment devices. 


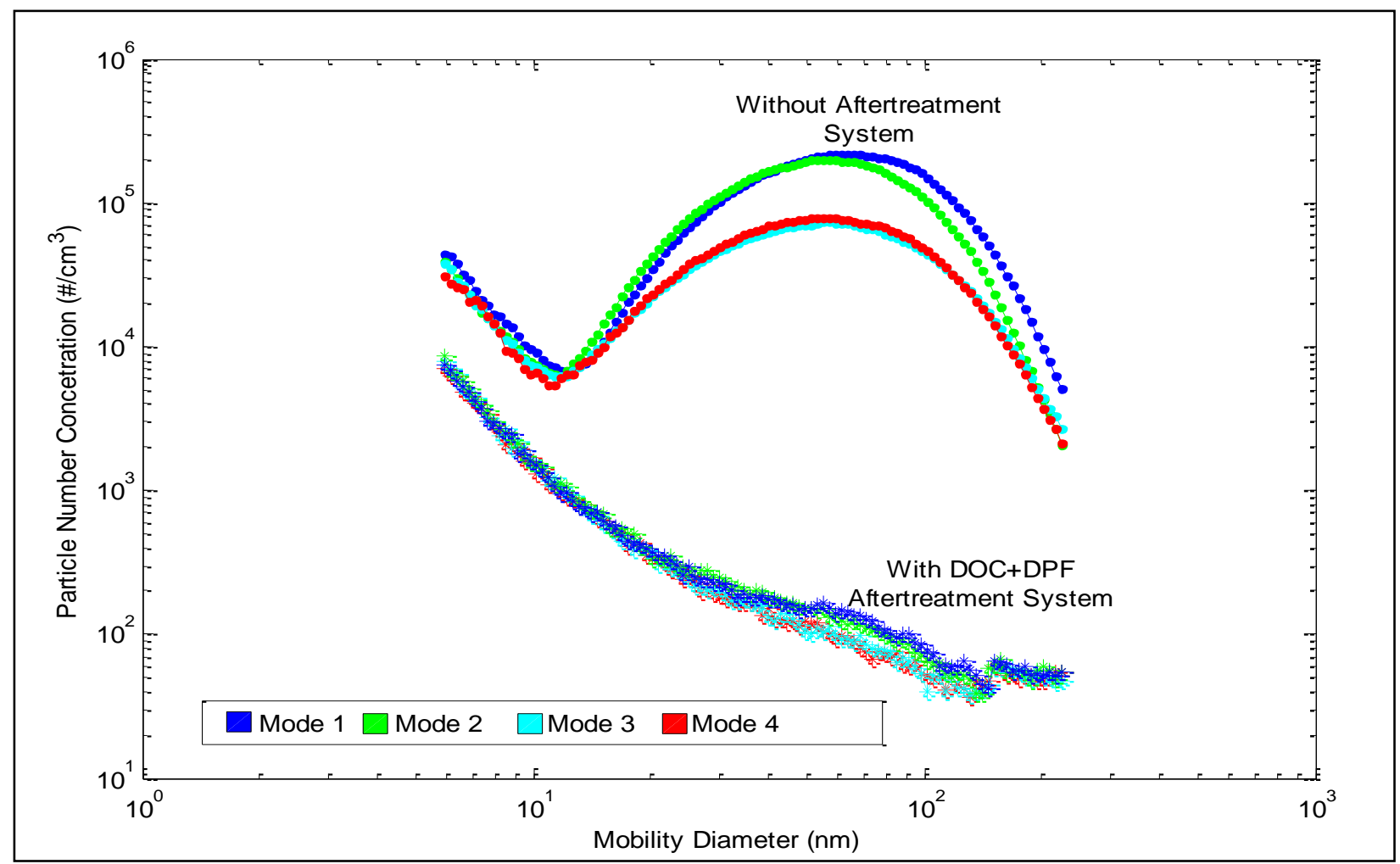

Figure 5.1 Number concentration and distribution of diluted diesel exhaust from the TRU engine, measured by the SMPS at the CVS tunnel sample plane

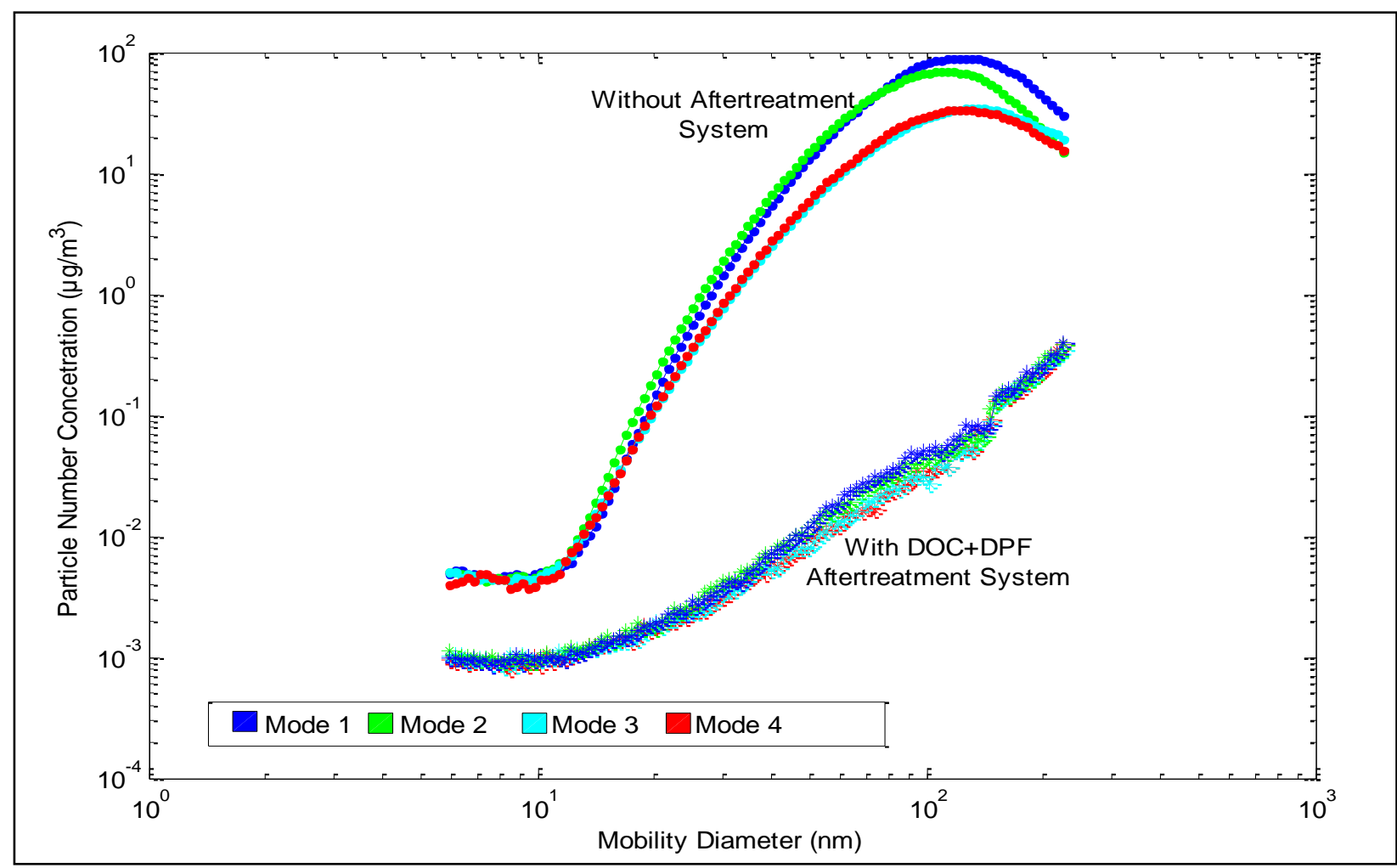

Figure 5.2 Mass concentration and distribution using unit density $(1 \mathrm{~g} / \mathrm{cc})$ of diluted diesel exhaust from the TRU engine, measure by the SMPS at the CVS tunnel sample plane 


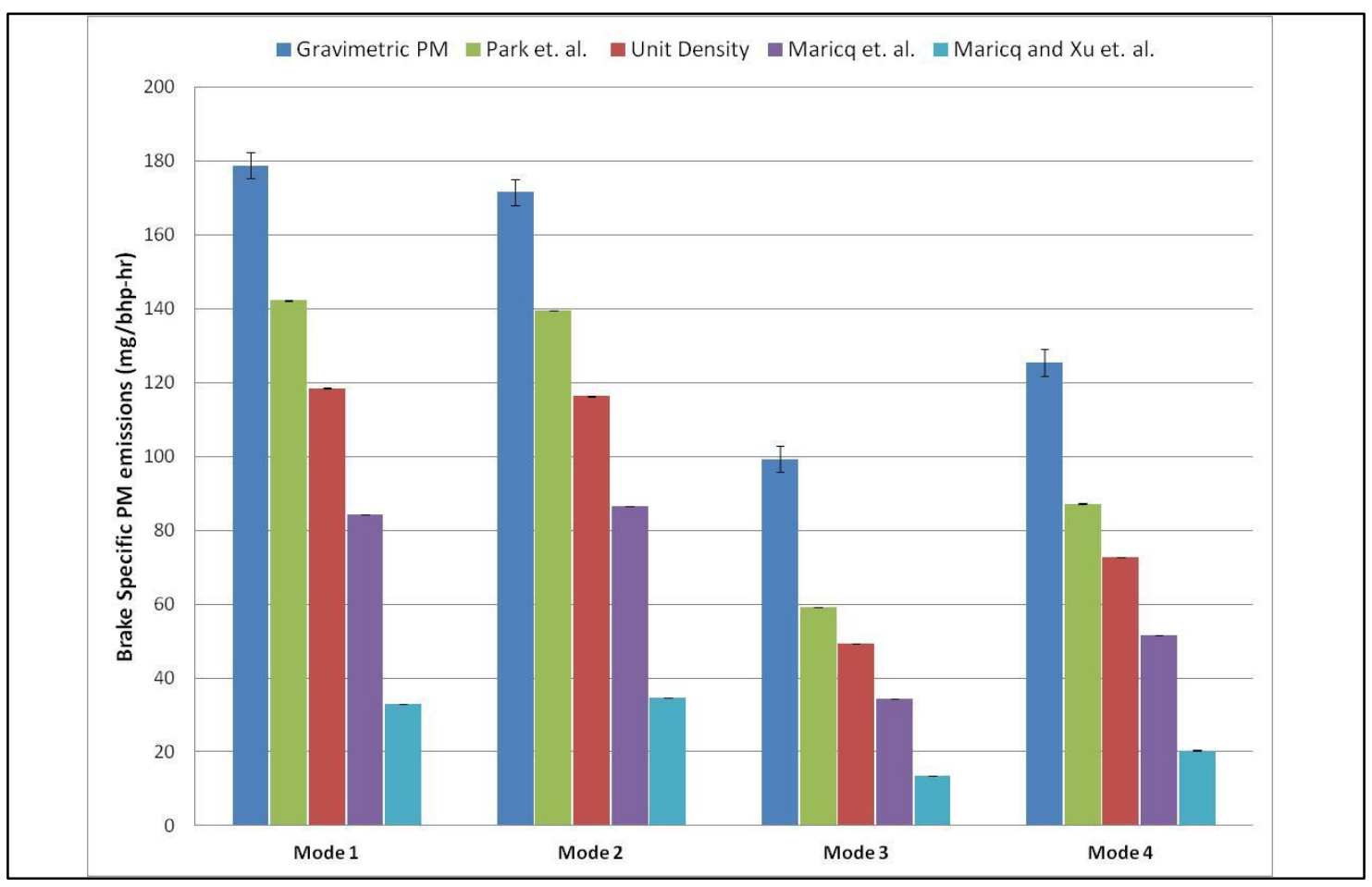

Figure 5.3 A comparison of the total mass emissions from TRU engine without any aftertreatment systems over the 4-Mode steady state test cycle as measured by the regulated gravimetric method and as calculated using different effective density functions

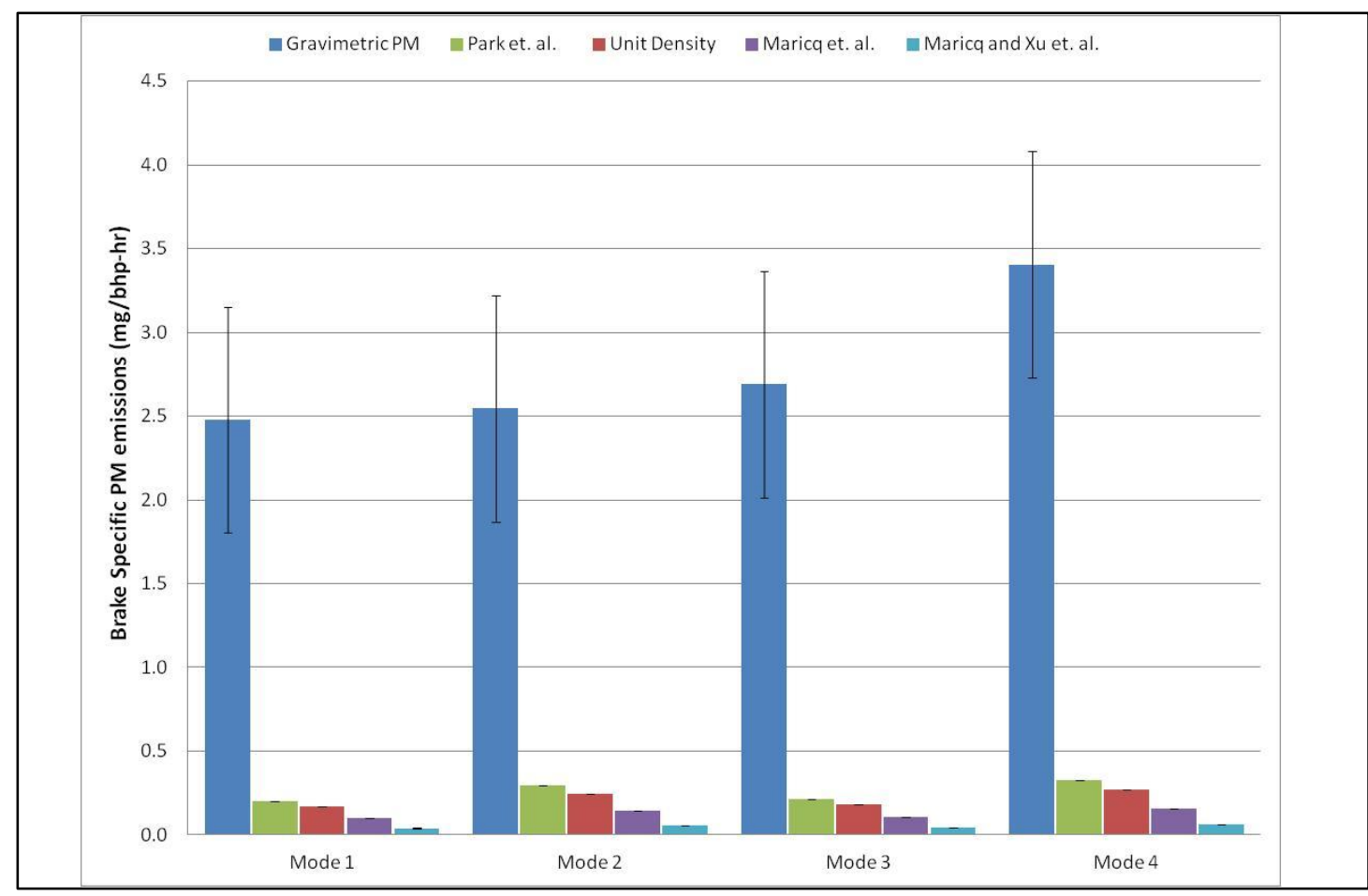

Figure 5.4 A comparison of the total mass emissions from TRU engine with a DOC-DPF aftertreatment system over the 4-Mode steady state test cycle as measured by the regulated gravimetric method and as calculated using different effective density functions 
The significant difference in mass measured by the regulated gravimetric method and mass derived from particle size distribution and number counts could be attributed to the different constituents of PM that each analyzer are measuring or taking into account. The SMPS or EEPS measures any particle that is able to carry an electrical charge. Whereas the regulated gravimetric is sensitive to various parameters such as humidity, VOCs and gas phase HC in the exhaust. Significant portion of the difference in mass measured could be due to gas phase artifacts adsorbed by the filter material [2]. The higher standard deviation observed in the gravimetric PM is influenced by various factors such as varying filtration efficiency, filter weighing and filter handling. However, these factors do not influence particle size distribution measurements[2].

\subsection{Variability Analysis}

In the previous section, controlled studies were performed to compare the mass measured gravimetrically to mass derived from particle size distributions and number counts using high precision particle sizing interments such as the TSI SMPS during steady state test cycles. However, in order to estimate PM mass emissions during transient test cycles real time particle sizing instruments such as TSI EEPS are needed to obtain real time PM mass emission rates. Statistical variability analysis was performed on the data obtained from chassis dynamometer testing. Real time, second by second size distribution and number counts were measured using the TSI EEPS for transient testing. Real time particle size distribution and particle number counts were used to calculate integrated particulate matter emission rates using different density functions. Variability gauge analysis was performed in order to study how measurement of PM emissions varies across the different measurement methods or density functions used for estimates. Gauge R\&R (repeatability and reproducibility) analysis plots were also used in order to estimate the variability in measurement using different measurement methods and density functions. Figure 5.5 and Figure 5.6 show results obtained gauge R\&R analysis showing the two main aspects, namely repeatability and reproducibility of using different measurement methods and density functions for PM mass estimations. Figure 5.5 shows the mean brake specific emissions for each measurement method and Figure 5.6 showing the mean standard deviation of each vehicle group for each measurement method. 


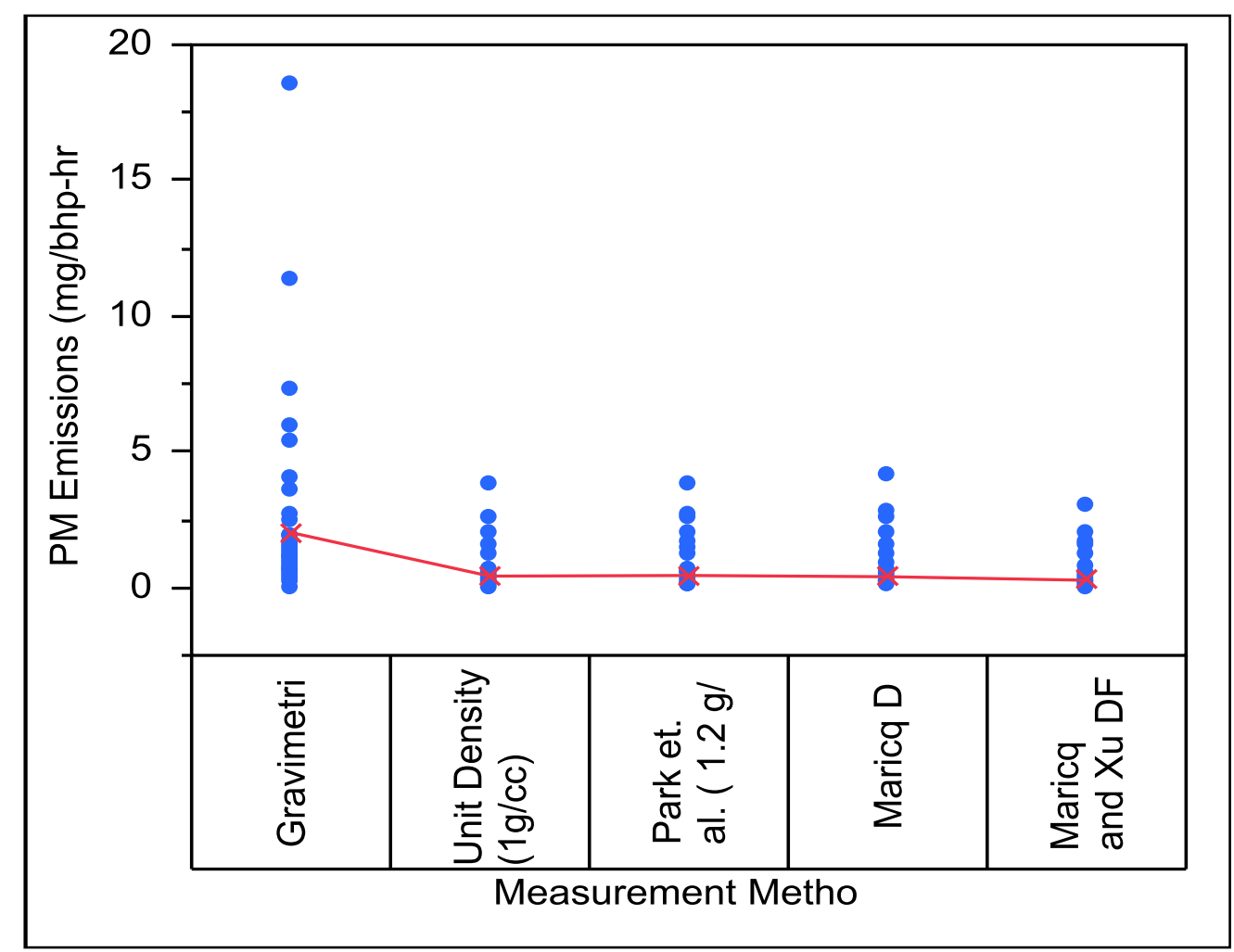

Figure 5.5 Brake specific PM emissions by measurement method with grand means shown in red mean lines

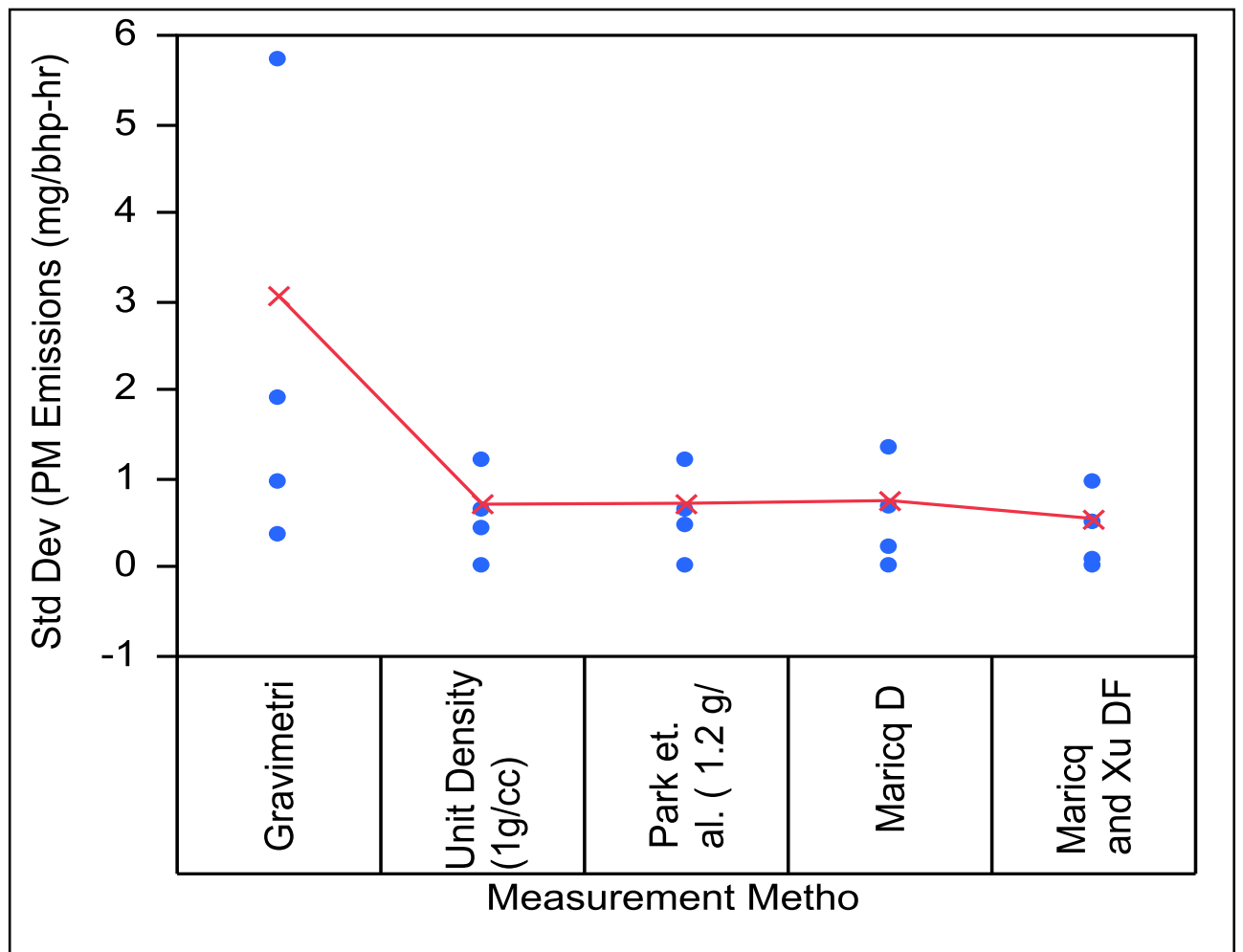

Figure 5.6 Mean standard deviation of brake specific PM emissions by measurement method with grand means in red 
The graph plots shown above are purely independent for each factors, the factors being measurement method (gravimetric mass or mass derived from size distributions and different density functions), vehicle type and test cycles. Initial results shown above in Figure 5.5 and Figure 5.6 show that the average mass measured through the regulated gravimetric method is higher and more widely spread compared to mass estimated derived from particle size distribution and number counts. Significantly higher grand mean and standards deviation was observed in gravimetric analysis as compared to mass derived from particle size distributions and number counts. This higher mass measured in gravimetric analysis is consistent with engine testing results shown in the previous section. Since the TSI EEPS is sensitive to only particles in the exhaust the higher mass could be due to gas phase artifacts adsorbed by the filter material[2]. However, the masses measured though gravimetric analysis also have a higher standard deviation which suggests that the variability could be due to errors associated with filter handling and weighing [2]. In addition to this ambient conditions such as barometric pressure, humidity and temperature that contribute to day-today and run-to-run variability also influence the variability observed during in-use chassis dynamometer testing [58], but these parameters are common to PM mass measured using regulated gravimetric method and PM mass derived from particle size distribution and number count measurements during sampling.

The variability charts shown in Figure 5.7 and Figure 5.8 show brake specific PM mass emissions and their variability between vehicle technologies and test cycles. Figure 5.7 is a variability chart grouped within the vehicle technology that was tested in chassis dynamometer testing. The blue range bars indicate the range of the entire data spread within each group, green diamonds indicate the mean and standard deviation of each groups dataset, and red solid lines indicate the upper and lower control limits of 6-sigma or six standard deviations. Figure 5.8 shows a more detailed variability chart that is grouped based on both test cycle and vehicle technology. 


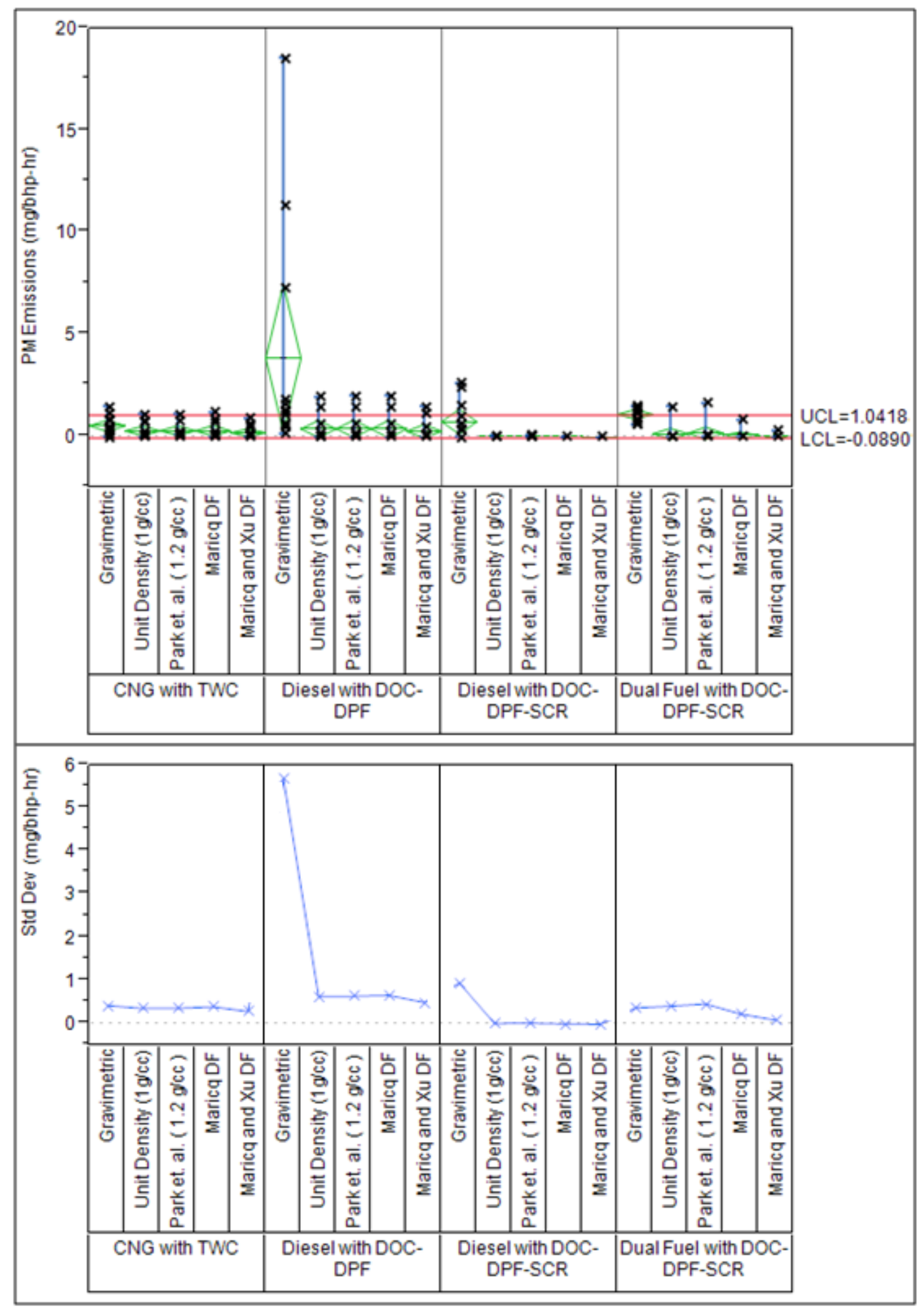

Figure 5.7 Variability chart for engine brake specific PM emissions showing variability between different measurement method that are grouped within different vehicle technologies 

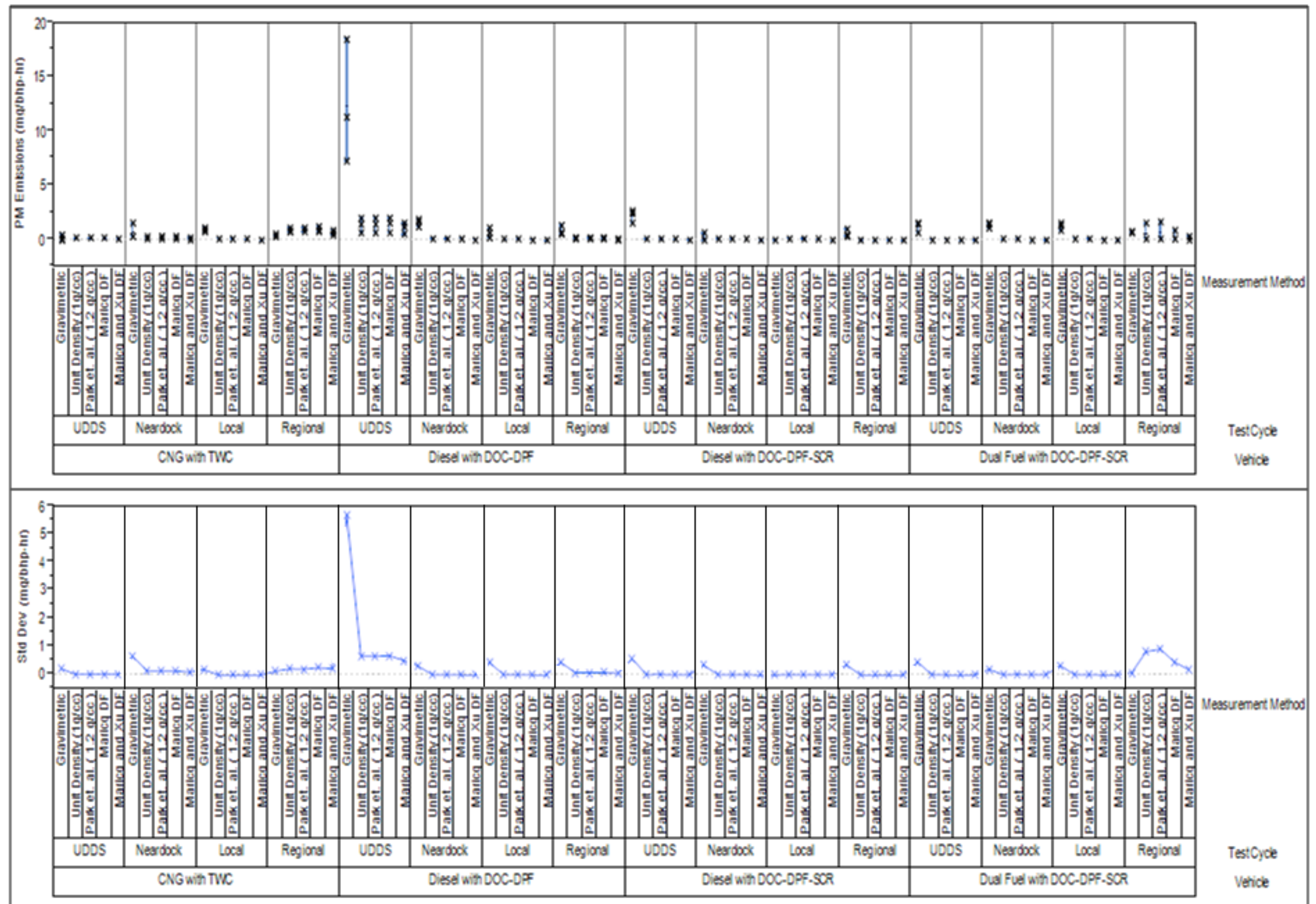

Figure 5.8 Variability Chart showing the engine brake specific PM emissions for different measurement method grouped across test cycle and vehicle tested 


\subsection{Influence of Background Correction on Gravimetric PM Mass Measurement}

The results presented in the previous section clearly show that there is high variability in measuring ultra-low levels of particulate matter from modern heavy duty vehicle with advanced aftertreatment systems. In addition to this, the mass measured though the regulated gravimetric method also happened to be higher than the mass derived from particle size distribution and number count measurement. The higher mass measured could be as a result of gas phase artifacts being absorbed by the filter material [2]. However, in some cases the gravimetric method measured a lower mass than the mass derived from particle size distribution and number count measurements, specifically in the case of natural gas engines operated at aggressive cycles such as the regional cycle as shown in Figure 5.8. Figure 5.9 shows the average brake specific PM mass emissions observed on the CNG with TWC vehicle during the regional cycle. The standard deviations of the PM mass measurements are indicated through the variation bars on the graph.

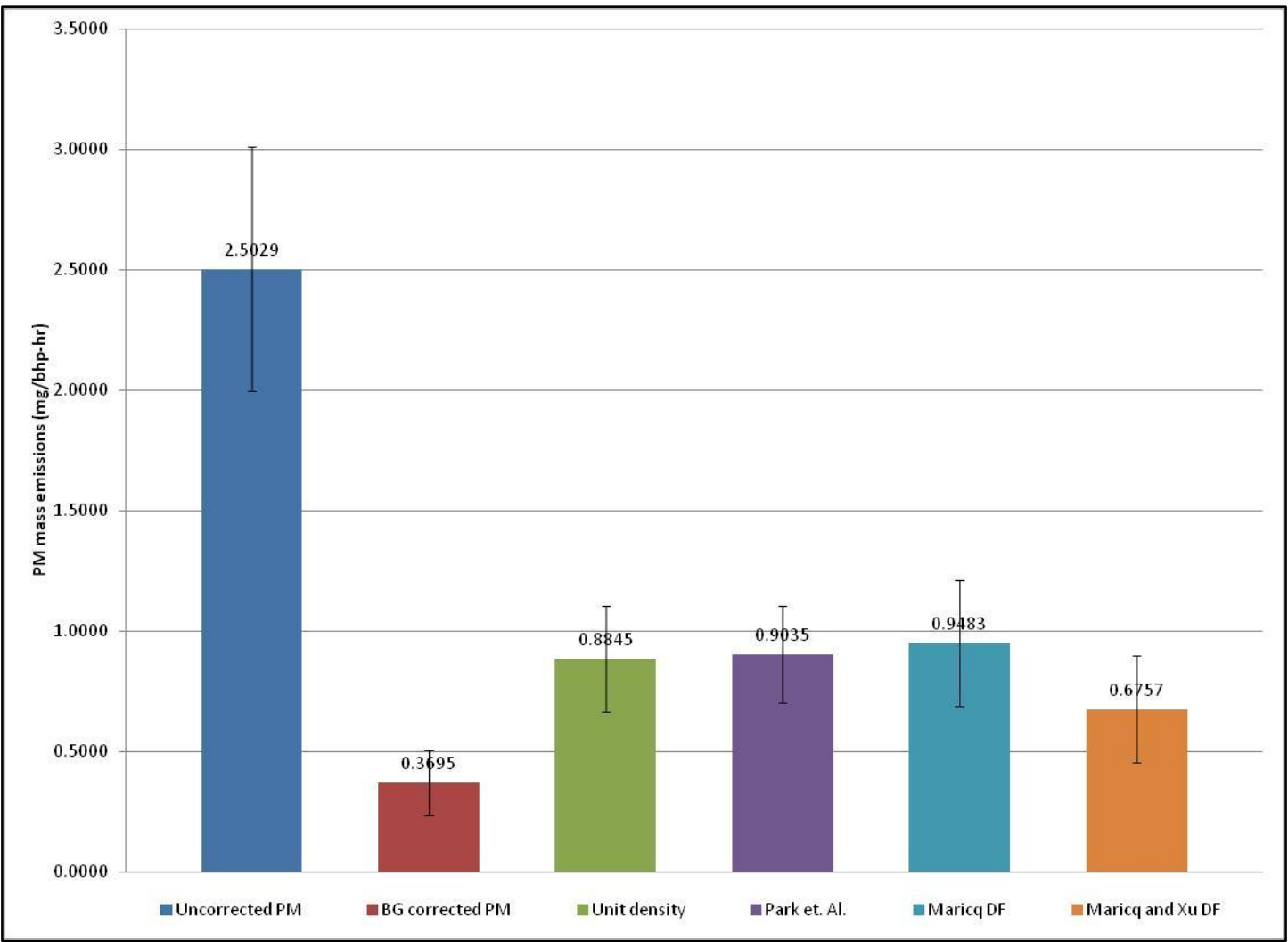

Figure 5.9 Average brake specific PM emissions observed in regional cycle from the CNG with TWC vehicle. Variation bars indicate standard deviation 
Since the regulated gravimetric analysis method requires the fraction of the dilution air in the CVS tunnel to be corrected for background PM contaminants, it is possible to over correct and report a lower value. This could be due to several reasons, first, the tunnel blanks are taken before and after the tests and not during the test themselves and is not mandated to be measured during the test. But the regulated method requires only the fraction of dilution air to be corrected for background contaminants. Second, the CVS dilution air and secondary dilution air are HEPA filtered [45] thus tunnel blanks are not representative of the dilution air rather the tunnel itself. Third, tunnel blanks taken while testing natural gas vehicles could have gas phase hydrocarbons and soot particles adhering to the tunnel walls to released and captured on the filter due to tunnel shedding that happens during the 20 minutes of background sampling period. A revised method of collecting background PM contaminant concentration of dilution air during the test could reduce the possibility of over correcting for background PM contaminants. Finally, the measurement errors associated with weighing and handling of PM filter media that can introduce additional errors into the measured mass [2].

Figure 5.10 shows a comparison between the coefficient of variation of brake specific PM mass measured through gravimetric analysis with and without back ground correction for the different vehicles. The figure shows an increase in variability due to background PM correction. A larger difference in the coefficient of variations is also observed for much cleaner vehicles such as the diesel with DOC-DPF-SCR and CNG with TWC vehicles. This also suggests that the variability increases with decrease in PM mass emissions which is in iterance with the work presented by Burtscher et. al. 2001 [1]. 


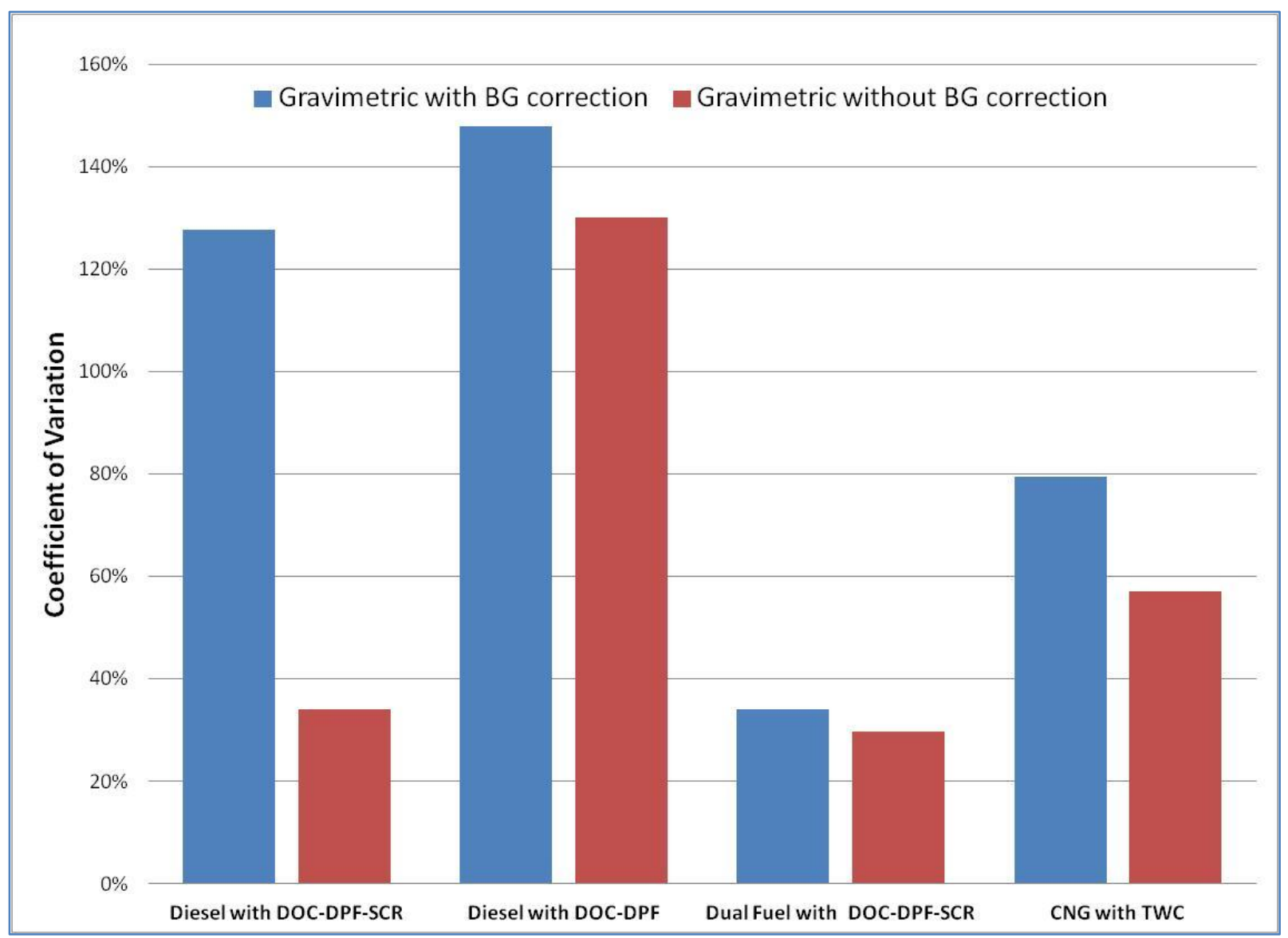

Figure 5.10 Comparison of coefficient of variations between gravimetric PM mass that has been corrected for background contaminants and not corrected for background contaminants in the dilution air

\subsection{Particulate Matter NTE Analysis}

Not-To-Exceed (NTE) test procedure was performed on the goods movement chassis dynamometer test cycle as per the NTE limits specified in US EPA's Title 40 Part 86 of the CFR. The NTE analysis event history is given in Table 5.1 along with the NTE PM emission threshold limits that the vehicle must comply with during in-use operation of the vehicle. The NTE analysis procedure was performed for all four vehicles operating over the four goods movement test cycles. Two out of four vehicles did not have any valid 30 second or greater NTE windows while being operated in the goods movement cycle. This is due to several reasons such as high engine load capacity, cycle aggressiveness and driving or gear shift pattern. The diesel with DOC-DPF had at least two valid greater than 30 seconds NTE window even though the vehicle was rated at $430 \mathrm{hp}$. The reason for this can be accounted due to the stringent driving or gear shift pattern that the vehicle had to be driven in. For example, the vehicle always had to be lugged at an engine speed of $1500 \mathrm{rpm}$, this vehicle will not allow the driver shift to a lower gear 
in order to accelerate during aggressive acceleration ramps, and the vehicle will also not allow the driver to shift gears at high engine speeds. However, the CNG with TWC vehicle was a smaller engine rated at $320 \mathrm{hp}$, operating for a higher vehicle load capacity.

Table 5.1 NTE analysis event history along with NTE threshold limits that the vehicle must comply with during in-use testing

\begin{tabular}{|c|c|c|c|c|c|c|c|c|}
\hline \multirow{3}{*}{ Test Cycle } & \multicolumn{8}{|c|}{ Vehicle } \\
\hline & \multicolumn{2}{|c|}{$\begin{array}{c}\text { Diesel with DOC- } \\
\text { DPF-SCR }\end{array}$} & \multicolumn{2}{|c|}{ Diesel with DOC-DPF } & \multicolumn{2}{|c|}{ CNG with TWC } & \multicolumn{2}{|c|}{$\begin{array}{c}\text { Dual Fuel with DOC- } \\
\text { DPF-SCR }\end{array}$} \\
\hline & $\begin{array}{c}\text { Min. } \\
\text { Candidate } \\
\text { Events }\end{array}$ & $\begin{array}{l}\text { Min. Valid } \\
\text { Events }\end{array}$ & $\begin{array}{c}\text { Min. } \\
\text { Candidate } \\
\text { Events }\end{array}$ & $\begin{array}{l}\text { Min. Valid } \\
\text { Events }\end{array}$ & $\begin{array}{c}\text { Min. } \\
\text { Candidate } \\
\text { Events }\end{array}$ & $\begin{array}{l}\text { Min. Valid } \\
\text { Events }\end{array}$ & $\begin{array}{c}\text { Min. } \\
\text { Candidate } \\
\text { Events }\end{array}$ & $\begin{array}{l}\text { Min. Valid } \\
\text { Events }\end{array}$ \\
\hline UDDS & 78 & 0 & 71 & 0 & 32 & 4 & 84 & 0 \\
\hline Neardock & 47 & 0 & 55 & 0 & 68 & 2 & 39 & 0 \\
\hline Local & 86 & 0 & 116 & 0 & 76 & 4 & 76 & 0 \\
\hline Regional & 206 & 0 & 224 & 2 & 114 & 7 & 192 & 0 \\
\hline $\begin{array}{l}\text { Compliance } \\
\text { Threshold }\end{array}$ & \multicolumn{2}{|c|}{$0.0105 \mathrm{~g} / \mathrm{bhp}-\mathrm{hr}$} & \multicolumn{2}{|c|}{$0.0075 \mathrm{~g} / \mathrm{bhp}-\mathrm{hr}$} & \multicolumn{2}{|c|}{$0.0156 \mathrm{~g} / \mathrm{bhp}-\mathrm{hr}$} & \multicolumn{2}{|c|}{$0.012 \mathrm{~g} / \mathrm{bhp}-\mathrm{hr}$} \\
\hline
\end{tabular}

The results for the NTE analysis are shown in Figure 5.11 and Figure 5.12, the variation bars indicate the standard deviations respectively. The solid filled portion of the bar graphs shown below indicates the average NTE emissions observed, while the total height of the bar graphs indicates average emissions over the entire test cycles. All the brake specific PM emissions during the valid 30 second or greater NTE windows were well within and several orders of magnitude less than the NTE compliance threshold shown in Table 5.1. However, the vast difference between the compliance threshold and brake specific NTE PM emissions can also be accounted towards the difference in measurement method. This is because the PM certification values are obtained from gravimetric analysis and the NTE compliance threshold is a function of these certification values. The average brake specific PM NTE emissions are about $30 \%$ lower for the diesel with DOC-DPF vehicle and about $60 \%$ lower for the CNG with TWC vehicle, compared to the average brake specific emissions measured over the entire cycle. In comparing the standard deviations between the brake specific emissions produced during valid NTE event and the entire cycle, it is observed that they are of similar magnitude. Thus it can be concluded that the variability in measuring NTE PM emissions using real time mass emission 
rates obtained from particle size distributions and number count measurements are similar to variability in measuring real time mass emission rates.

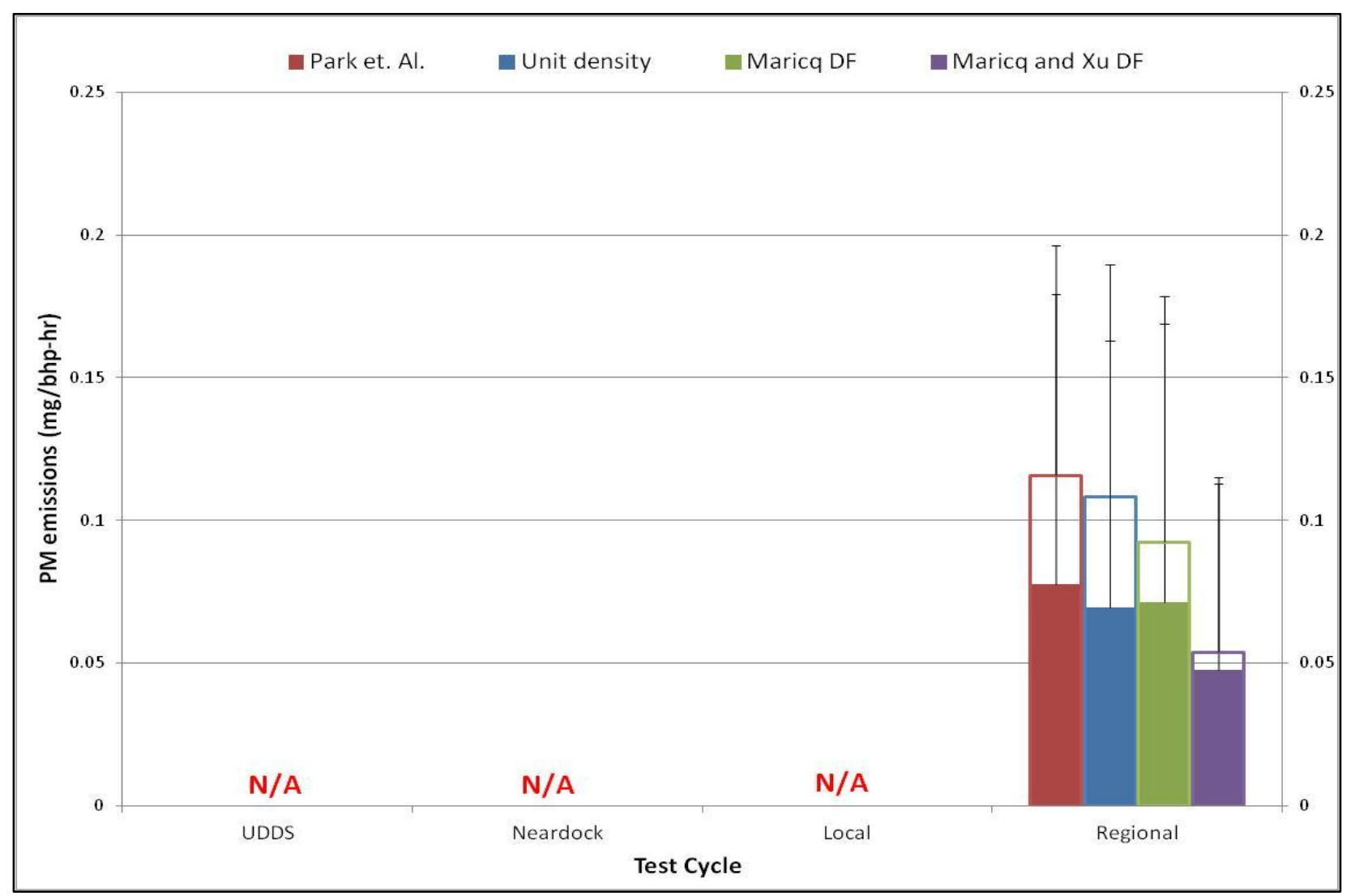

Figure 5.11 Average brake specific NTE emissions from diesel with DOC-DPF vehicle. The filled portion of the bar graph indicates the average NTE emissions observed, while the total height of the bar indicates average emissions over the entire cycles. The standard deviations are indicated by the variation bars respectively 


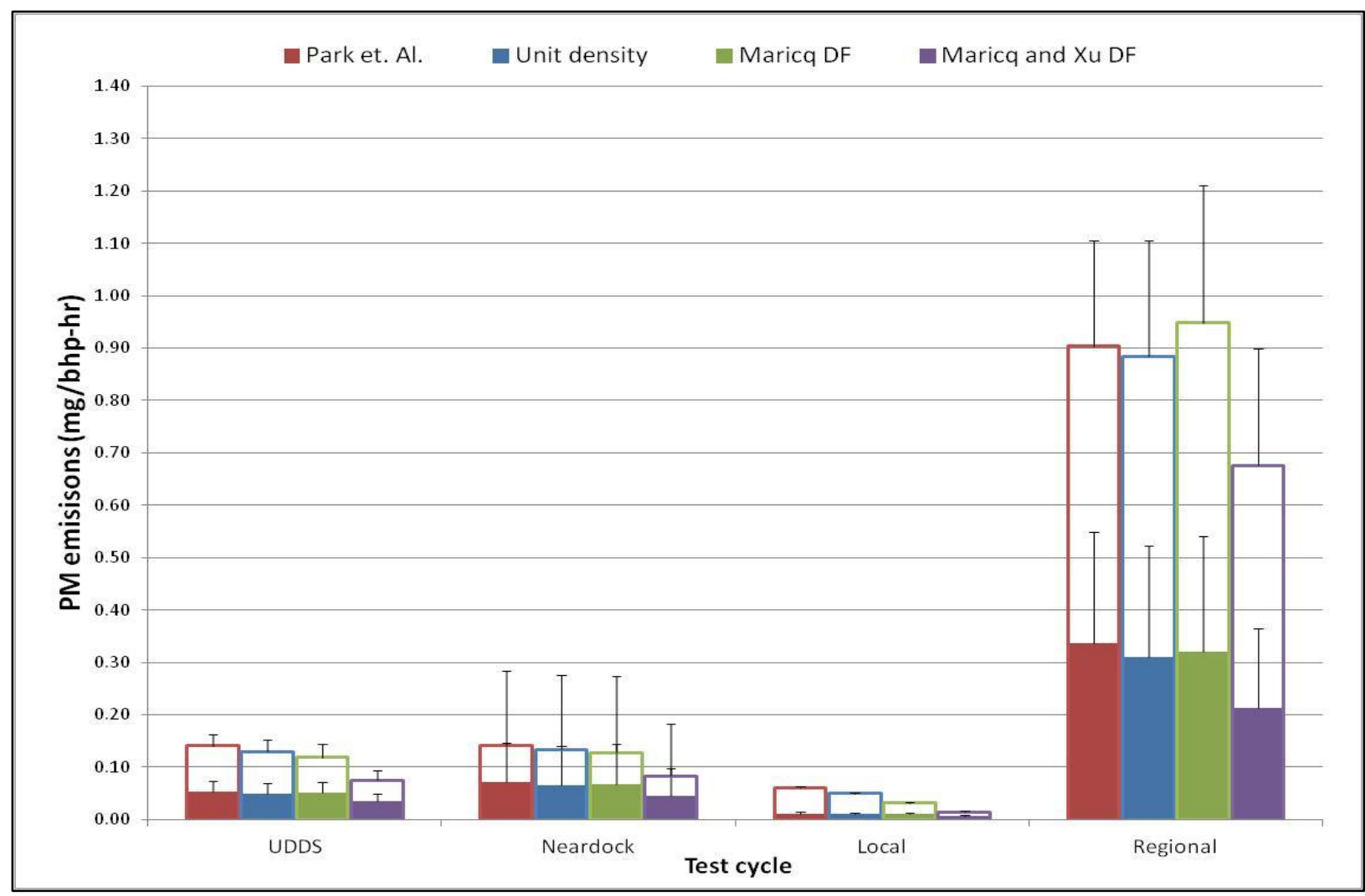

Figure 5.12 Average brake specific NTE emissions from CNG with TWC vehicle. The filled portion indicates the average NTE emissions observed, while the total height of the bar indicates average emissions over the entire cycles. The standard deviations are indicated by the variation bars respectively

\subsection{Total Particle Number Count Emissions}

With emphasis on 2013 EURO-VI regulations, the particle number (PN) emission rates is analyzed in this section. The Particle Measurement Program (PMP) for EURO-VI standard requires only particle greater than $23 \mathrm{~nm}$ to be measured for PN emissions. With this in mind, two particle size distributions ranges of $6 \mathrm{~nm}$ to $254 \mathrm{~nm}$ and $23 \mathrm{~nm}$ to $254 \mathrm{~nm}$ where considered. Figure 5.13 shows the results obtained from variability analysis performed on the results obtained from these two size ranges for the four vehicles operated over the goods movement cycles. The green mean diamonds show the mean and standard deviation of the brake specific PN emission along with blue range line showing the range of the dataset itself within each group. The standard deviation of brake specific PN emissions for the $23 \mathrm{~nm}$ to $254 \mathrm{~nm}$ size range is significantly lower than standard deviation of brake specific PN emissions for the $6 \mathrm{~nm}$ to $254 \mathrm{~nm}$ size range. This suggest that a significant amount of variability is caused dues to the particles below the $23 \mathrm{~nm}$ size range. Moreover the average brake specific PN emissions from these modern heavy duty vehicles are significantly higher than the EURO-VI standards of $4.47 \times 10^{11}$ 
bhp-hr ${ }^{-1}$ for compression ignition engines and $4.47 \times 10^{12} \mathrm{bhp}-\mathrm{hr}^{-1}$ for spark ignited engines. However, the PMP regulation requires the use of VPR systems that use very high two stage hot and cold dilution to reduce particle formation due to condensation of hydrocarbons [35]. This vast difference in dilution ratios between the two methods could account for the higher PN emissions measured at the CVS tunnel [36]. 


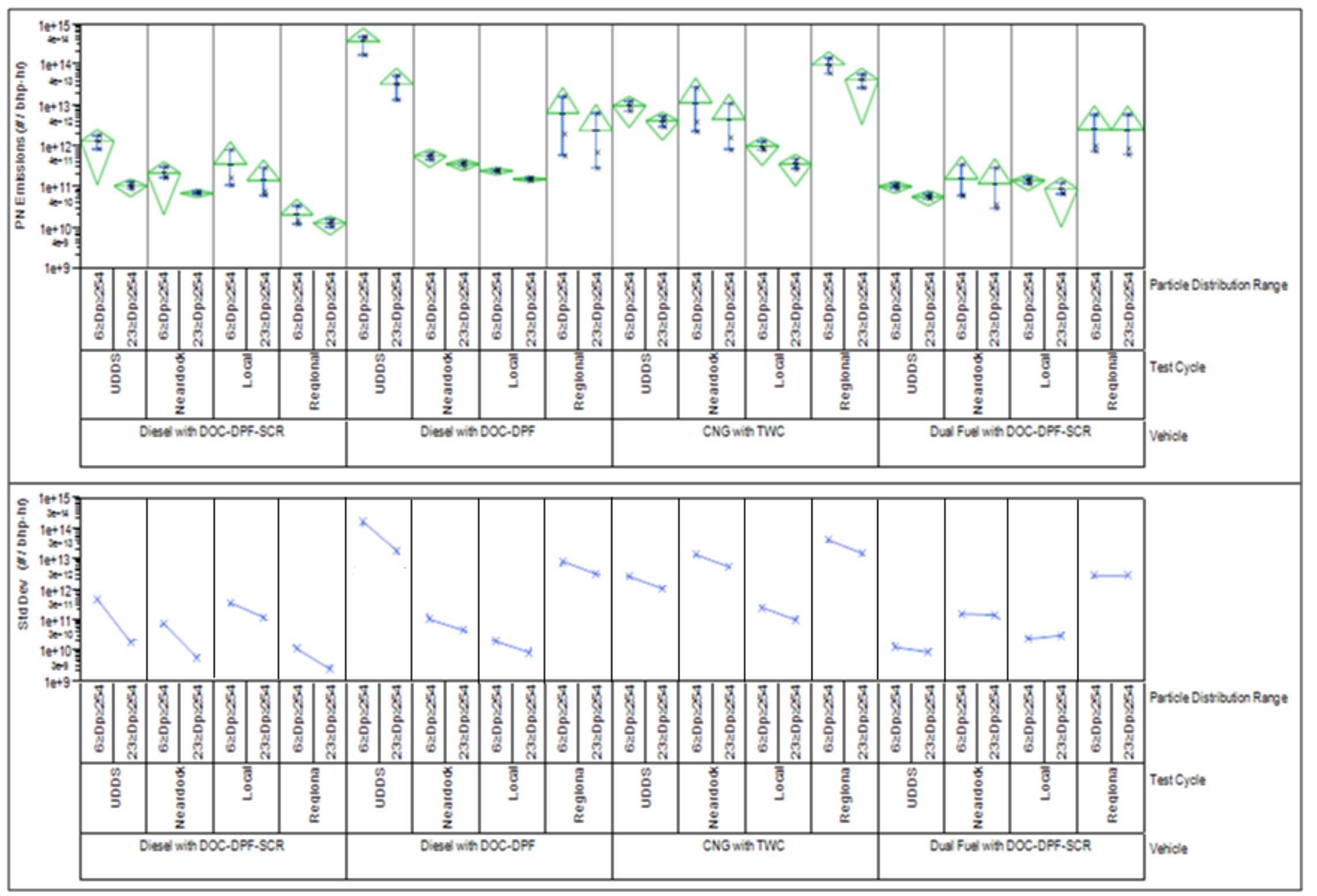

Figure 5.13 Variability chart for brake specific particle number count emissions showing variability between the two different ranges particle size distribution used in this study. Mobility Diameter (Dp) in nm 


\subsection{Drawbacks in PM Measurement Technique}

Since all vehicles tested in this study were low emitting modern heavy duty vehicles, no secondary dilution was used while sampling directly from the CVS tunnel. This was done in order to better correlate the gravimetric PM and the particle size distribution and concentration formed as a result of dilution within the CVS. However, when the vehicles were being operated at high engine load conditions during aggressive chassis dynamometer test cycles such as the regional cycle TSI EEPS analyzer over ranging was observed. The over ranging was typically caused due to sudden increase in particle number concentration of the uni-modal distribution peaking at $22 \mathrm{~nm}$ as seen in Figure 5.14. This uni-modal distribution was typically observed during high exhaust temperatures over $400{ }^{\circ} \mathrm{C}$. The temperature dependence and size distribution range of these ultrafine particle suggest that these are metal emissions due to lube oil consumption [3]. These short over ranging events introduced significant errors in measuring real time mass emissions rates. On the other hand, these high temperature events where observed only for the diesel with DOC-DPF and CNG with TWC vehicles during aggressive cycles with steep acceleration ramps, such as the UDDS and regional cycle.

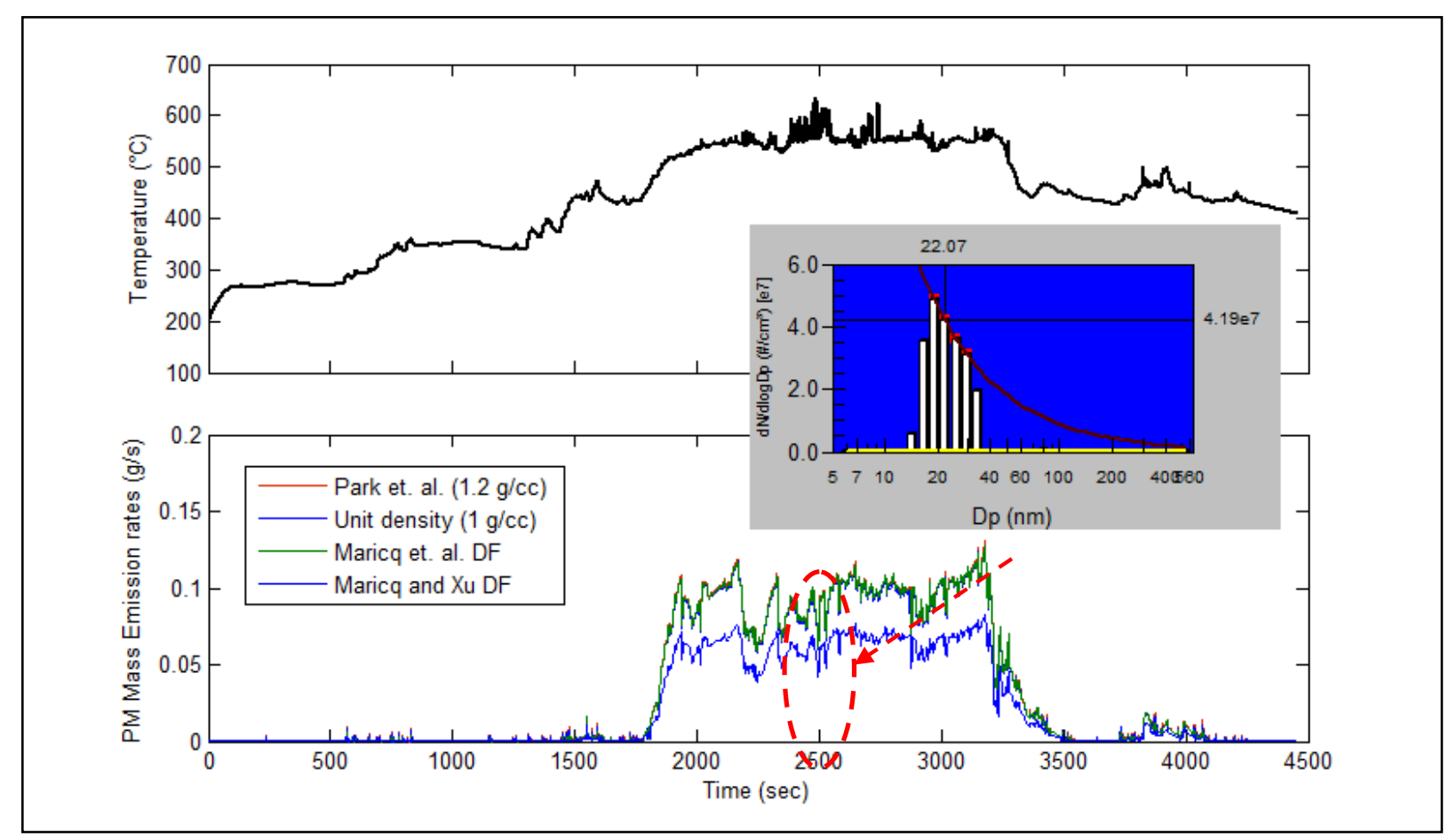

Figure 5.14 PM mass emission rates long with post three way catalyst temperature for the CNG with TWC vehicle. Particle number distribution plot shows TSI EEPS is over ranging at high temperature operation during the regional goods movement cycle. Particle number distribution plot represents PM number concentrations in the CVS tunnel 


\section{CHAPTER 6. CONCLUSIONS}

The key objective of this research is to study the variability in measuring very low PM mass emissions from modern heavy duty vehicles with advanced aftertreatment systems and compare the results against particle number count measurement method. This was performed successfully. The results further established the magnitude and source of variability for the different measurement methods used in this study.

Controlled engine dynamometer studies performed on Tier-IV compliant diesel engine without any advanced emission reduction system, show that particle size distribution and number count measurements are able to account for about $73 \%$ of the mass measured by the gravimetric method. However this percent difference is greatly increased when the engine was retro-fitted with DOC-DPF aftertreatment system. This suggest that the difference in measured mass emissions is due to inaccuracies in the two measurement methods being used.

Results obtained from data driven variability analysis performed on the brake specific emissions obtained from the different methods show the magnitude and source variability in PM mass measurement. Higher average mass emissions were observed in mass measured though gravimetric analysis as compared to the other methods as seen in controlled engine dynamometer testing. Higher standard deviations of $3.1 \mathrm{mg} / \mathrm{bhp}-\mathrm{hr}$ was observed on mass measured though gravimetric analysis. However, the standard deviation of masses derived from particle size distribution and number counts were as low as $0.36 \mathrm{mg} / \mathrm{bhp}-\mathrm{hr}$, suggesting lower variability over regulated gravimetric method of measuring PM mass emissions.

On further investigation, it was found the introduction of background correction on PM mass emissions in the regulated gravimetric method introduced more errors into the measurement method. The difference in variability between PM mass emissions with and without background PM correction was larger for cleaner low PM emitting engines as in the case of the diesel with DOC-DPF-SCR and CNG with TWC vehicles.

The study was extended to an in-use study in order to compare NTE zone PM mass measurement. Only two out of four vehicles had valid NTE windows during in-use operation on the goods movement chassis dynamometer cycles. Results of the NTE analysis showed that 
mass measured through real time particle size distribution and number count measurements during valid NTE windows were well below the NTE threshold limit. However, the value of NTE threshold limit is derived from certification value obtained during engine certification process that utilizes gravimetric method of PM mass measurement.

PN emission rates were also analyzed with emphasis on 2013 EURO-VI standards. Two size distribution size ranges where assessed in order to determine the influence of less than 23 $\mathrm{nm}$ particles on variability of measurement. The results of brake specific total particle number count emissions were significantly higher than the EURO-VI standard. However, the measurement method utilized in this study were at lower dilution ratios as compared to the dilution ratios used in the PMP regulation. Moreover, PMP regulation require the use of VPR systems that reduce the number of condensed nucleation mode particle due to partial pressure of hydrocarbons in the exhaust. Thus resulting in the measurement of higher concentration of higher particle number counts through the method employed for this study. On the other hand, the total number counts measured between $23 \mathrm{~nm}$ to $254 \mathrm{~nm}$ size range showed a lower standard deviation suggesting that less than $23 \mathrm{~nm}$ particles influence a lot on the variability of PN and PM mass emission measurement.

It was also observed that primary dilution at the CVS tunnel alone was not enough to measure particle size distribution and number counts using the TSI EEPS. This is because, during higher exhaust temperature operations large amounts of uni-modal distribution particles peaking at $22 \mathrm{~nm}$ seemed to be emitted by the vehicle causing the TSI EEPS electrometer to over range. Thus requiring the need for a suitable secondary dilution.

Variability studies have been performed in order to determine the effect of various factors such as dilution ratios, filter adsorption and desorption and filter handling and weighing [2] on repeatability and reproducibility of PM mass measurement at low levels of mass emissions [1]. However these studies performed in the past did not use results obtained from laboratories compliant with the current US EPA standards and from modern cleaner heavy duty vehicles with advances emission reduction systems. The finding of this study show the magnitude of variability and their sources in measuring PM mass emissions from these modern ultra low PM emitting vehicles. 


\section{REFERENCES}

1. Burtscher, H., Tailpipe Particulate Emission Measurement for Diesel Engines. 2001, Fachhochschule Aargau, Unversity of Applied Science: CH 5210 Windisch, Switezerland.

2. Kittelson, D.B. and J.H. Johnson, Variability in Particulate Emissions Measurements in the Heavy-Duty Transient Test*, in International Congress and Exposition. 1991.

3. Thiruvengadam Padmavathy, A., Characterization of the composition and toxicity of particulate matter emission from advaced heavy-duty natural gas engines, in Department of Mechanical and Aerospace Engineering. 2012, West Virginia University: Morgantown, WV.

4. Scheer, V., U. Kirchner, R. Casati, R. Vogt, B. Wehner, S. Philippin, A. Wiedensohler, N. Hock, J. Schneider, S. Weimer and S. Borrmann, Composition of Semi-volatile Particles from Diesel Exhaust, in SAE 2005 World Congress \& Exhibition. 2005, SAE International.

5. Biswas, S., S. Hu, V. Verma, J.D. Herner, W.H. Robertson, A. Ayala and C. Sioutas, Physical properties of particulate matter (PM) from late model heavy-duty diesel vehicles operating with advanced PM and NOx emission control technologies. Atmospheric Environment, 2008. 42(22): p. 5622-5634.

6. Biswas, S., V. Verma, J.J. Schauer and C. Sioutas, Chemical speciation of PM emissions from heavy-duty diesel vehicles equipped with diesel particulate filter (DPF) and selective catalytic reduction (SCR) retrofits. Atmospheric Environment, 2009. 43(11): p. 1917-1925.

7. Kitsopanidis, I., Experimental and computational study of soot formation under diesel engine conditions, in Massachusetts Institute of Technology. Dept. of Mechanical Engineering. 2004, Massachusetts Institute of Technology.

8. DieselNet.com. Emission Standards-Summary of worldwide engine emission standards. Available from: www.dieselnet.com/standards/.

9. Bockhorn, H., Soot Formation in Combustion: Mechanism and Models. Berlin: Springer, 1994.

10. Heywood, J.B., Internal Combustion Engine Fundamentals. 1988: McGraw Hill Inc.

11. Mansurov, Z.A., Soot Formation in Combustion Process (Review). Combustion, Explosion and Shock Waves, 2005. 41.

12. Boulanger, J., F. Liu, W.S. Neill and G.J. Smallwood, An Imporved Soot Fomation Model for 3D Diesel Engine Simulations. Journal of Engineering for Gas Turbine and Power, 2007. 129.

13. Plee, S.L., T. Ahmad and J.P. Myers, Flame Temperature Correlation for the effects of Exhaust Gas Recirculation on Diesel Particulate and NOx Emissions. SAE International, 1981.

14. Swanson, J.J., D.B. Kittelson, W.F. Watts, D.D. Gladis and M.V. Twigg, Influence of storage and release on particle emissions from new and used CRTs. Atmospheric Environment, 2009. 43(26): p. 3998-4004.

15. Somers, J.H., Automotive Sulphate Emission Data. Environmental Health Perspectives, 1975. 10.

16. Allanson, R., P.G. Blakeman, B.J. Cooper, P.R. Phillips, J.E. Thoss and A.P. Walker, The Use of the Conitnuosly Regenerating Trap (CRT) to Control Particulate Emissions: 
Minimizing the Impact of Sulphur Poisoning. Society of Automotive Engineers, 2002(2001-01-3012).

17. Maricq, M.M., Chemical characterization of particulate emissions from diesel engines: A review. Journal of Aerosol Science, 2007. 38(11): p. 1079-1118.

18. Agency, U.S.-E.P., Clean Air Act, U.S.F. Government, Editor. 1977.

19. Zelenka, P., W. Kriegler, P.L. Herzog and W.P. Cartellieri, Ways Toward the Clean Heavy-Duty Diesel. 1990, SAE International.

20. Kittelson, D.B., Engines and nanoparticles: a review. Journal of Aerosol Science, 1998. 29(5-6): p. 575-588.

21. Durbin, T.D., J.M. Norbeck, D.R. Cocker III and T. Younglove, Particulate Matter Mass Measurement and Physical Characterisation - Techniques and Instrumentation for Laboratory Source Testing. 2004, Unversity of California: Riverside, CA.

22. Liu, Z.G., V.N. Vasys, M.E. Dettmann, J.J. Schauer, D.B. Kittelson and J. Swanson, Comparison of Strategies for the Measurement of Mass Emissions from Diesel Engines Emitting Ultra-Low Levels of Particulate Matter. Aerosol Science and Technology, 2009.

23. Desantes, J.M., V. Bermúdez, J.M. García and E. Fuentes, Effects of current engine strategies on the exhaust aerosol particle size distribution from a Heavy-Duty Diesel Engine. Journal of Aerosol Science, 2005. 36(10): p. 1251-1276.

24. Krishnan, R. and T.J. Tarabulski (2005) Economics of Emission Reduction For Heavy Duty Trucks.

25. Khair, M.K., Diesel Engine Technology. SAE Seminar, 1993.

26. Gill, A.P., Design Choices for 1990s Low Emissions Diesel Engines. SAE Technical Paper, 1988.

27. Handbook of Air Pollution from Internal Combustion Engines: Pollutant Formation and Control, ed. E. Sher. 1998: ACADEMIC PRESS Ltd.

28. Truex, T.J., W.R. Pierson and D.E. McKee, Sulphate in diesel exhaust. Environmental Science and Technology, 1980. 14(1118-1121).

29. Harayama, N., K. Niimura and Y. Watanabe, Effects of Sulfate Adsorption on Performance of Diesel Oxidation Catalyst**, in International Congress and Exposition. 1992.

30. Baranescu, R.A., Influence of Fuel Sulphur on Diesel Particulate Emissions**, in Transportation Technology Conference and Exposition. 1988.

31. Wall, J.C., S.A. Shimpi and M.L. Yu, Fuel Sulfur Reduction for Control of Diesel Particulate Emissions*, in International Fuels and Lubricants Meeting and Exposition. 1987.

32. Yan, F., E. Winijkul, S. Jung, T.C. Bond and D.G. Streets, Global emission projections of particulate matter $(P M):$ I. Exhaust emissions from on-road vehicles. Atmospheric Environment, 2011. 45(28): p. 4830-4844.

33. Hu, S., J.D. Herner, M. Shafer, W. Robertson, J.J. Schauer, H. Dwyer, J. Collins, T. Huai and A. Ayala, Metals emitted from heavy-duty diesel vehicles equipped with advanced PM and NOX emission controls. Atmospheric Environment, 2009. 43(18): p. 2950-2959.

34. Holemen, B.A. and A. Ayala, Ultrafine PM Emissions from Natural Gas, Oxidation Catalyst Diesel and Particulate-Trap Diesel Heavy-Duty Transit Buses. Environmental Science and Technology, 2002. 
35. United Nations, Uniform Provisions Concerning The Approval Of Vehicles With Regard To The Emission Of Pollutants According To Engine Fuel Requirements- Regulation No. 83, UNECE, Editor. 2009: Geneva.

36. Venkatasubramaniam, K.C., Effect of Dilution Method on Diesel Exhaust Particulate Matter Concentration, in Department of Mechanical and Aerospace Engineering. 2007, West Virginia University: Morgantown, West Virginia.

37. TIAX, U.S. and Canada Natural Gas Vehicle Market Analysis: Compressed Natural Gas Infrastructure (Final Report), A.s.N.G. Alliance, Editor.

38. Thiruvengadam Padmavathy, A., Evaluation of Exhaust After-Treatment Device Effectivenss in Reducing Regulated and Unregulated Emissions from Natural Gas Fueled Heavy Duty Transit Bus, in Department of Mechanical and Aerospace Engineering. 2008, West Virginia University: Morgantown, WV.

39. Burlingame, T.S., Reduction of Natural Gas Engine Emissions Using a Novel Aftertreatment System, in Department of Mechanical and Aerospace Engineering. 2004, West Virginia University: Morgantown, WV.

40. Kappanna, H.K., Reduction of Toxic Air Contaminants (TACs) and Particulate Matter Emissions from Heavy-Duty Natural Gas Engines, in Department of Mechanical and Aerospace Engineering. 2006, West Virginia University: Morgantown, WV.

41. Thiruvengadam Padmavathy, A., M.C. Besch, D. Carder, A. Oshinuga and M. Gautam, Influence of Real-World Engine Load Conditions on Nanoparticle Emissions from a DPF and SCR Equipped Heavy-Duty Diesel Engine. Evironmental Science \& Technology, 2011.

42. Saito, S., R. Shinozaki, A. Suzuki, H. Jyoutaki and Y. Takeda, Development of Urea-SCR System for Commercial Vehicle - Basic Characteristics and Improvement of NOx Conversion at Low Load Opeartion. SAE International, 2003.

43. Cho, I., S. Lee, H. Kang and D.S. Baik, A Study on the NOx Reduction of Urea-Selective Catalystic Reduction (SCR) System in a Heavy-Duty Diesel Engine. SAE International, 2007.

44. Defoort, M., D. Olsen and B. Willson, The effect of air-fuel ratio control strategie on nitrogen compound formation in three-way catalysts. International Journal of Engine Research, 2003. 5(1).

45. Agency, U.S.E.P. Title 40-Protection of Environment. Available from: www.epa.gov.

46. Janas, S. and S. Karpisz, Buoyancy Force in Mass Measurement, RADWAG BALANCES AND SCALES: Bracka, POLAND.

47. HORIBA, On-Board Transient Response Measurement OBS-TRPM. 2005, HORIBA Automotive Systems, Ltd.

48. Whitby, R., R. Johnson and R. Gibbs. Second Generation TEOM Filters--Diesel Particulate Mass Comparisons between TEOM and Conventional Filtration Techiniques**. in International Congress and Exposition. 1985: SAE International.

49. Schindler, W., C. Haisch, H.A. Beck, R. Neissner, E. Jacob and D. Rothe, A Photoacoustic Sensor System for Time Resolved Quantification of Diesel Soot Emissions. SAE International, 2003.

50. Giechaskiel, B., M. Carriero, P. Bonnel, W. Schindler, D. Scheder, C. Bassoli and V. Niemela, Feasibility of Particulate Mass and Number Measurement with Protable Emission Measurement Systems (PEMS) for In-Use Testing. SAE International, 2011.

51. TSI, Model 3090 Engine Exhaust Particle SizerTM Spectrometer. 2009. 
52. Green, D.C., G.W. Fuller and T. Baker, Development and validation of the volatile correction model for PM10 - An empirical method for adjusting TEOM measurements for their loss of volatile particulate matter. Atmospheric Environment, 2009. 43(13): p. 2132-2141.

53. Ferguson, D.H., Design, Fabrication and Testing of an Emissions Measurement System for a Transportable Heavy-Duty Vehicles Emissions Testing Laboratory, in Department of Mechanical and Aerospace Engineering. 1993, West Virginia University: Morgantown.

54. Liu*, Z., J. Swanson, D.B. Kittleson and D.Y.H. Pui, Comparison of Methods for Online Measurement of Diesel Particulate Matter. Environmental Science and Technology, 2012.

55. Maricq, M.M. and N. Xu, The effective density and fractal dimension of soot particles from premixed flames and motor vehicle exhaust. Journal of Aerosol Science, 2004.

56. Maricq, M.M., D.H. Podsiadlik and R.E. Chase, Size Distributions of MotorVehicle Exhaust PM: A Comparison Between ELPI and SMPS Measurements. Aerosol Science and Technology, 2000.

57. Park, K., F. Cao, D.B. Kittelson and P.H. McMurry, Relationship between Particle Mass and Mobility for Diesel Exhaust Particles. Evironmental Science \& Technology, 2003. 37.

58. Flaim, K.A.C., Study of the Variations in Continuous Diesel Pariculate Matter Size Measurement and Effect of Fuel Properties on DPM Size, in Mechanical Engineering. 2008, West Virginia University: Morgantown. 


\section{APPENDIX A- REGULATED $\mathrm{CO}_{2}$ EMISSIONS RESULTS}

Table A.1. Brake specific CO2 emissions from engine dynamometer testing on the TRU engine

\begin{tabular}{|l|l|l|l|l|c|}
\hline & \multicolumn{1}{|c|}{ (g/bhp-hr) } & Mode 1 & Mode 2 & Mode 3 & Mode 4 \\
\hline \multirow{4}{*}{ Without aftertreatment system } & Average: & 613.53 & 673.90 & 566.34 & 611.43 \\
\cline { 2 - 7 } & Std. Dev.: & 1.4670 & 5.1481 & 2.7956 & 1.6047 \\
\cline { 2 - 7 } & COV: & $\mathbf{0 . 2 4 \%}$ & $\mathbf{0 . 7 6 \%}$ & $\mathbf{0 . 4 9 \%}$ & $\mathbf{0 . 2 6 \%}$ \\
\hline \multirow{3}{*}{ With DOC+DPF aftertreatment system } & Average: & 599.05 & 657.73 & 551.36 & 600.22 \\
\cline { 2 - 7 } & Std. Dev.: & 4.6718 & 2.9897 & 4.6084 & 4.5004 \\
\cline { 2 - 7 } & COV: & $\mathbf{0 . 7 8 \%}$ & $\mathbf{0 . 4 5 \%}$ & $\mathbf{0 . 8 4 \%}$ & $\mathbf{0 . 7 5 \%}$ \\
\hline
\end{tabular}

Table A.2. Distance specific CO2 emissions from chassis dynamometer testing for four different vehicles over four different test cycles

\begin{tabular}{|c|c|c|c|c|c|}
\hline \multirow{2}{*}{$\begin{array}{c}\text { Vehicle Type } \\
\text { Diesel With } \\
\text { DOC-DPF-SCR }\end{array}$} & (g/mile) & UDDS & Near dock & Local & Regional \\
\cline { 2 - 6 } & Stand. Dev. : & 47.740 & 38.904 & 17.243 & 7.9372 \\
\cline { 2 - 6 } & COV: & $1.97 \%$ & $\mathbf{1 . 4 1 \%}$ & $\mathbf{0 . 6 9 \%}$ & $\mathbf{0 . 4 2 \%}$ \\
\hline \multirow{4}{*}{$\begin{array}{c}\text { Diesel with } \\
\text { DOC-DOF }\end{array}$} & Average: & 2756.67 & 3175.67 & 2979.33 & 2069.6 \\
\cline { 2 - 6 } & Stand. Dev. : & 65.163 & 74.096 & 27.501 & 38.397 \\
\cline { 2 - 6 } & COV: & $\mathbf{2 . 3 6 \%}$ & $\mathbf{2 . 3 3 \%}$ & $\mathbf{0 . 9 2 \%}$ & $\mathbf{1 . 8 6 \%}$ \\
\hline \multirow{3}{*}{\begin{tabular}{c} 
CNG with TWC \\
\cline { 2 - 6 }
\end{tabular}} & Average: & 2405.0 & 2854.0 & 2412.6 & 1739.6 \\
\cline { 2 - 6 } & Stand. Dev. : & 29.546 & 14.142 & 16.862 & 22.143 \\
\cline { 2 - 6 } & COV: & $\mathbf{1 . 2 3 \%}$ & $\mathbf{0 . 5 0 \%}$ & $\mathbf{0 . 7 0 \%}$ & $\mathbf{1 . 2 7 \%}$ \\
\hline \multirow{2}{*}{$\begin{array}{c}\text { Dual Fuel with } \\
\text { DOC-DPF-SCR }\end{array}$} & Stand. Dev. : & 23.302 & 28.536 & 35.921 & 18.027 \\
\cline { 2 - 6 } & COV: & $\mathbf{1 . 0 8 \%}$ & $\mathbf{0 . 8 8 \%}$ & $\mathbf{1 . 3 7 \%}$ & $\mathbf{1 . 1 5 \%}$ \\
\hline
\end{tabular}

